Reference NBS

NAT'L INST OF STAND \& TECH R.I.C CatiomS

A】】】05 891943

$31-2244$

Temperature Effects on the Strength-Maturity Relation of Mortar

Nicholas J. Carino

Structures and Materials Division Center for Building Technology National Engineering Laboratory U.S. Department of Commerce National Bureau of Standards

Washington, DC 20234

March 1981
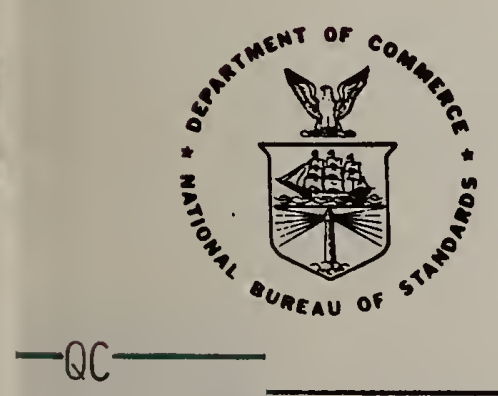

100 DEPARTMENT OF COMMERCE

. U56 INAL BUREAU OF STANDARDS

81-2244

1981 

NBSIR 81-2244

Nicholas J. Carino

Structures and Materials Division

Center for Building Technology National Engineering Laboratory U.S. Department of Commerce National Bureau of Standards

Washington, DC 20234

March 1981

U.S. DEPARTMENT OF COMMERCE, Malcolm Baldrige, Secretary NATIONAL BUREAU OF STANDARDS, Ernest Ambler, Director 



\title{
TEMPERATURE EFFECTS ON THE STRENGTH-MATURITY \\ RELATION OF MORTAR
}

\author{
Nicholas J. Carino
}

\begin{abstract}
$\Lambda$ study was performed to gain a fundamental understanding of the traditional maturity method used to predict the in-place strength of concrete. Research was undertaken to answer two questions: 1) What are the quantitative effects of curing temperature on the compressive strength-maturity relation of concrete? 2) Is there an age beyond which temperature no longer affects the strength-maturity relation of concrete? To simplify testing, mortar cubes were used as specimens for compressive strength determinations. Penetration resistance measurements were performed to determine initial and final setting times. Phase I of the research addressed the first question and involved preparing and curing specimens at $5^{\circ}, 12^{\circ}, 23^{\circ}, 32^{\circ}$ and $43^{\circ} \mathrm{C}$. Phase II addressed the second question and involved curing specimens at $5^{\circ}$ and $32^{\circ} \mathrm{C}$ for short periods, followed by additional curing at $23^{\circ} \mathrm{C}$. It was found that initial set occurred at approximately the same maturity regardless of the curing temperature. A three-parameter hyperbolic equation was used to represent the strength-maturity relation. The parameters, determined by regression analysis, were found to vary systematically with curing temperature. Theoretical justification for the hyperbolic equation is presented and a key assumption in the maturity method is identified. The strength versus age data were also analyzed and a new concept, effective age, is suggested as a possible alternative for representing the combined effects of time and temperature on the compressive strength development of concrete.
\end{abstract}

Keywords: Concrete; compressive strength; curing temperature; early age; final set; hydration; initial set; laboratory testing; maturity; mortar; regression analysis; strength prediction; temperature effects. 


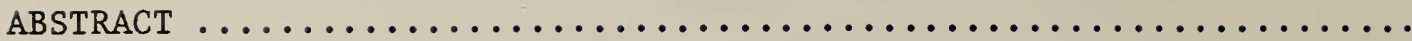

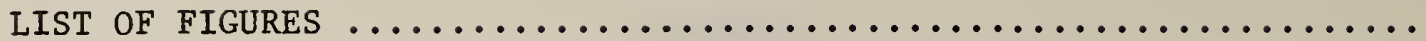

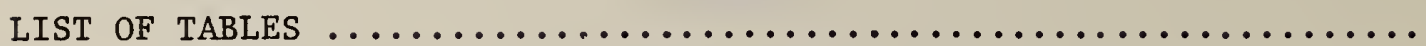

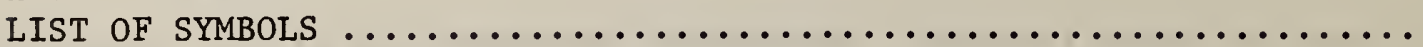

1.0 INTRODUCTION $\ldots \ldots \ldots \ldots \ldots \ldots \ldots \ldots \ldots \ldots \ldots \ldots \ldots \ldots \ldots \ldots \ldots \ldots \ldots$

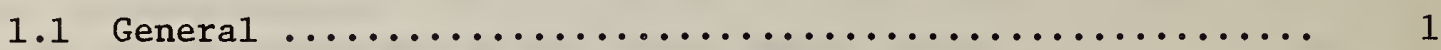

1.2 Background of the Maturity Concept ................. 2

2.0 EXPERIMENTAL PROCEDURE $\ldots \ldots \ldots \ldots \ldots \ldots \ldots \ldots \ldots \ldots \ldots \ldots \ldots \ldots \ldots$

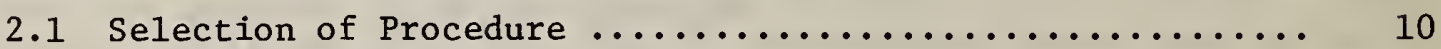

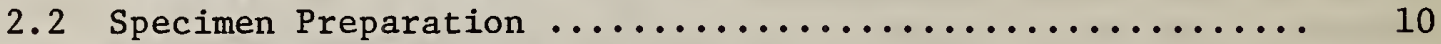

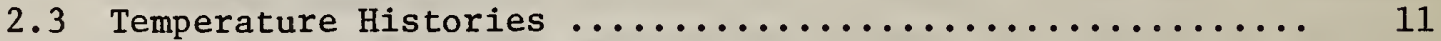

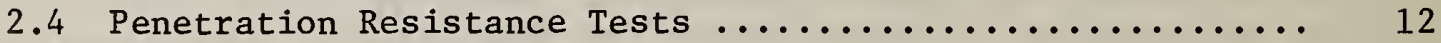

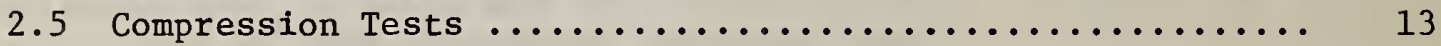

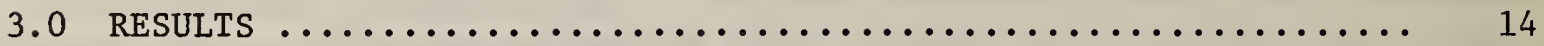

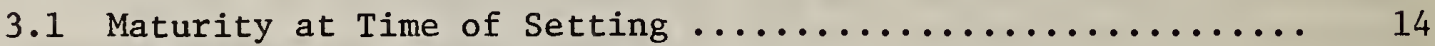

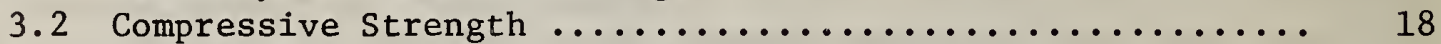

3.2.1 Equation for Strength-Maturity Relation ......... 18

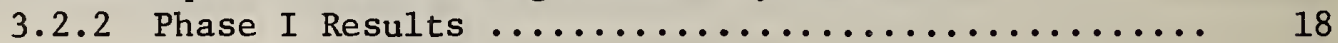

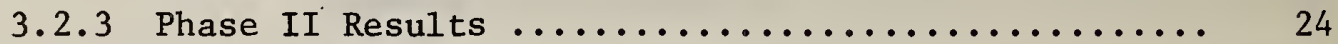

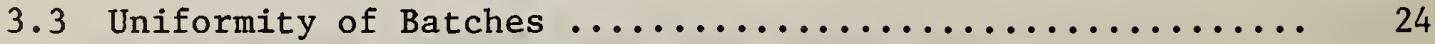

4.0 ANALYSIS AND DISCUSSION OF RESULTS $\ldots \ldots \ldots \ldots \ldots \ldots \ldots \ldots \ldots$

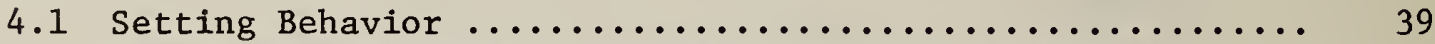

4.2 Temperature Effects on Strength-Maturity Relations ...... 43

4.3 When is "Early Age" ............................. 52

5.0 BASIS OF CLASSICAL MATURITY CONCEPT $\ldots \ldots \ldots \ldots \ldots \ldots \ldots \ldots \ldots$

6.0 AN ALTERNATIVE APPROACH FOR COMPUTING MATURITY $\ldots \ldots \ldots \ldots \ldots$

7.0 SUMMARY AND RECOMMENDATIONS $\ldots \ldots \ldots \ldots \ldots \ldots \ldots \ldots \ldots \ldots \ldots \ldots \ldots$

8.0 REFERENCES $\ldots \ldots \ldots \ldots \ldots \ldots \ldots \ldots \ldots \ldots \ldots \ldots \ldots \ldots \ldots \ldots \ldots \ldots \ldots$

APPENDIX A PENETRATION RESISTANCE TEST DATA ................ 77

APPENDIX B COMPRESSIVE STRENGTH TEST DATA $\ldots \ldots \ldots \ldots \ldots \ldots \ldots \ldots \ldots$ 


\section{LIST OF FIGURES}

Figure

1.1 The "crossover effect" due to dissimilar initial

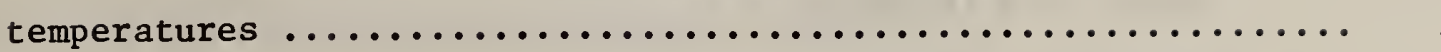

1.2 The hyperbolic strength-maturity function (a) and linear

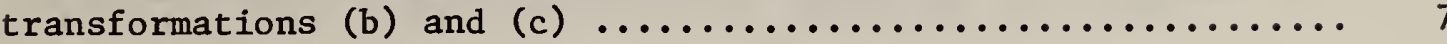

3.1 Penetration resistance versus maturity (phase I, high w/c)

3.2 Penetration resistance versus maturity (phase $I$, low $w / c) \ldots . .$.

3.3 Penetration resistance versus maturity (phase II, $5^{\circ} \mathrm{C}$ initial temperature)

3.4 Penetration resistance versus maturity (phase II, $32^{\circ} \mathrm{C}$ initial temperature)

3.5 Shapes of the probable and assumed strength-maturity relation $\ldots \ldots \ldots \ldots \ldots \ldots \ldots \ldots \ldots \ldots \ldots$

3.6 Compressive strength versus maturity (phase $\mathrm{I}$, high w/c) ..... 25

3.7 Compressive strength versus maturity (phase $I$, low w/c) ......

3.8 Compressive strength versus maturity (phase II, $5^{\circ} \mathrm{C}$ initial temperature)

3.9 Compressive strength versus maturity (phase II, $32^{\circ} \mathrm{C}$ initial temperature)

3.10 Average weight of cubes and 95 percent confidence intervals

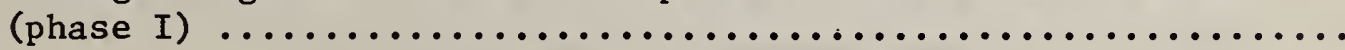

3.11 Average weight of cubes and 95 percent confidence intervals

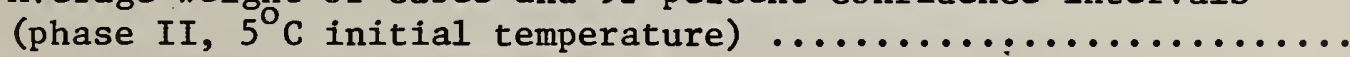

3.12 Average weight of cubes and 95 percent confidence intervals

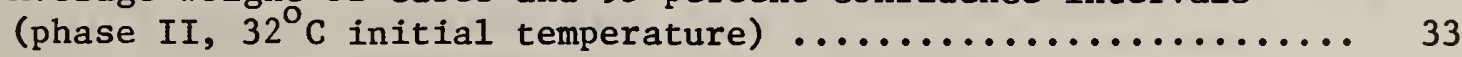

3.13 Individual cube weights (phase $\left.\mathrm{I}, 5^{\circ} \mathrm{C}\right) \ldots \ldots \ldots \ldots \ldots \ldots \ldots$

3.14 Individual cube weights (phase $\left.\mathrm{I}, 12^{\circ} \mathrm{C}\right) \ldots \ldots \ldots \ldots \ldots \ldots$

3.15 Individual cube weights (phase $\left.\mathrm{I}, 23^{\circ} \mathrm{C}\right) \ldots \ldots \ldots \ldots \ldots$

3.16 Individual cube weights (phase $\left.\mathrm{I}, 32^{\circ} \mathrm{C}\right) \ldots \ldots \ldots \ldots \ldots$ 
3.17 Individual cube weights (phase $\left.\mathrm{I}, 43^{\circ} \mathrm{C}\right) \ldots \ldots \ldots \ldots \ldots \ldots \ldots \ldots$

4.1 Age at initial set versus cumulative average

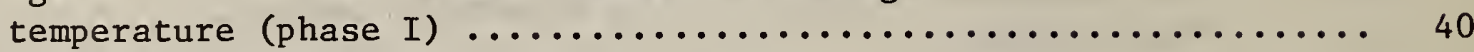

4.2 Maturity at initial set versus cumulative average

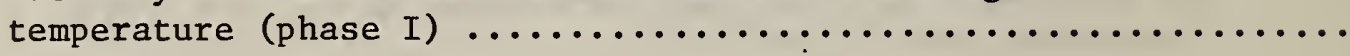

4.3 Maturity at initial and final set versus cumulative

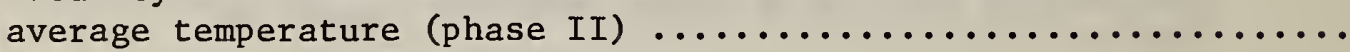

4.4 Initial slopes of strength-maturity relations versus cumulative average temperature (phase I) $\ldots \ldots \ldots \ldots \ldots \ldots \ldots \ldots . \ldots 45$

4.5 Variation of $\mathrm{K}_{\mathrm{m}}$ with cumulative average temperature (phase I) ...

4.6 Variation of offset maturity, $M$, with cumulative average

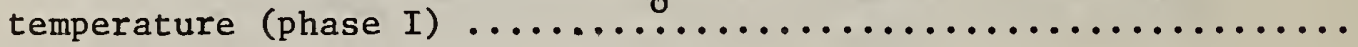

4.7 Schematic representation of strength-maturity

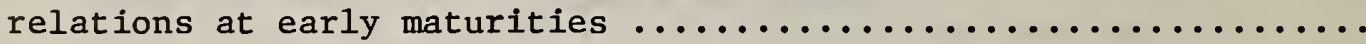

4.8 Variation of limiting compressive strength with temperature

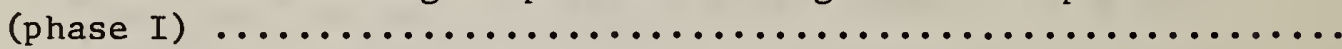

4.9 Early age temperature histories of phase II specimens ........ 53

5.1 Comparison of exponential and hyperbolic strength-age

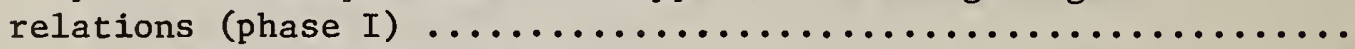

5.2 Compressive strength versus age (phase $I$, high $w / c) \ldots \ldots \ldots 1$

5.3 Compressive strength versus age (phase $I$, low $w / c) \ldots \ldots \ldots . \ldots 2$

5.4 Variation of rate constant, $k$, with cumulative average temperature (phase I) ........................ 64

6.1 Fit of Arrhenius function to k-temperature data: (phase I) ...... 67

6.2 Variation of offset age, $t_{0}$, with cumulative average

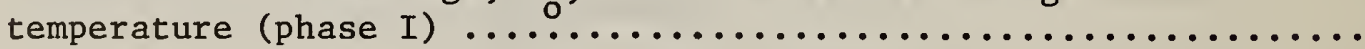

6.3 Strength ratio versus effective age (phase I, low w/c) ....... 71 


\section{LIST OF TABLES}

Table

$\underline{\text { Page }}$

1 Penetration Resistance Data Analysis, Phase I ........... 15

2 Penetration Resistance Data Analysis, Phase II ............. 19

3 Results of Strength-Maturity Data Analysis, Phase I ......... 24

4 Results of Strength-Maturity Data Analysis, Phase II ........ 27

5 Summary of Parameters (Phase I) $\ldots \ldots \ldots \ldots \ldots \ldots \ldots \ldots \ldots \ldots$

6 Summary of $F-T e s t$ of Variances $\ldots \ldots \ldots \ldots \ldots \ldots \ldots \ldots \ldots \ldots \ldots$

7 Comparison of Exponential and Hyperbolic Strength-Age

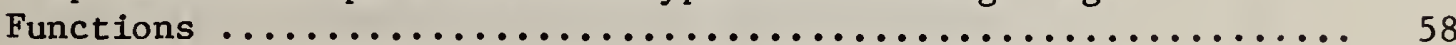




\section{LIST OF SYMBOLS}

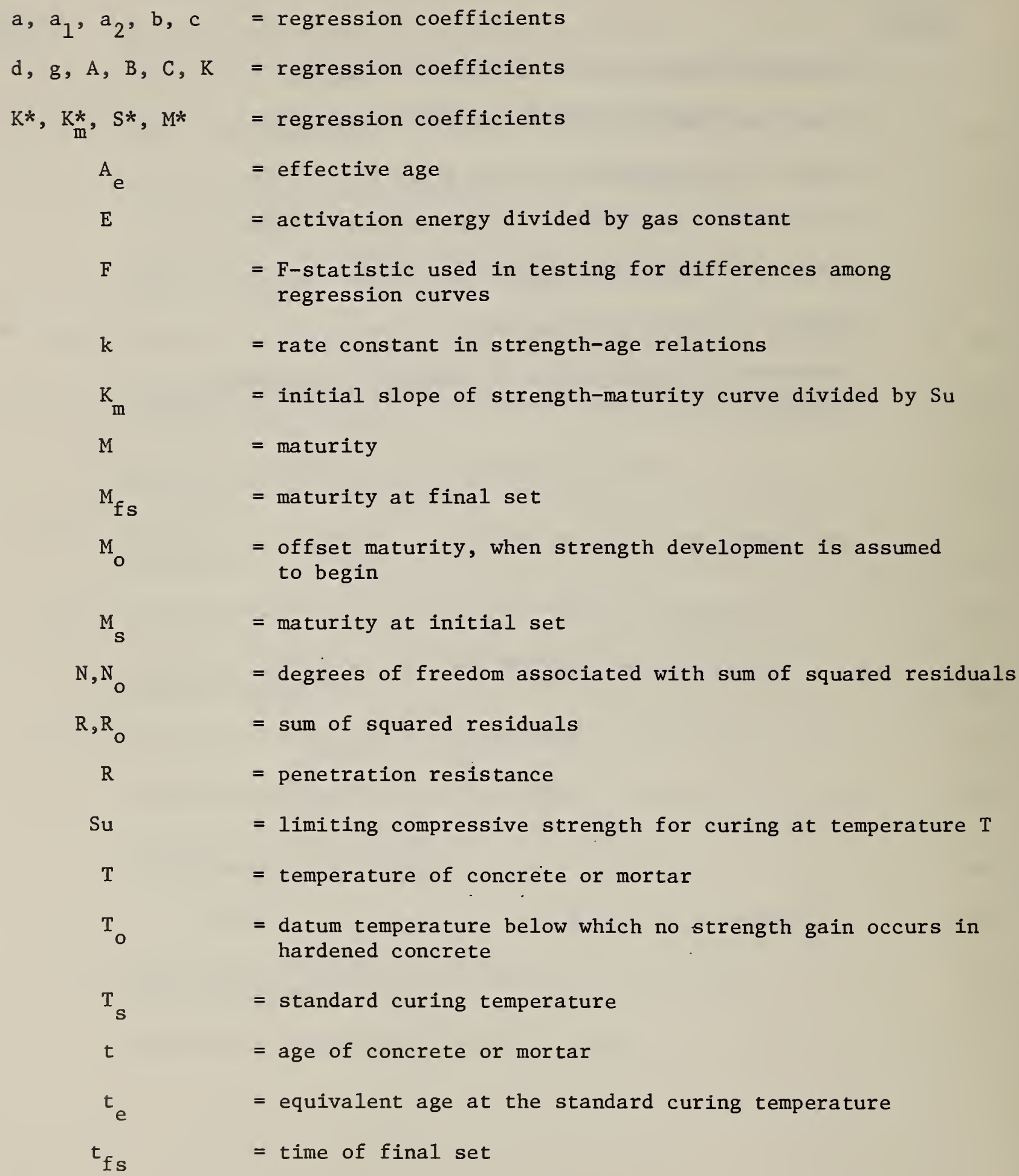




\section{LIST OF SYMBOLS (Continued)}

$$
\begin{array}{ll}
t_{0} & =\begin{array}{l}
\text { offset age, when strength development is assumed } \\
\text { to begin }
\end{array} \\
t_{s} & =\text { time of initial set } \\
\Delta t \quad= & \text { period of time }
\end{array}
$$





\subsection{INTRODUCTION}

\subsection{GENERAL}

In the life of a typical reinforced concrete structure, the most critical period is during construction. During this time, concrete is weak and, if unanticipated construction loads are applied, catastrophic collapse may occur. There exists, therefore, a need to provide, and encourage the use of, methods for estimating the in-place strength of concrete, so that formwork removal will be safe. The maturity method is one possible procedure for this application and that is the subject of this report.

Concrete gains strength gradually as a result of chemical reactions (hydration) between cement and water. For a specific concrete mixture, strength at any age is related to the degree of hydration. The rate of hydration and, therefore, strength development of a given concrete mix will be a function of the concrete temperature during hydration. Thus, strength of concrete depends on its timetemperature history (assuming that sufficient moisture is always present for hydration). Maturity is a term used to represent quantitatively the cumulative effects of temperature and time up to any given age; it is computed from the temperature-time history of the concrete.

It has been postulated that for a given mixture, concrete specimens tested at equal maturities will have equal strengths, irrespective of their thermal histories; that is, there exists a unique strength-maturity relation for each concrete mixture. This hypothesis is referred to as the "maturity concept." By monitoring the in-place temperature of newly-placed concrete, maturity at any age can be computed and strength can be estimated.

To apply the maturity method, the strength-maturity relation for the concrete mixture is developed in the laboratory and used to estimate strength for various in-place maturity values. However, it has been shown [26]* that the estimated strengths may be inaccurate if the in-place temperature history at early ages was significantly different from that of the laboratory specimens used to develop the calibration curve. The error may be on either the high or low strength side, depending on the temperature history of field cured concrete. Thus, the strength-maturity relation of a given concrete is not unique, but is a function of the temperature history at early ages and, perhaps, other factors.

In order to enhance the reliability of the maturity method as a tool for in-place strength predictions of new concrete constructions, it is necessary to gain a fundamental understanding of the quantitative effects of early age temperature on the strength-maturity relation. This was the motivation for the study reported herein.

The study sought to answer two questions:

1) What are the quantitative effects of curing temperature on the compressive strength-maturity relation of concrete?

* Refers to numbered references at end of report. 
2) Is there an age beyond which temperature no longer effects the strength-maturity relation of concrete?

Phase I of this study addressed the first question and Phase II addressed the second question.

The following section gives a brief history of the development of the maturity concept.

\subsection{BACKGROUND OF THE MATURITY CONCEPT}

Since complete reviews of the maturity concept have been written [1, 2] only a brief history dealing with the most significant developments will be presented.

The roots of the concept are found in a series of papers that deal with accelerated curing methods for concrete. In 1949, McIntosh 13] reported on experiments to develop procedures for electric curing of concrete. In seeking a procedure to predict the strength development characteristics for different temperature-time histories during electric curing, he suggested that the product of time and temperature above a datum temperature could be used to summarize the effects of curing history. A datum temperature of $-1.1^{\circ} \mathrm{C}\left(30^{\circ} \mathrm{F}\right)$ was suggested, and the product of time and temperature above the datum was called the "basic age." However, he found that when strength was plotted as a function of basic age, there was not a unique relation as expected. McIntosh concluded that strength development of concrete was governed by more complex factors than a simple product of temperature and time.

Several months after McIntosh's paper had appeared, Nurse [4] described the principles of low-pressure steam curing. He suggested that the product of time and temperature could be used to summarize the effects of different steam curing cycles. Nurse did not suggest using a datum temperature and his calculations involved the curing chamber temperatures not the actual concrete temperatures. Nevertheless, he showed that when the relative strength development was plotted as a function of (time $\mathrm{x}$ temperature), the data for different concretes and curing cycles fell reasonably close to a single non-linear curve. This was the first evidence to show that the product of time and temperature could be used to approximate the combined effects of these two factors on strength development.

In 1951, Saul [5] summarized the conclusions drawn from research at the Cement and Concrete Association in England on the principles of steam curing. This presentation can be regarded as the basis of our current maturity concept. The term "maturity" was for the first time linked to the product of time and temperature. Saul recognized that once concrete has set it will continue to harden at temperatures below $0^{\circ} \mathrm{C}$, and he suggested that maturity should be reckoned with respect to the lowest temperature at which hardening is observed. Thus, maturity should be computed as follows:

$$
M=\sum\left(T-T_{0}\right) \Delta t
$$

where $M$ is the maturity, $T$ is the average temperature of the concrete over the time interval $\Delta t$ and $\mathrm{T}$ is the datum temperature. Saul recommended a datum temperature of $-10.5^{\circ} \mathrm{C}\left(13^{\circ} \mathrm{F}\right)$. Equation (1.1) is the definition of maturity currently used in the United States and is the definition used in this report. 
Saul stated that, under special conditions, samples of similar concrete will have approximately equal strengths if they have equal maturities, independent of the temperature-time history. The special conditions were that the concrete should not be heated too rapidly during the start of the steam curing cycle. Saul recognized an important phenomenon which helps to explain why the maturity concept is intrinsically an approximation. During early ages, temperature has a greater effect than time on strength development, while at later ages time is more important. We now understand that this is because hydration is primarily a thermally-activated reaction which at later ages becomes diffusion controlled [32]. Thus, the assumption, implied by the maturity concept, that time and temperature play equal roles in the strength development of concrete can not be completely valid. Nevertheless, Saul demonstrated that as an approximation, the maturity concept provided a simple method to account for the effects of different temperature-time histories on the strength development of concrete.

Saul's maturity function (eq 1.1) can also be used to convert a temperaturetime history to an equivalent age at a standard temperature, as follows:

$$
t_{e}=\frac{\left(T-T_{0}\right) \Delta t}{\left(T_{s}-T_{0}\right)}
$$

where $t_{e}$ is the equivalent age at the standard temperature $T_{s}$, and $T_{0}$ is the datum temperature. In application of eq (1.2) only those time intervals in which the concrete temperature was greater than $\mathrm{T}_{0}$ would be considered.

In 1953, Bergstrom [6] demonstrated that the maturity concept was a useful approach for accounting for the effects of different normal curing histories. He analyzed previous data on temperature effects on strength development in terms of maturity and found that, in most cases, there was little deviation of the data from a common curve. To calculate maturity, Bergstrom assumed that the temperatures of the concrete specimens were the same as the ambient curing temperatures.

Plowman [7] presented a controversial paper on the maturity concept in 1956. One objective of his work was experimental determination of the datum temperature to be used for calculating maturity. He found it to be $-11.7^{\circ} \mathrm{C}\left(11^{\circ} \mathrm{F}\right)$. Further, he made standard concrete cubes which were cured at temperatures varying between $-11.5^{\circ}$ and $18^{\circ} \mathrm{C}$ after an initial 24 hour curing period at normal curing temperature $\left(16^{\circ}\right.$ to $\left.19^{\circ} \mathrm{C}\right)$. Cubes were tested at regular intervals and the results were plotted as strength versus the logarithm of maturity. The data was well grouped about a straight line, so Plowman proposed the following strength-maturity relation:

$$
S=a+b \log M
$$

where $\mathrm{S}$ is compressive strength, $\mathrm{M}$ is maturity, and $\underline{\mathrm{a}}$ and $\underline{\mathrm{b}}$ are constants which can be predicted from the water-cement ratio of the concrete and the type of cement. There was much objection [8] to the proposed relation; the following major points were raised and they indicate the limitations of Plowman's proposal: 
1) The relation predicts infinite strength as maturity approaches infinity.

2) The linear relation is not valid at very early maturities, and only intermediate maturity values result in an approximately linear relationship between strength and $\log$ (maturity).

3) The datum temperature may not be constant with increasing maturity.

Thus, it appeared that Plowman's proposal was too simplistic and of limited applicability. A deficiency in Plowman's procedure was that all specimens were initially cured at a standard temperature for 24 hours before being exposed to different curing temperatures. Thus, the early age temperature histories of all specimens were identical.

McIntosh [9] presented the results of a study in which specimens were exposed to different early age temperatures. For equal maturities, it was shown that those specimens exposed to low early age temperature were weaker at early maturities and stronger at later maturities than specimens exposed to a higher early age temperature. It was concluded that a strength-maturity relation that is based solely on the product of time and temperature above a datum value can not account for the "quality of cure" as affected by initial curing temperature. Klieger [10] also reported that initial curing temperature influenced the shape of the strength-maturity relation.

The great flurry of activity and'interest in the maturity concept that occurred in the early to mid $1950^{\prime} \mathrm{s}$ was followed by a period of inactivity in which only a few research reports dealt with the topic. In 1962, Alexander and Taplin [11] reported the results of a study to determine how well concrete and cement paste obeyed the maturity concept when cured at different temperatures $\left(5^{\circ}, 21^{\circ}\right.$ and $42^{\circ} \mathrm{C}$ ). In agreement with previous results, they found that the curing temperature had systematic effects on the strength-maturity relations of the pastes and concretes. The nature of the effects are summarized in a schematic fashion in figure 1.1. In 1968, Verbeck and Helmuth [12] presented a qualitative explanation of why the "cross-over effect" in figure 1.1 occurs. An increase in initial temperature will result in more than proportional increases in the initial rate of hydration and the initial rate of strength development. However, with rapid hydration, reaction products do not have time to become uniformly distributed within the pores of the hardening paste, and a "shell" of low permeability hydration products builds up around the cement grains. The shell impedes hydration of the unreacted portion of the grains at later ages. Thus, what appears as a strength reduction at higher maturities due to high temperature, may be because of the inability of the cement grains to continue hydrating due to the "she11" of low permeability reaction products.

In the late $1960^{\prime} \mathrm{s}$, a new interest in the maturity concept appeared. Swenson [13] reported the first case in which the concept was used in an engineering application. He used the maturity concept in a collapse investigation to estimate what the concrete strength might have been at the time of collapse. In the United States, Hudson and Steele [14, 15] proposed the use of the maturity concept for predicting the 28-day strength of concrete based upon tests at early ages. Their results have recently been incorporated in ASTM C 918-80 Standard Test Method for Developing Early Age Compression Test Values and Projecting Later Age Strengths. 


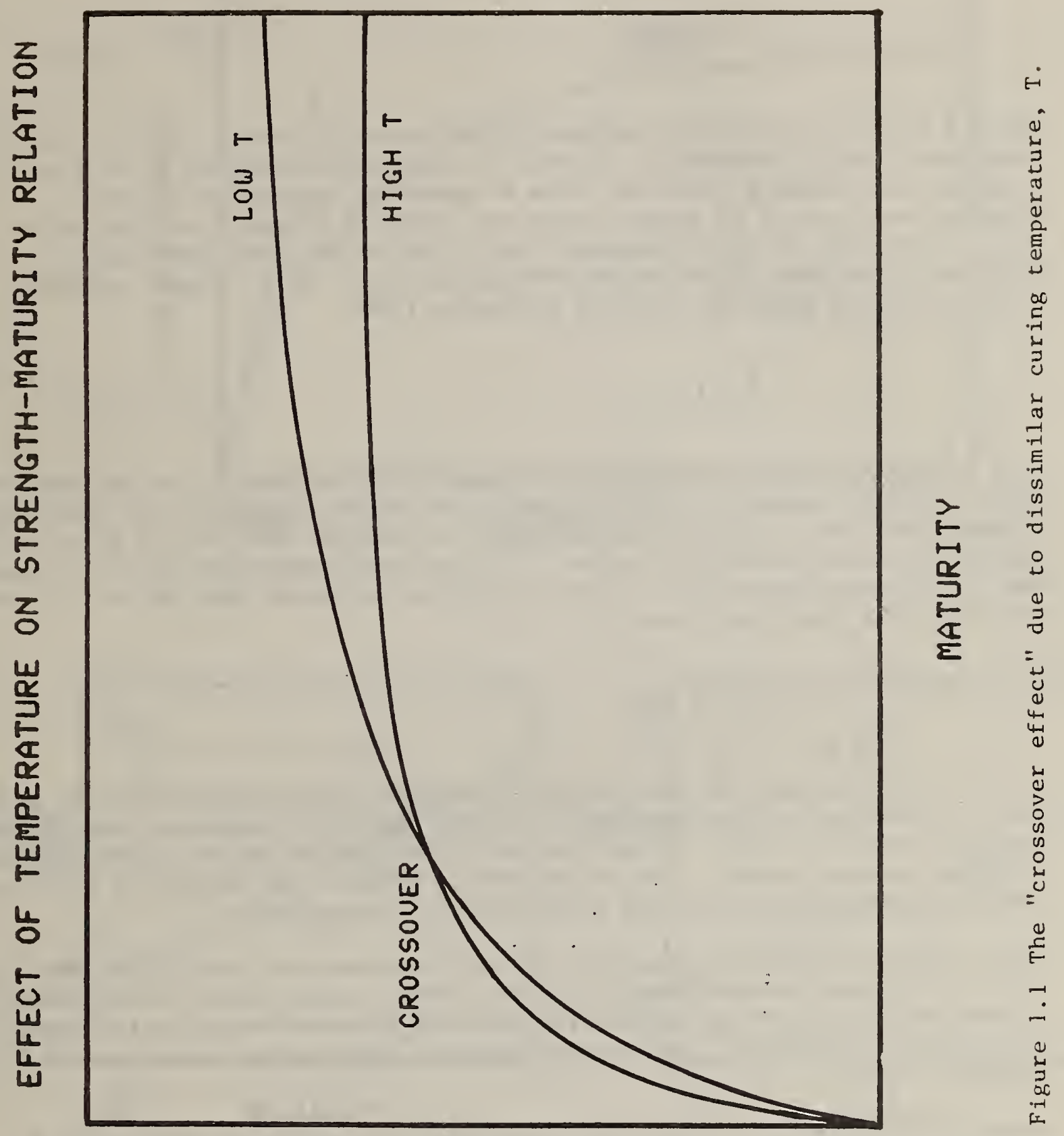

のト 
An alternative to Plowman's logarithmic strength-maturity relation was presented by Chin [16] in 1971, who suggested that a hyperbolic function be used as follows:

$$
\mathrm{S}=\frac{\mathrm{M}}{\mathrm{CM}+\mathrm{A}}
$$

where $\mathrm{A}$ and $\mathrm{C}$ are constants defining the hyperbolic curve. Chin's equation overcomes a major drawback of Plowman's relation. According to eq (1.4), strength approaches a limiting value as maturity approaches infinity. Examination of eq $(1.4)$ reveals that the limiting strength has the value $1 / C$. The values of the constants $A$ and $C$ can be obtained from linear regression analysis of the strength-maturity data; this is made possible by transforming eq (1.4) into the following form:

$$
\frac{M}{S}=C M+A
$$

Thus $C$ is the slope and A is the intercept of the straight line obtained when $\mathrm{M} / \mathrm{S}$ is plotted versus $\mathrm{M}$. The inverse of the slope represents the limiting strength and the inverse of the intercept represents the initial slope of the hyperbolic strength-maturity curve. Clifton and Pommersheim [17J recommend that it is more appropriate to use the following linear form of eq (1.4) to determine the constants $\mathrm{A}$ and $\mathrm{C}$ :

$$
\frac{1}{S}=C+\frac{A}{M}
$$

In this case the inverse of strength is plotted against the inverse of maturity and the intercept of the straight line represents the inverse of the limiting strength while the slope is the inverse of the initial slope of the hyperbolic strength-maturity curve. The relationships between the hyperbolic curve and the linear transformations are illustrated in figure 1.2 .

Chin showed that his own data [18] was well represented by eq (1.5) with correlation coefficients varying from 0.939 to 0.999 . In the study reported herein, a modified version of the hyperbolic function represented by eq (1.4) was used to analyze the data and further discussion of the function is presented in chapters 3 and 5 .

Weaver and Sadgrove [19] used the equivalent age concept in developing a manual for formwork striking times under various temperature conditions. They suggested that the following expression for equivalent age gave better strength predictions at early ages than the Saul function eq (1.2):

$$
t_{e}=\frac{\sum[\mathrm{T}+16]^{2}}{1296} \Delta t
$$



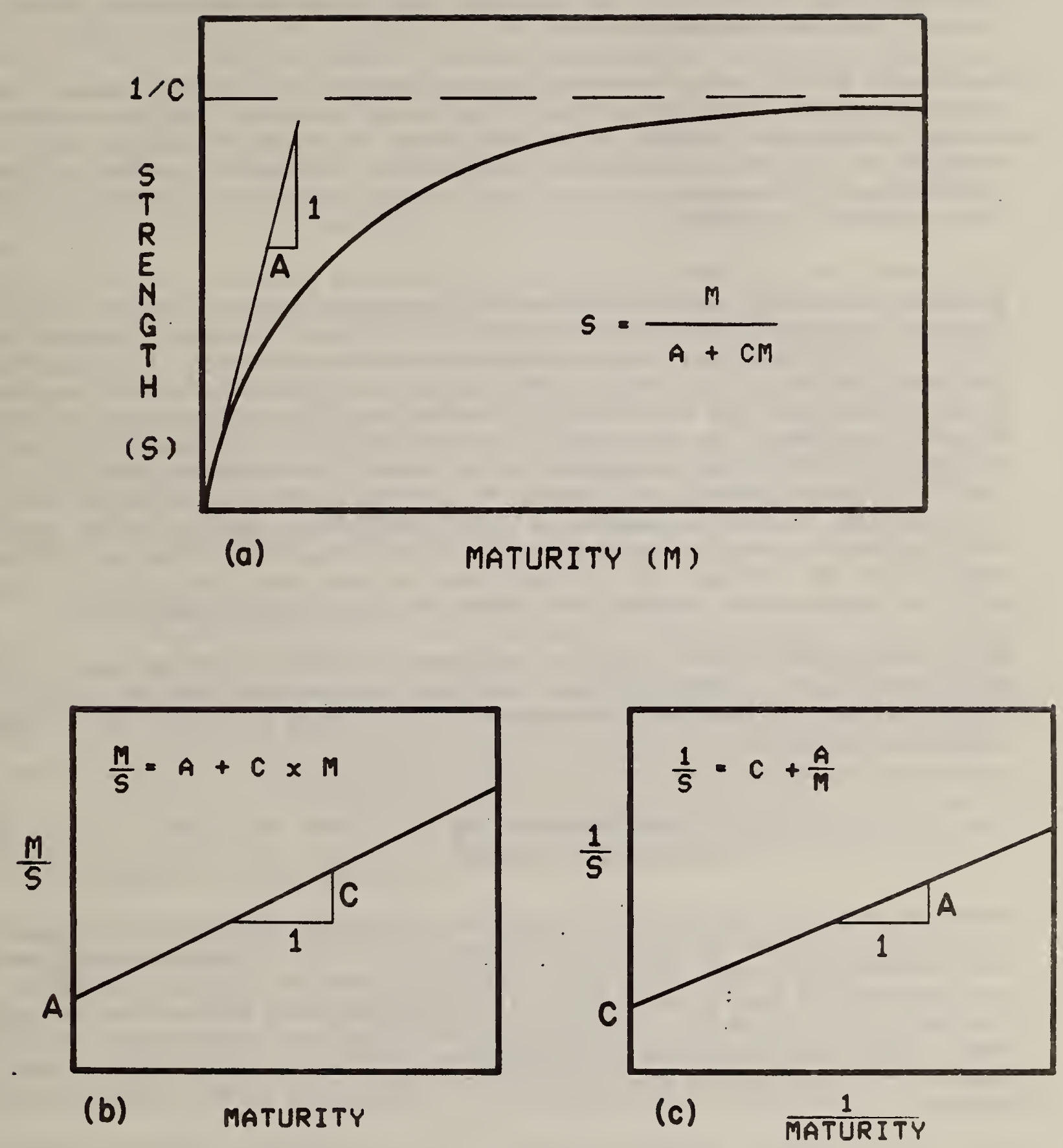

Figure 1.2 The hyperbolic strength-maturity function (a), and linear transformations (b) and (c). 
By using eq (1.7), the actual age of the concrete is transformed to an equivalent age of curing at $20^{\circ} \mathrm{C}$. In another report [20], Sadgrove reported that for later maturities, the Saul function for equivalent age was more precise than his recommendation.

In the mid 1970's several reports appeared dealing with application of the maturity concept under actual field conditions. Bickley [21] reported on using it during slipforming of the C.N. Tower in Canada, Mukherjee [22] reported on its use for predicting the in-place strength of slabs, and Nisbett and Maitland [23] used the concept for in-place strength predictions on a canal bypass project in Ontario.

As a result of its investigations of construction failures, the Center for Building Technology, National Bureau of Standards (NBS) has become involved in the application of the maturity concept as a tool for in-place strength determination of concrete at early ages. Research has been conducted to demonstrate the applicability of the method and at the same time point out the important deficiencies. Lew and Reichard [24] demonstrated the applicability of using maturity to predict the development of other mechanical properties of concrete besides its compressive strength. It was shown that the development of indirecttensile strength, modulus of elasticity and pullout bond strength of steel bars could also be related to maturity. These experiments were conducted using nominal constant curing temperatures of $2^{\circ}, 12^{\circ}$, and $23^{\circ} \mathrm{C}$. The initial mix temperature was constant for all specimens and specimens were moved into the different temperature chambers soon after molding had been completed.

In a second study at NBS [25], the influence of cement type and cement content were investigated. Based on their test data and previous data published elsewhere, Lew and Reichard recommended the following model for the strengthmaturity relation:

$$
S=\frac{K}{1+K a[\log (M-30)]^{b}}
$$

where maturity is expressed in ${ }^{\circ} \mathrm{F}$-days and $30^{\circ} \mathrm{F}$-days represents the maturity below which compressive strength is effectively zero. The constants $K$, $a$ and $b$ were obtained from non-linear least squares regression analysis using the program DATAPLOT developed at NBS. It was demonstrated that the values of the constants were systematic functions of cement type and water-cement ratio, so that a user could determine an approximate strength-maturity relation for his concrete mix by choosing the appropriate values of $K$, $a$ and $b$ from the published figures.

In a later study at NBS [26], the applicability of the maturity method under simulated field conditions was investigated. Three different concrete mixes were used to fabricate plain concrete slabs containing push-out cylinder molds. In addition, push-out cylinder molds were filled and stored in a moist curing room. The slabs were coated with a membrane curing compound, covered with wet burlap and stored outdoors (during the spring). The object was to determine whether the strength-maturity relations for the field-cured push-out cylinders were the same as those for the companion 1aboratory-cured cylinders. 
The results of this study were perplexing: for batches 1 and 2, there was good agreement between the strength-maturity relations of the field-cured and lab-cured specimens, but for batch 3 there was considerable discrepancy. Closer examination of the temperature histories of all specimens revealed that for batch 3 the field-cured cylinders experienced much higher early age temperatures than the $1 \mathrm{ab}$-cured ones. On the other hand, for the other batches the early age temperatures were not as dissimilar for field and lab-cured specimens. Thus, an important deficiency of the maturity concept was confirmed: when the initial temperature history of the field-cured concrete is significantly different from that present during the development of the laboratory calibration curve, the reliability of the strength predictions becomes questionable.

The aim of a still later study performed at NBS [27] was to determine during which stage of the early age of concrete did temperature affect the subsequent strength-maturity relation. Cylindrical specimens (76 x $152 \mathrm{~mm}$ high) were molded at ambient temperature (mix temperature was $30^{\circ} \mathrm{C}$ ) and then moved into temperature chambers at $43^{\circ} \mathrm{C}$ and $-1^{\circ} \mathrm{C}$. At ages of $6,18,30$ and 48 hours, groups of the cylinders were moved out of these chambers and allowed to cure in a $21^{\circ} \mathrm{C}$ environment until tested for compressive strength. In addition, another series of specimens was kept continuously in the $21^{\circ} \mathrm{C}$ chamber. At ages of 1, 3, 5, 7 and 28 days, strength tests were performed; and, from recorded temperature data, the strength-maturity relations were constructed.

The results of this study were surprising. For the specimens initially stored in the $43^{\circ} \mathrm{C}$ chamber, there were no significant differences among the strengthmaturity relations for the different storage times. Similar conclusions were drawn, for the specimens stored at $-1{ }^{\circ} \mathrm{C}$. In addition, there was no significant difference between the maturity relation of the specimens stored continuously at $21^{\circ} \mathrm{C}$ and those stored initially at $43^{\circ} \mathrm{C}$. However, there was a difference between the maturity relations of the $43^{\circ} \mathrm{C}$ and $21^{\circ} \mathrm{C}$ treatments compared with the $-1^{\circ} \mathrm{C}$ treatments; the difference being the "crossover" effect represented in figure 1.1. From these results it was concluded the critical early age, when temperature affects the shape of the subsequent strength-maturity relation, occurred during the first six hours.

In summary, the maturity concept has demonstrated itself as being a useful approximation to account for the combined effects of time and temperature on the strength development of properly cured concrete (that is, an adequate supply of moisture is available for hydration). It has been demonstrated [26] that the reliability of the method is reduced when the early age temperatures of the in-place concrete are significantly different from those present in the specimens used for the development of the calibration strength-maturity function.

In order to enhance confidence in using the maturity concept for in-place strength prediction, a more fundamental and quantitative understanding is required of the early age temperature effects. 


\subsection{PROCEDURE}

\subsection{SELECTION OF PROCEDURE}

As previously discussed, there were two objectives in the present study:

1) To determine in quantitative terms the effects of temperature on the strength-maturity relation of concrete.

2) To determine the age of concrete beyond which temperature no longer affects the strength-maturity relation.

Since it is known that the strength development of concrete is primarily affected by the strength development of the cement paste, it was decided to conduct the experiments with mortar specimens rather than concrete. This would greatly simplify the testing procedure, since $50 \mathrm{~mm}$ mortar cubes could be used instead of the much larger standard cylindrical specimens of concrete. Also, the cubes would not require special preparations prior to testing, that is, no capping with sulfur is needed. In addition, the mortar cubes would require less material to fabricate and less storage space would be required during curing compared to standard concrete specimens. Since the main effects of temperature would be on the cement hydration, these effects would manifest themselves with mortar specimens as well as if concrete were used.

In addition to performing compression tests, it was decided to conduct early age setting tests using the resistance to penetration method as described in ASTM test method C 403 [28]. Such tests would furnish information on the initial stages of strength development which could not be obtained from compression testing.

The test program was divided into two phases: Phase I addressed the first objective and Phase II addressed the second objective.

\subsection{SPECIMEN PREPARATION}

Mortar was produced with Type I portland cement, Ottawa sand (ASTM C 109) and tap water. For Phase I, the following sand-cement-water mixtures were used ( $\mathrm{S}: \mathrm{C}: \mathrm{W}$ oven-dry weight basis):

$$
\begin{aligned}
& \text { 1. High w/c }(3: 1: 0.56) \\
& \text { 2. Low } w / c(2: 1: 0.43)
\end{aligned}
$$

For Phase II, only the low water/cement ratio mix was used.

Mortar was mixed in an environmental chamber having 50 percent relative humidity and at various temperatures as to be discussed. A bench top mortar mixer was used and the mixing sequence was as follows:

1) With a trowel, dry $\mathrm{mix}$ the preweighed quantities of sand and cement in the bowl.

2) Add the preweighed quantity of water and mix for about 10 seconds with a trowel.

3) Mix at low speed for 30 seconds. 
4) Cover bow1 and let stand for 1-1/2 minutes.

5) Final mix at low speed for 1 minute.

For Phase I, twenty-four (24) cubes having $50 \mathrm{~mm}$ (2 in) sides and one $50 \times 50 \times 305$ $\mathrm{mm}(2 \times 2 \times 12$ in) prism were molded per batch. For Phase II, 18 cubes and two prisms were molded per batch. Steel molds were lightly coated with oil, and grease was used as a water seal between the side molds and the removable bottom plates. The molds were filled in two layers, tamping each layer with a rubber tamper. After striking off the mortar, the molds were carefully submerged in lime-saturated water baths within the environmental chamber. Immersion was used, rather than covering the top surface of the molded specimens, to ensure no evaporation occurred after molding. Evaporation would affect the early setting characteristics.

Due to the large number of specimens and the limited table space in the chamber, the specimens for Phase $I$ were prepared in the following sequence:

1) Fill prism and two cube molds (three cubes per mold) and submerge.

2) Fill three cube molds and submerge.

3) Fill three cube molds and submerge.

For Phase II the sequence was as follows:

1) Fill the two prism molds and submerge.

2) Fill two cube molds and submerge.

3) Fill two additional cube molds and submerge.

4) Fill the remaining two cube molds and submerge.

The entire operation, from the addition of the water to placement of the last mold under water took from 30 to 45 minutes to complete. Age was reckoned from the time water and cement came into contact.

The molds were stripped from the cubes at maturities (as defined by eq 1.1 but using a datum temperature of $-11.7^{\circ} \mathrm{C}\left(11^{\circ} \mathrm{F}\right)$ ) varying between 12 and $17^{\circ} \mathrm{C}$-days and were returned to the water baths.

\subsection{TEMPERATURE HISTORIES}

For the Phase I study, mortar cubes were prepared and maintained within $\pm 1{ }^{\circ} \mathrm{C}$ of the following temperatures: $5^{\circ}, 12^{\circ}, 23^{\circ}, 32^{\circ}$ and $43^{\circ} \mathrm{C}$. All ingredients and molds were stored in the environmental chamber overnight to bring these to uniform temperature, and all specimens were prepared in the chamber. After demolding, the pans which comprised the water baths were stored in refrigerators and ovens to maintain the desired temperatures. The $23^{\circ} \mathrm{C}$ bath was located in an air-conditioned room. Ice or warm water was added to the water baths as required to maintain the desired temperatures during the critical early ages.

Temperature histories were recorded for the prism specimen and two cube specimens per batch. It was felt that storing the specimens under water would minimize temperature variations among specimens, and so two instrumented cubes were felt to be sufficient for each batch. Copper-constantan thermocouples were 
embedded at the approximate center of the specimens. For each batch, a thermocouple was embedded in a cube from the first and final series in the molding sequence.

The Phase I specimens were designated as follows:

$$
\begin{aligned}
& I-X X-H \\
& I-X X-L
\end{aligned}
$$

where $\mathrm{XX}$ indicates the curing temperature in degrees Celsius and the letters $\mathrm{H}$ and $\mathrm{L}$ denote the high and low water-cement ratio mixes, respectively.

For the Phase II study, prism and cube specimens were prepared and initially stored at $5^{\circ} \mathrm{C}$ and $32^{\circ} \mathrm{C}$; then at three different stages in the setting process, they were moved to $23^{\circ} \mathrm{C}$ water baths located in an air-conditioned room. A separate batch of mortar was made for each treatment process since the mixer capacity was insufficient to produce at one time the required mortar for all the specimens.

The Phase II specimens were designated as follows:

$$
\begin{aligned}
& \text { II-5-X } \\
& \text { II-32-X }
\end{aligned}
$$

where $\mathrm{X}$ is a letter (F, I or $\mathrm{H}$ ) which was used to identify when the molds were moved from the environmental chamber to the $23^{\circ} \mathrm{C}$ water baths. The letter $\mathrm{F}$ indicates that the transfer occurred after final set had occured, I indicates the transfer occurred at initial set, and $\mathrm{H}$ signifies that the transfer was made at a time equal to one-half the time needed to reach initial set. These stages in the setting process are explained in the next section. It took from 30 minutes to 1 hour to bring the temperature of the specimens from $5^{\circ}$ or $32^{\circ} \mathrm{C}$ to $23^{\circ} \mathrm{C}$.

\subsection{PENETRATION RESISTANCE TESTS}

The transformation of concrete from its initial fluid state to a hardened condition is a gradual process and is referred to as setting. Since the transition is gradual there are no well-defined boundaries between hardened and unhardened concrete. In order to compare the setting characteristics of different concrete mixtures, arbitrary stages of setting have been adopted. The most widely used approach for quantifying the degree of setting is by resistance to penetration of a round flat-faced rod. Resistance to penetration is measured by a springloaded device, and the test must be performed on mortar, wet-sieved from the concrete so that interference with coarse aggregate particles is avoided. By convention, the term "initial set" is used to indicate the degree of setting corresponding to $3.5 \mathrm{MPa}$ (500 psi) penetration resistance; this is roughly the stage beyond which vibration can not be used to further consolidate concrete. The term final set corresponds to a penetration resistance of $27.6 \mathrm{MPa}$ (4000 psi) and is roughly equivalent to a compressive strength of about $0.7 \mathrm{MPa}$ (100 psi) [29]. 
In Phase I, a small pocket penetrometer was used which was only capable of recording a maximum resistance of $4.8 \mathrm{MPa}$. Penetration resistances were recorded at five times during the initial ages; the first reading was taken at a resistance of roughly $1 \mathrm{MPa}$ and the remaining tests were performed at regular intervals so that the final reading was more than $3.5 \mathrm{MPa}$. Each test consisted of two insertions of the penetrometer into the prism specimen. The distance between centers of insertion was roughly $25 \mathrm{~mm}$. The prisms were removed from the water baths for penetration testing and returned to the baths after testing.

In Phase II, a penetration device meeting the requirements of ASTM C 403 was used so that the setting procuss could be followed up to final set. In this case two prisms were used so that 10 tests could be performed at regular time intervals; each test consisted of one insertion in each of the two prisms. The locations for the tests were chosen in a random fashion using a random number table so that any non-uniformity would not bias the results. A center-tocenter distance of $25 \mathrm{~mm}$ was maintained between adjacent penetration test insertions.

It must be mentioned that the prisms did not strictly comply with the standard procedure of ASTM C 403, which requires a minimum mortar depth of $140 \mathrm{~mm}$. However, the prisms were used because less mortar was required than the standard specimen, and there would be less problem with temperature rise due to heat of hydration. Use of $50 \mathrm{~mm}$ deep mortar specimens would probably result in slightly greater values of penetration resistance than the deeper specimen due to interference from the bottom of the mold. However, it is unlikely that this difference would obscure the temperature effects that were being studied.

\subsection{COMPRESSION TESTS}

Compression tests were performed using a universal hydraulic testing machine of $267 \mathrm{kN}$ ( $60 \mathrm{kip}$ ) capacity. The cubes were loaded at a convenient rate up to one-half the expected ultimate load and thereafter loaded at $3.2 \mathrm{kN} / \mathrm{minute}$ (7.2 kip/minute) until ultimate load was reached.

For Phase I, three cubes were tested at each of seven maturity levels, chosen so that the shape of the strength-maturity curve could be wel1-defined.

Prior to testing, the cubes were weighed to the nearest $0.001 \mathrm{~kg}$ after blotting with a rag to remove surface water. The weights of the cubes were used as a rough indicator of the homogeneity of the mortar from batch to batch. In Phase II, three cubes were tested at five maturity levels per batch.

Anticipating that there would be differences between the cubes molded at the beginning and those molded at the end of the casting sequence, because of evaporation and sand absorption of the water, the cubes were tested in random order. The cubes were numbered in sequence as they were cast, and the sequence for compression testing was based upon selections from a random number table. As will be seen, this procedure was not entirely successful, and it was modified for Phase II so that one cube was selected from each of the three stages of the casting sequence for each compression test. 


\subsection{RESULTS}

\subsection{MAIURITY AT TIME OF SETTING}

As discussed in section 2.4, the setting behavior for the various temperature treatments was monitored by measuring penetration resistance of the mortar prisms. For each penetration test, the age was recorded and the corresponding maturities were computed according to eq (1.1) from the temperature records using $-11.7^{\circ} \mathrm{C}\left(11^{\circ} \mathrm{F}\right)$ as the datum temperature.

The normal practice for determining the time required to reach initial and final set is by plotting the test results and drawing a best fit smooth curve; the curve is then used to interpolate (or extrapolate) the setting time. In this study, a non-linear, least-squares fit analysis was used to determine the best line for interpolation and extrapolation. The principal objective was to determine whether setting times had any correlation with maturity.

\section{Phase I Results:}

The complete data showing age, penetration resistance values, and computed maturities are presented in Appendix A. The usual practice has been to plot penetration resistance on a log scale versus time, and use a best-fit straight line for determining the times of initial and final set. In this study, penetration resistances were plotted against maturity and several equations were used in the least squares fit analysis to determine which had the best fit, as measured by the estimated residual standard deviation and the significance level of the lack-of-fit F-test. The following equations were studied:

$$
\begin{aligned}
R & =a b^{M} \text { (power function) } \\
\log (\mathrm{R}) & =c+d M \quad(\text { logarithmic function) } \\
R & =a+a_{1} M+a_{2} M^{2} \text { (parabolic function) }
\end{aligned}
$$

where $\mathrm{R}$ represents penetration resistance, $\mathrm{M}$ is maturity and the other symbols represent regression coefficients. It is emphasized that these equations were not chosen for physical significance, but to give a smooth curve with the best precision for interpolating the values of maturity at initial set. Regression analysis was performed with DATAPLOT [31], an interactive non-linear least squares fit program with plotting capabilities. Overall, it was found that the parabolic model gave the best fit of the data.

Table 1 summarizes the results of the Phase $I$ data analysis. The column labelled $\alpha_{F}$ represents the significance level of the lack-of-fit F-test; values of less than 5 percent are usually indicators that the chosen model is not the best to use. However, low values of $\alpha_{F}$ may also result when there are outliers in the data which have small values of replication standard deviation. So, plots of the data should be used to evaluate whether the lack of fit is real or due to outliers.

Figures 3.1 and 3.2 present the penetration resistance versus maturity data along with the best fit parabolas. Inch-pound units are shown since data were recorded in these units. 


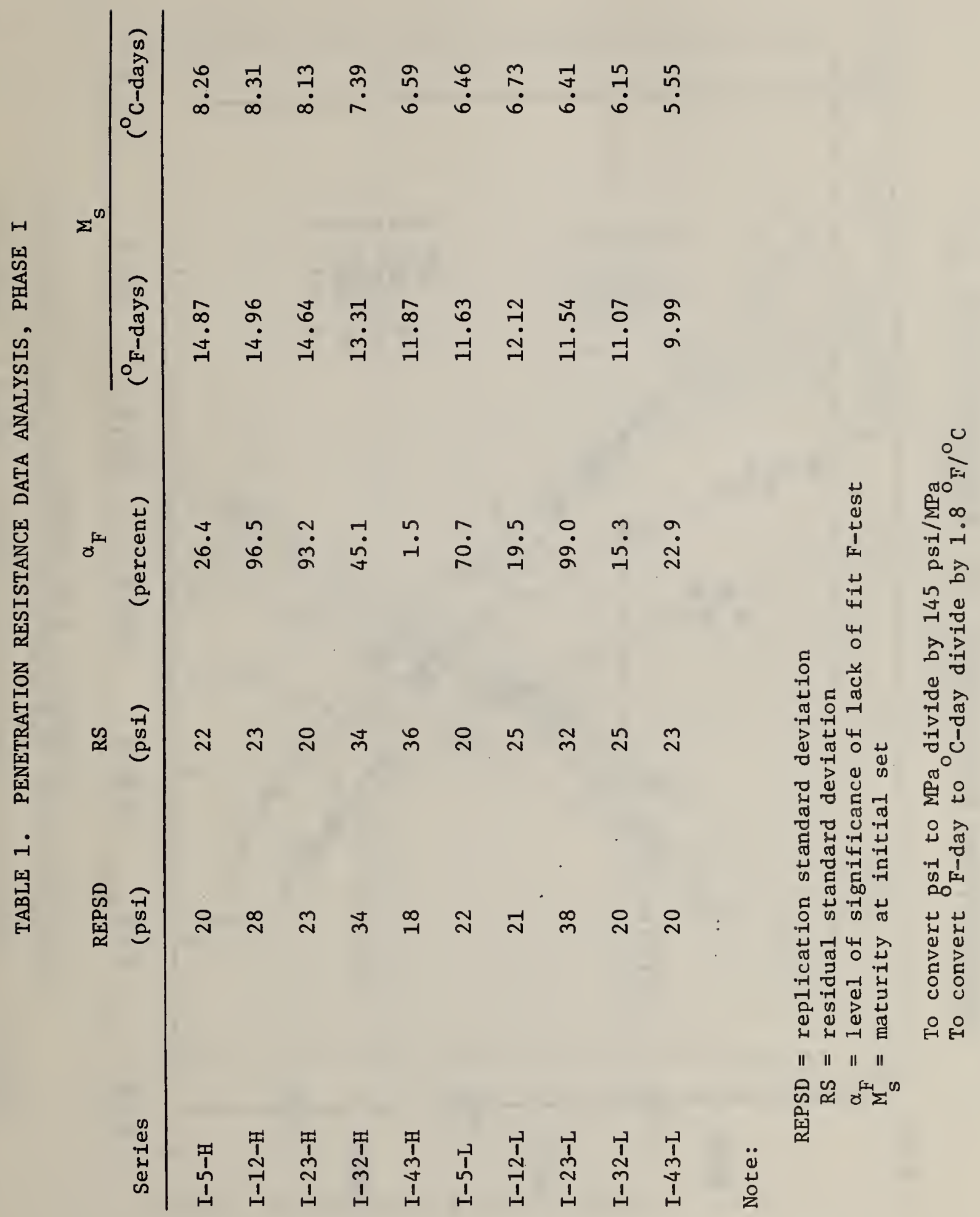




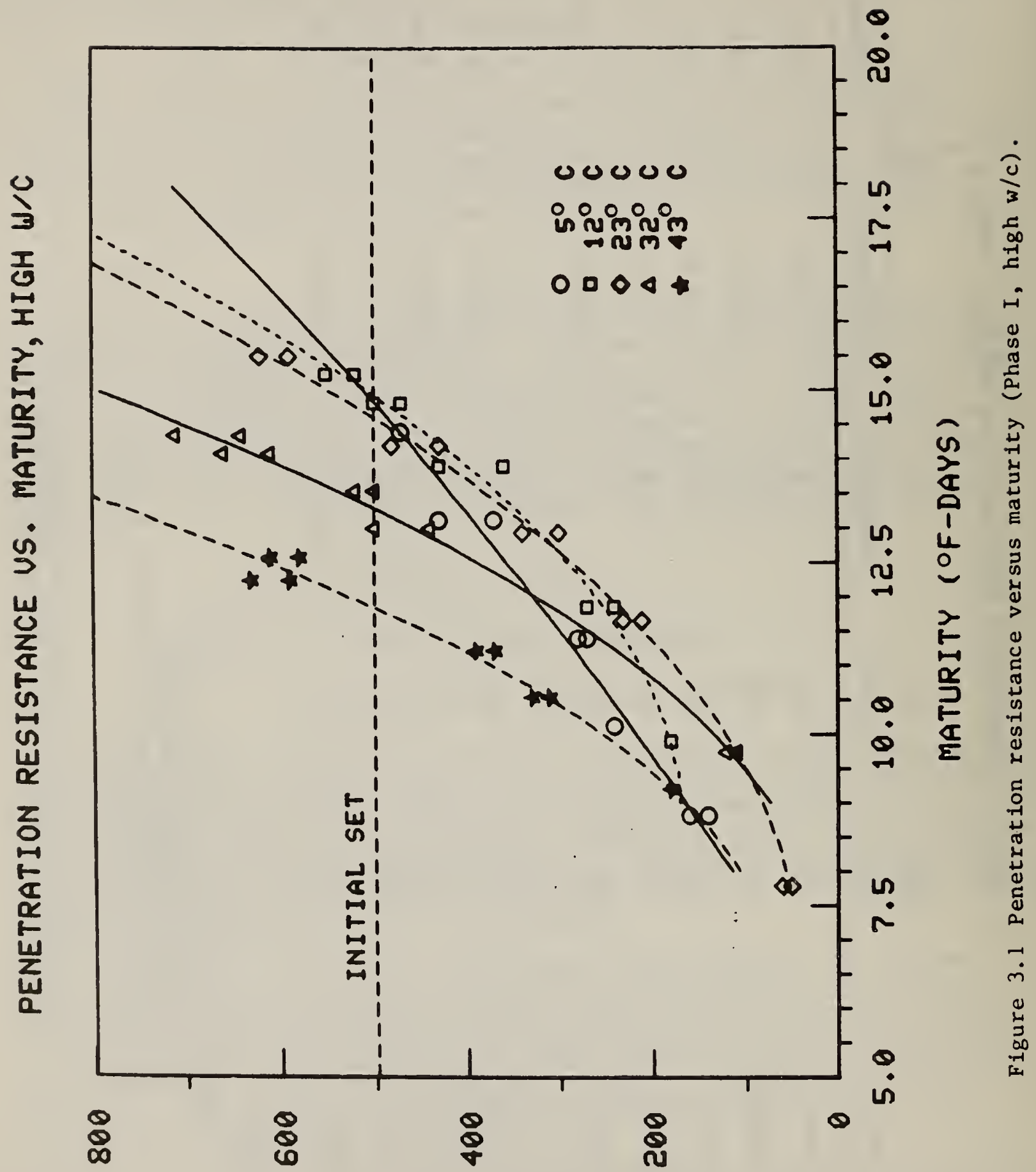

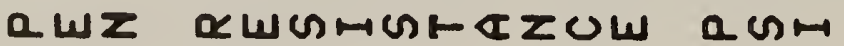




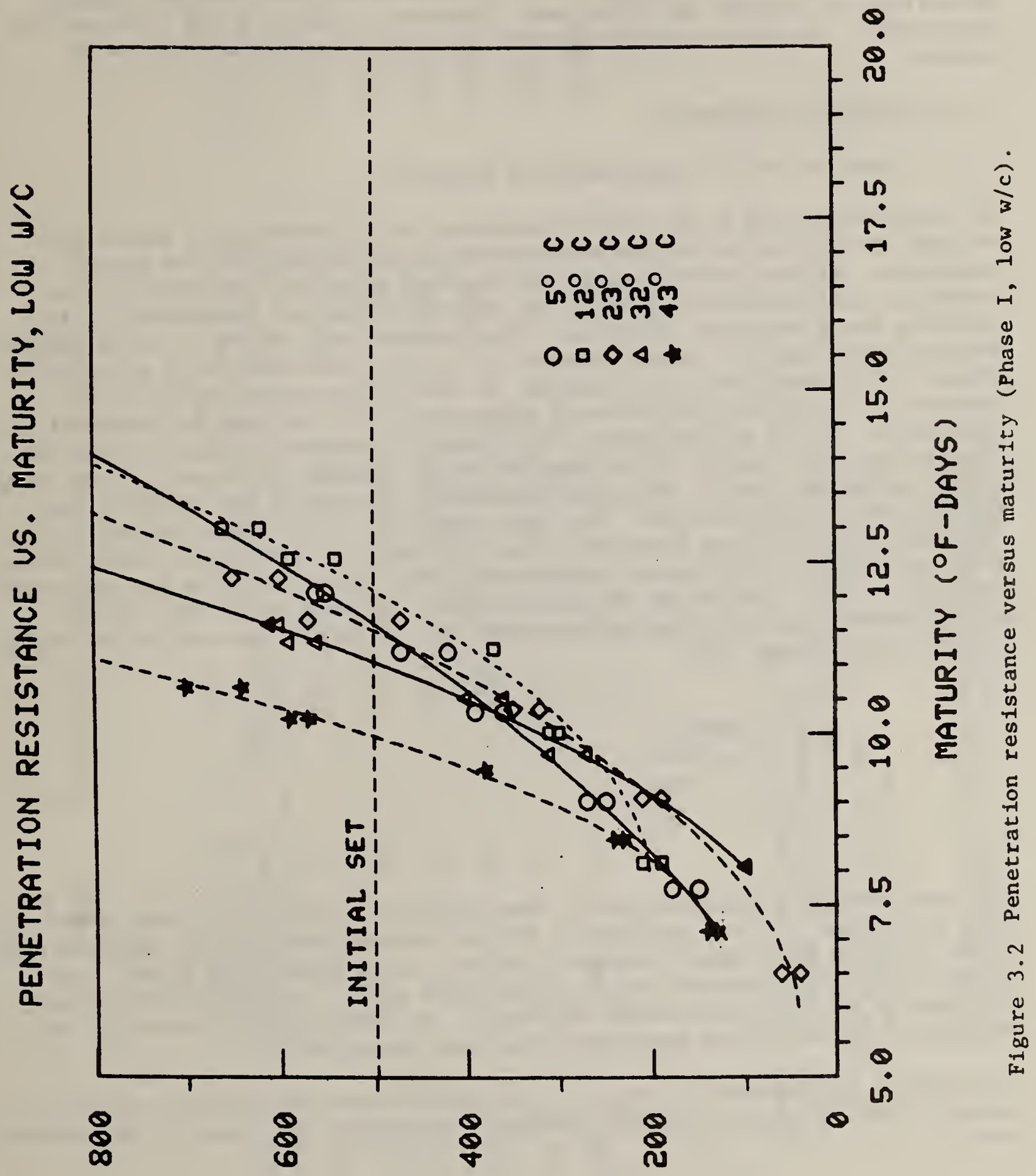

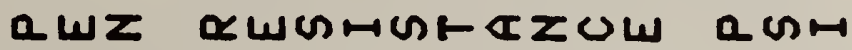




\section{Phase II Results:}

Data for the Phase II penetration tests are also presented in Appendix A. Table 2 presents the results of the regression analysis and the computed maturities at initial and final set. Figures 3.3 and 3.4 are plots of the penetration resistance versus maturity data and the best fit parabolic curves.

\subsection{COMPRESSIVE STRENGTH}

\subsubsection{Equation for Strength-Maturity Relation}

An objective of the study was to determine, in a quantitative manner, the effects of temperature on the strength-maturity relation of the mortar specimens. If the strength-maturity relation could be represented by an equation, determining the effects of temperature on the parameters of the equation would meet the objective. The probable true shape of the strengthmaturity relation of a given concrete at a given temperature is as shown in figure 3.5. There are four regions: 1) the plastic state during which concrete is fluid and incapable of supporting a static load in an unconfined condition; 2) the setting stage during which concrete transforms from the plastic to rigid state; 3) a stage of rapid strength gain; and 4) the stage during which the rate of strength development decreases and strength slowly approaches a limiting value. The exact shape of the initial portion of the curve is not well known because of the difficulty in testing concrete at such early maturities; and from an engineering point of view, it is not important because of the low strength of the concrete. In this study, the actual strength-maturity curve was approximated by a hyperbola having the following formula (see figure 3.5):

$$
S=\frac{\left(M-M_{0}\right)}{\frac{1}{B}+\frac{\left(M-M_{0}\right)}{S u}}
$$

This equation is a modification of that.proposed by Chin [16], with a refinement to account for the fact that a finite value of maturity is required before rapid strength development begins to occur. As written in eq (3.4), the parameter $B$ is the initial slope of the curve at $M_{0}$, and $S u$ is the limiting strength as maturity approaches infinity. The parameters $\mathrm{B}, \mathrm{Su}$ and $\mathrm{M}_{\mathrm{O}}$ were determined by non-linear regression analysis using DATAPLOT.

In Phase I, the adequacy of eq (3.4) in representing the various strengthmaturity relations was studied. Chapter 5 discusses the basis of the hyperbolic curve. 


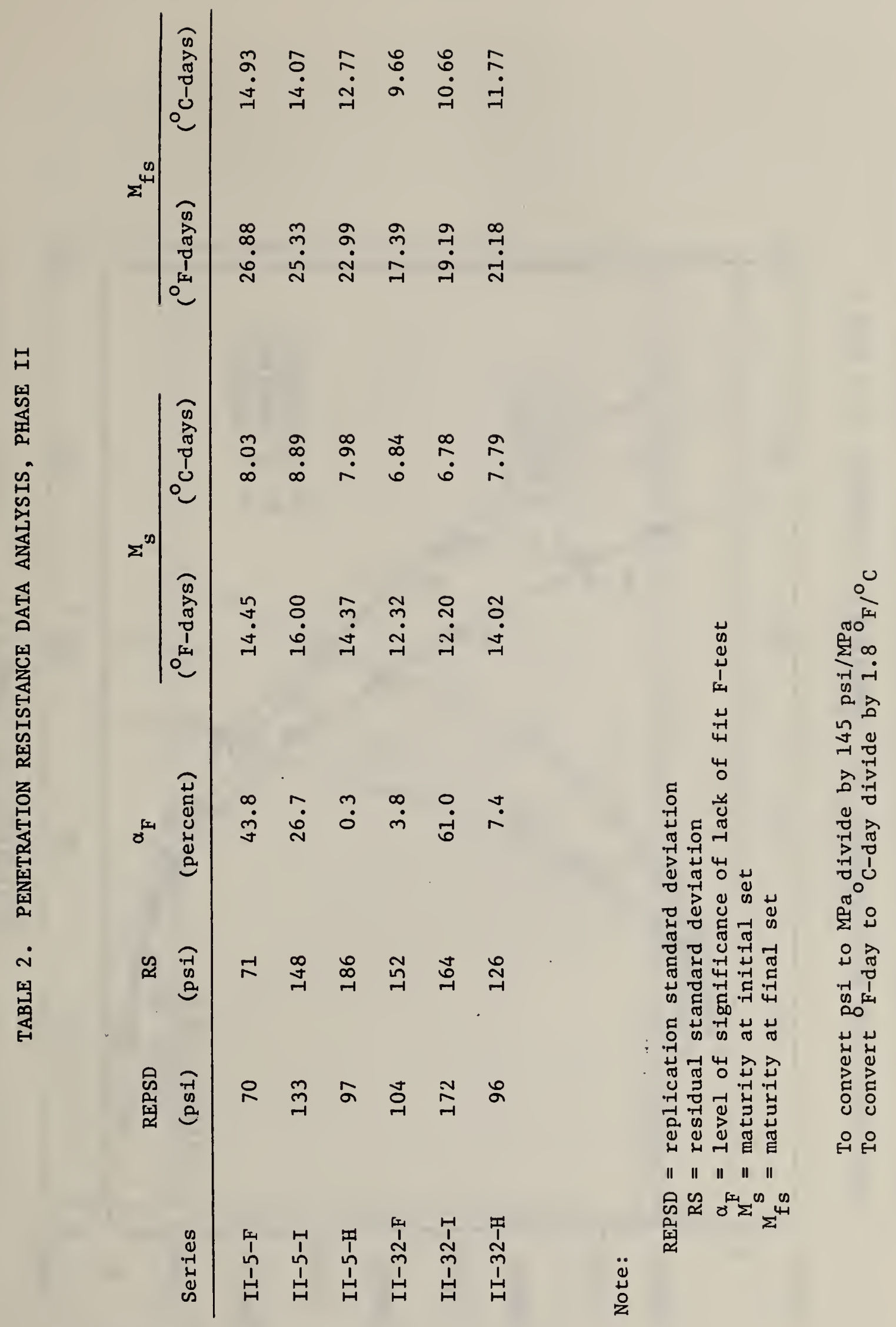




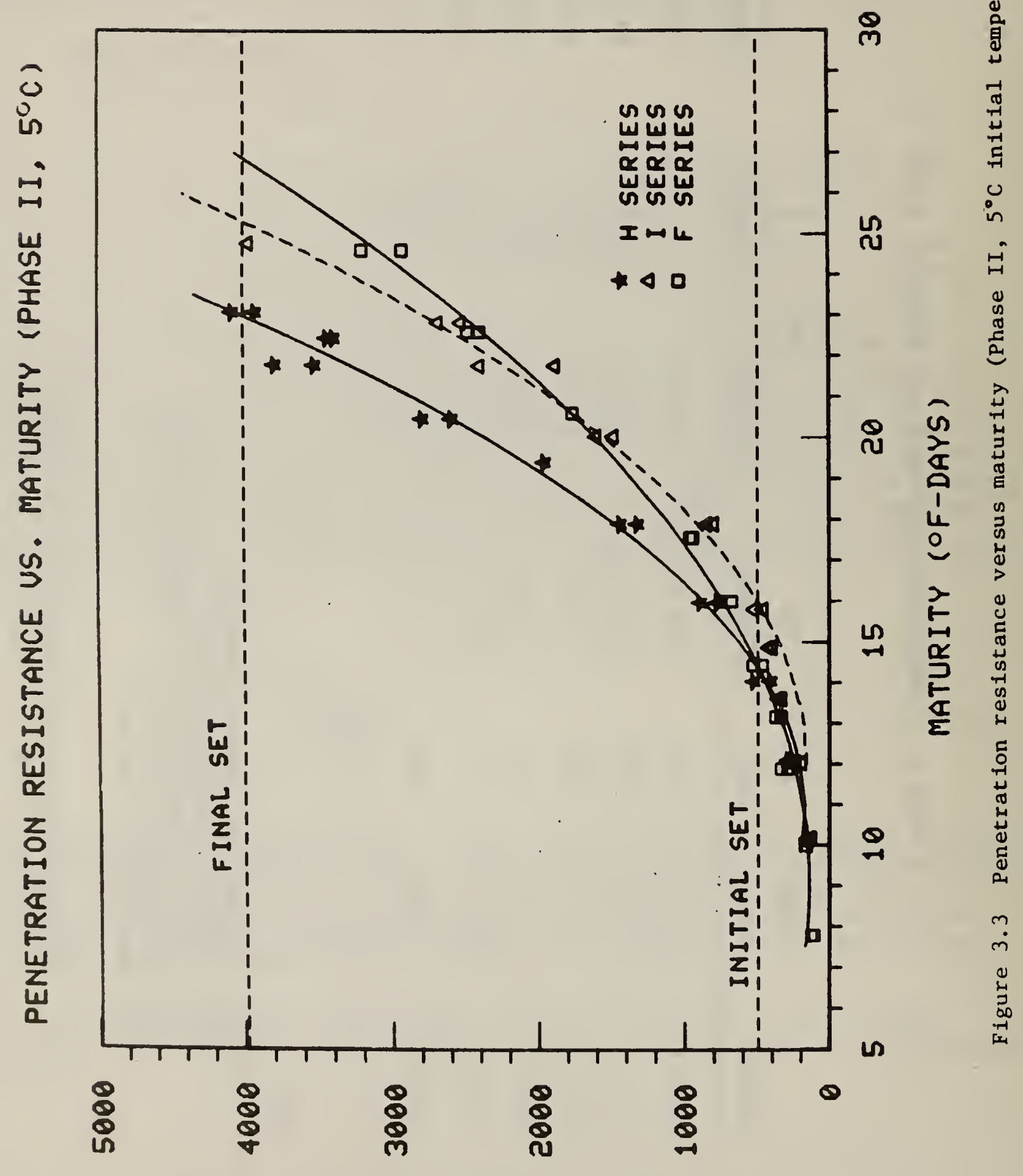

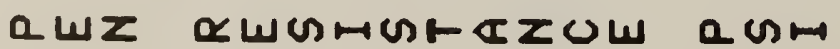




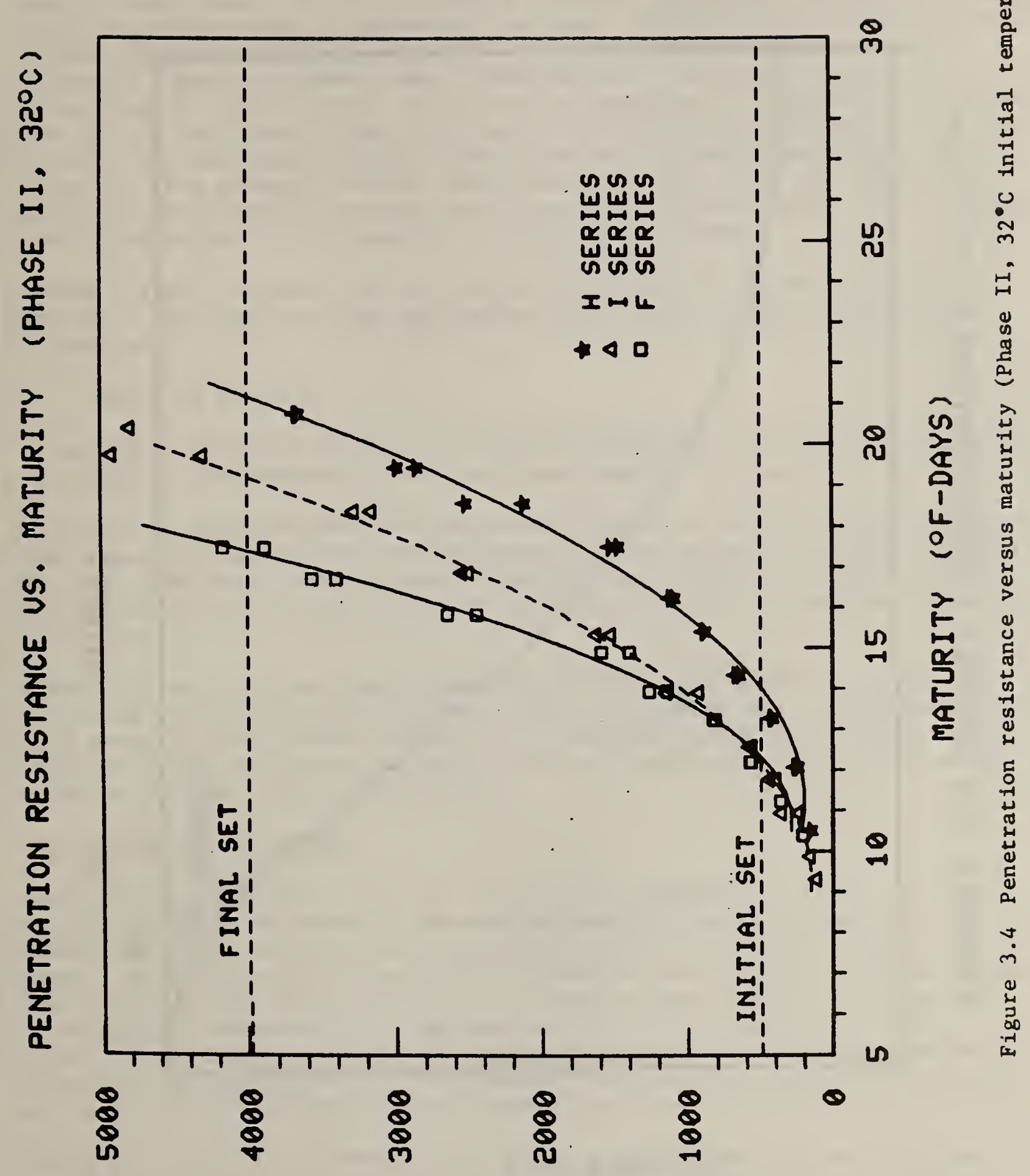

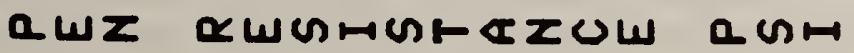




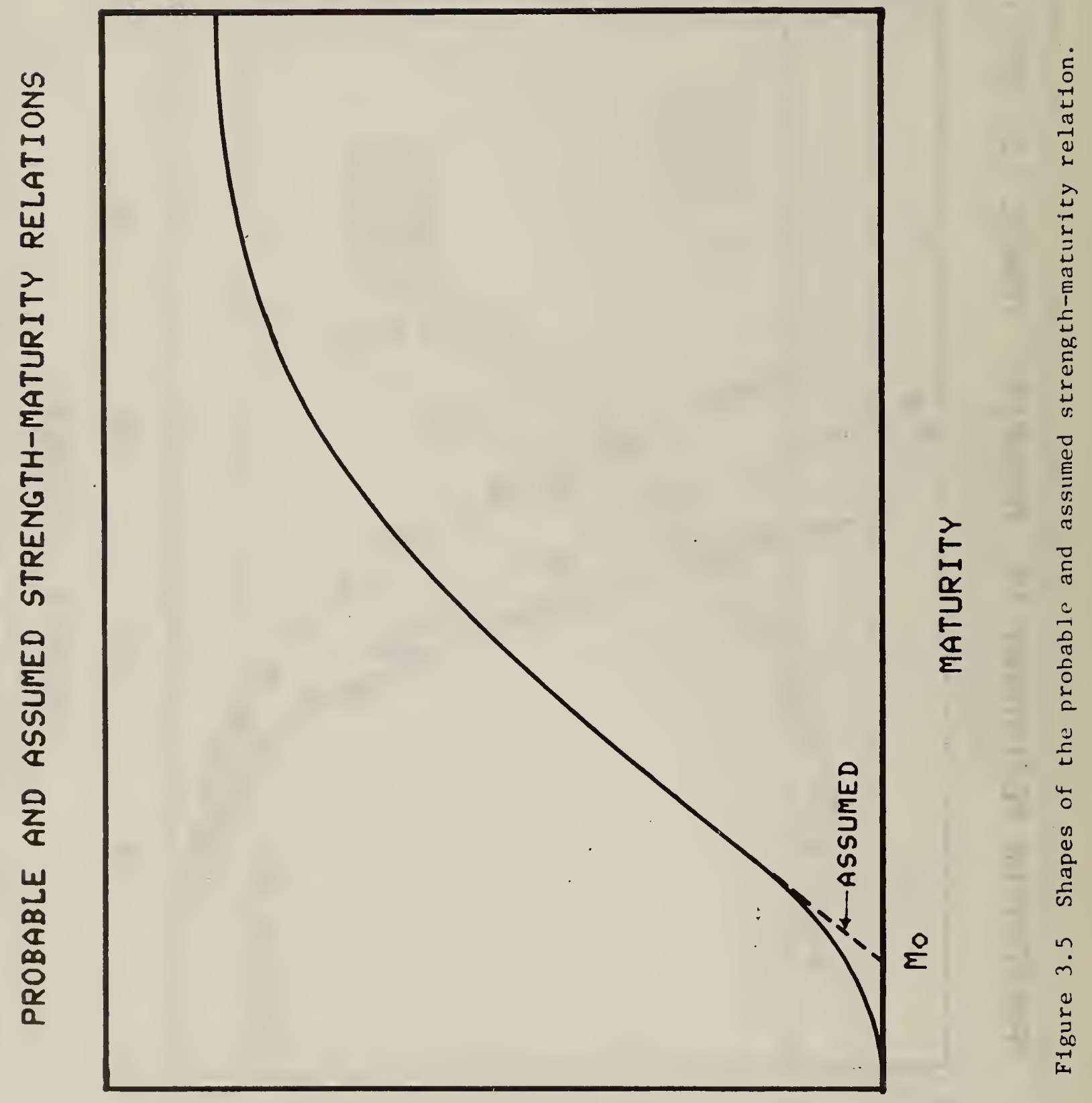

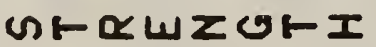




\subsubsection{Phase I Results}

The complete data of the Phase I compressive strength tests are presented in Appendix B. The results of the least squares fit analysis are given in table 3. Except for the $12^{\circ} \mathrm{C}$ low water-cement ratio mix, the lack-of-fit F-test level of significance is greater than 5 percent, indicating the appropriateness of the hyperbolic model to represent the data. However, the replication and residual standard deviations appear to indicate a lack of batch-to-batch uniformity. This is probably due to the method of selecting the sequence for testing the mortar cubes. As previously mentioned, a random selection was used, but it now appears that the cubes should have been selected so that the tests at each maturity included a cube from the beginning, middle and end of the batch. The strength results showed that the cubes from the end of the batch were consistently stronger than those from the beginning. More discussion of this problem will be presented in a following section.

Figures 3.6 and 3.7 show average compressive strength data as a function of maturity. Also shown are the hyperbolic curves based on the least-squares fit analysis.

\subsubsection{Phase II Results}

The data for the Phase II tests are given in Appendix B, and table 4 summarizes the values of the parameters from the least-squares fit analysis.

In Phase II, the cubes were selected so that tests at each maturity included a cube randomly selected from the beginning, middle and end of each batch. This procedure resulted in high values of replication standard deviation, but the lack-of-fit F-tests indicate that the hyperbolic model is a good representation of the data.

Figures 3.8 and 3.9 show the average strengths at each maturity and the best fit curves for the appropriate Phase I data for comparison. In figure 3.8, the solid curve is for constant curing at $5^{\circ} \mathrm{C}$, and the dashed line is for constant curing at $23^{\circ} \mathrm{C}$. In figure 3.9 , the solid and dashed curves are for constant curing at $23^{\circ}$ and $32^{\circ} \mathrm{C}$, respectively.

\subsection{UNIFORMITY OF BATCHES}

Since an objective of Phase I was to determine temperature effects on the strength-maturity relations of two mortar mixes, it was important that the batches of mortar have the same water content for the various thermal treatments. It was anticipated that the evaporation rate would vary as the mixing temperature varied from $5^{\circ}$ to $43^{\circ} \mathrm{C}$. In order to have a general indicator of batch-to-batch uniformity, the weights of the mortar cubes were recorded prior to compression testing. If a particular batch had excessive evaporation during the casting phase, the water-cement ratio of that batch would decrease and result in an increase in the weight of the cubes.

Figure 3.10 shows the average weight of the mortar cubes and the 95 percent confidence intervals for the two mortar mixes as a function of the nominal mixing temperature (Phase I). The results show that there were no significant differences among the weights of the $5^{\circ}, 12^{\circ}, 23^{\circ}$ and $32^{\circ} \mathrm{C}$ mixes, but the $43^{\circ} \mathrm{C}$ 


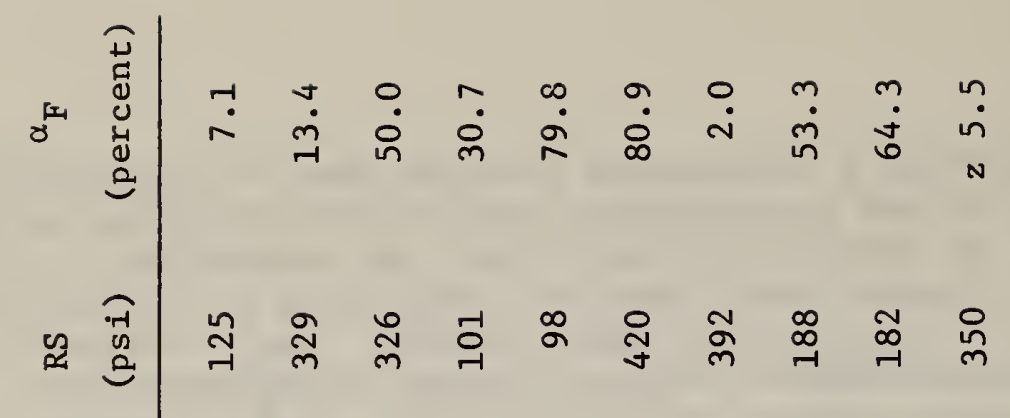

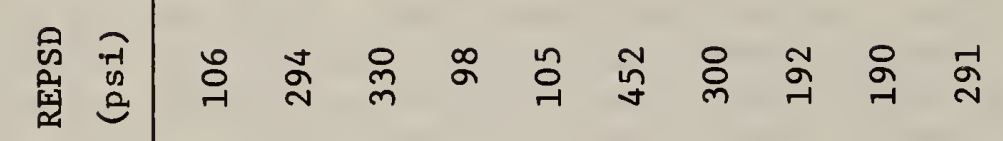

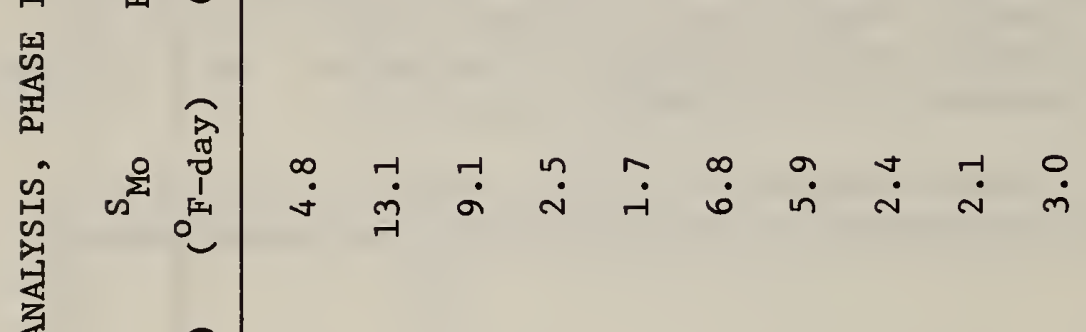

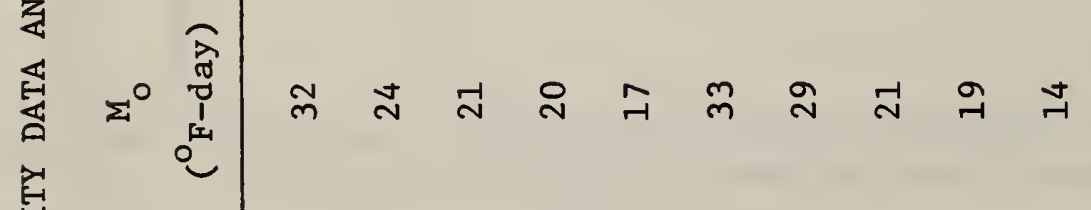

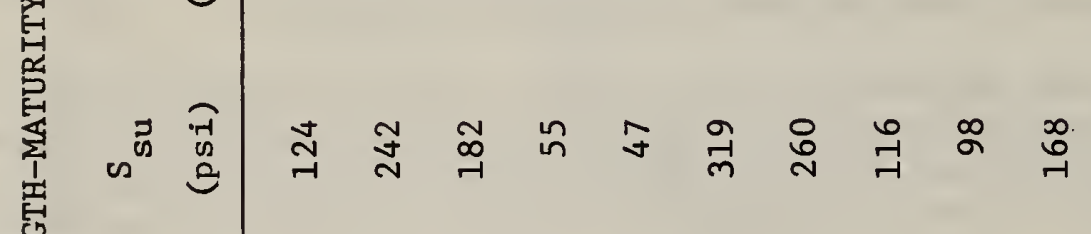

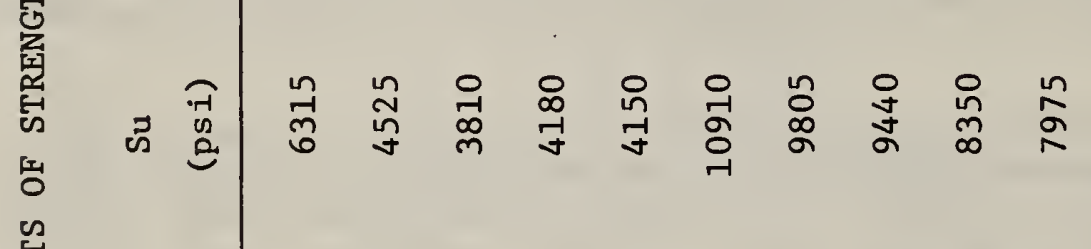

$$
\begin{aligned}
& \text { 毁 } \\
& \text { 害 }
\end{aligned}
$$

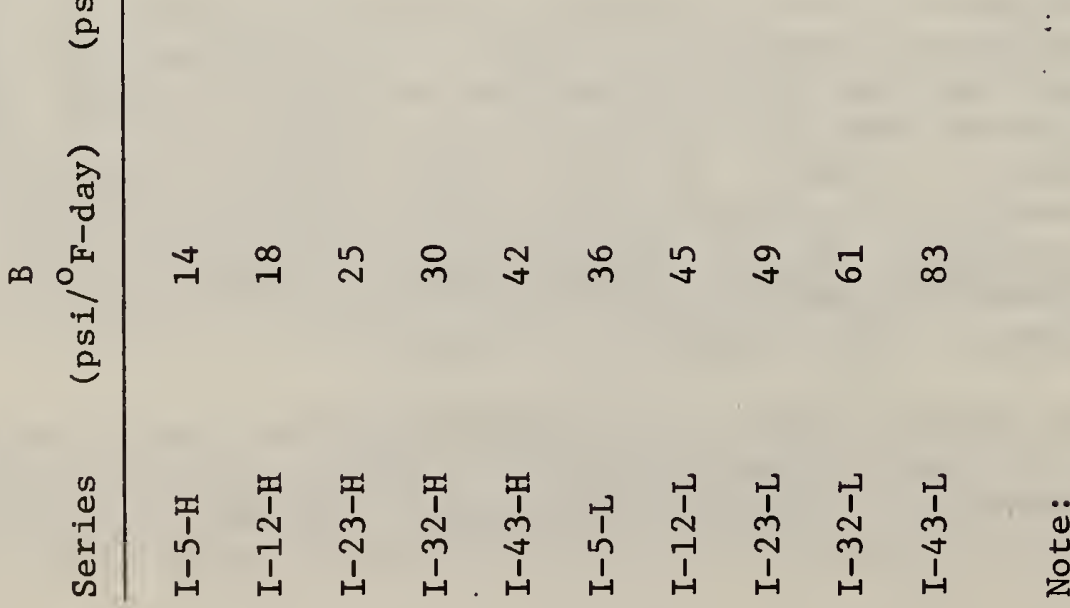

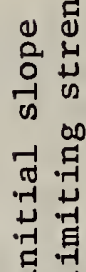

$$
\begin{aligned}
& \text { 站 } \\
& \text { क जे }
\end{aligned}
$$

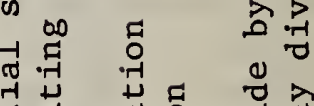

$$
\begin{aligned}
& \text { 点 } \\
& \text { न }
\end{aligned}
$$

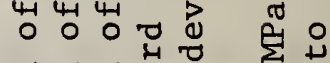

$$
\begin{aligned}
& \text { म म }
\end{aligned}
$$

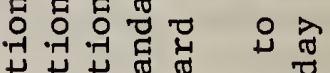

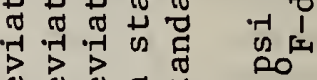

$$
\begin{aligned}
& \text { (1) } 5
\end{aligned}
$$

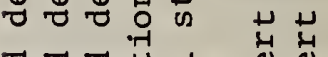

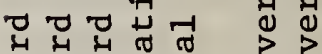

$$
\begin{aligned}
& \text { त } \\
& \text { क त }
\end{aligned}
$$

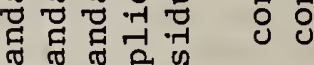

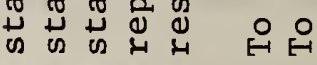

$$
\begin{aligned}
& \text { || || || || || } \\
& \text { की में क्री थि }
\end{aligned}
$$




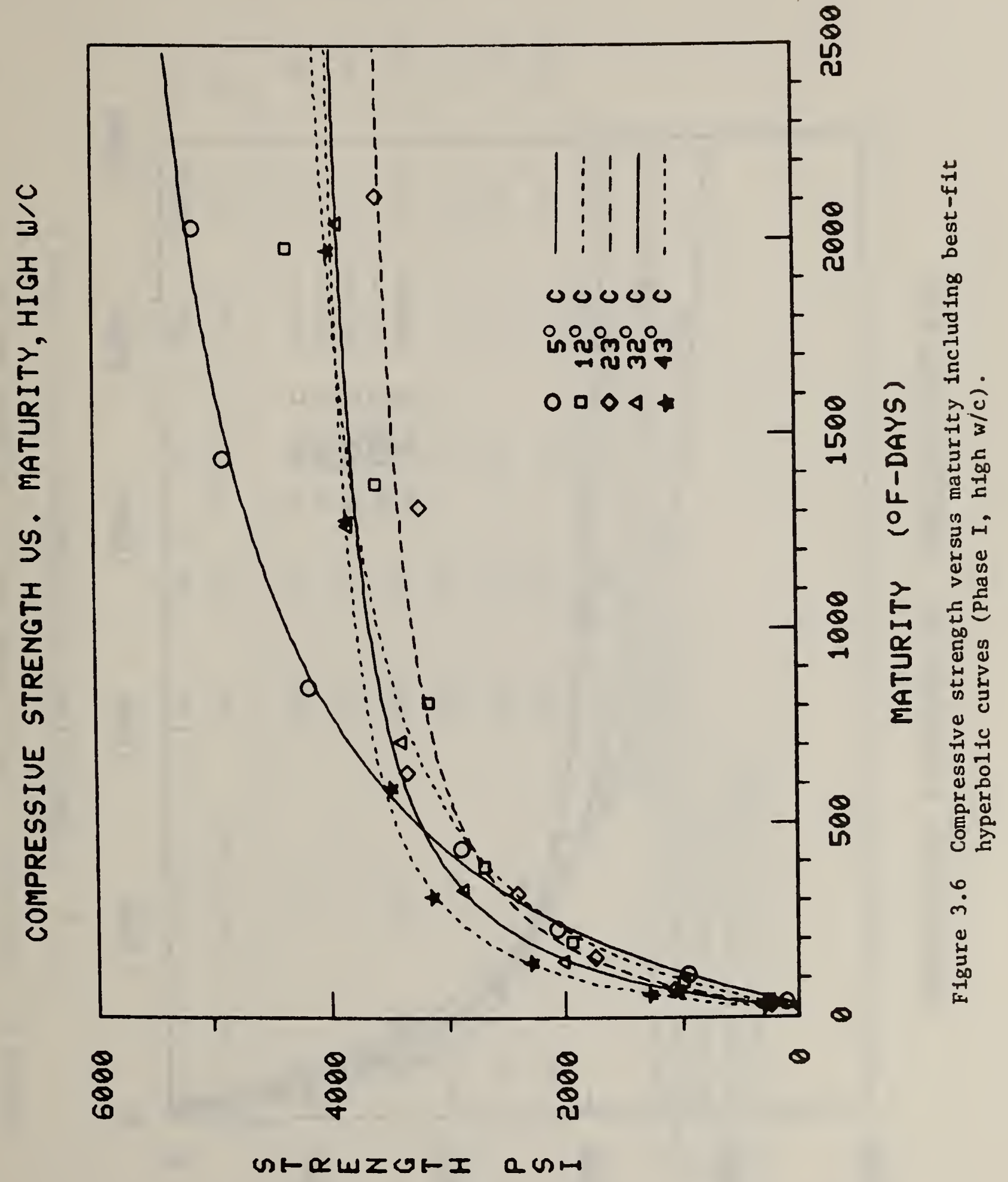




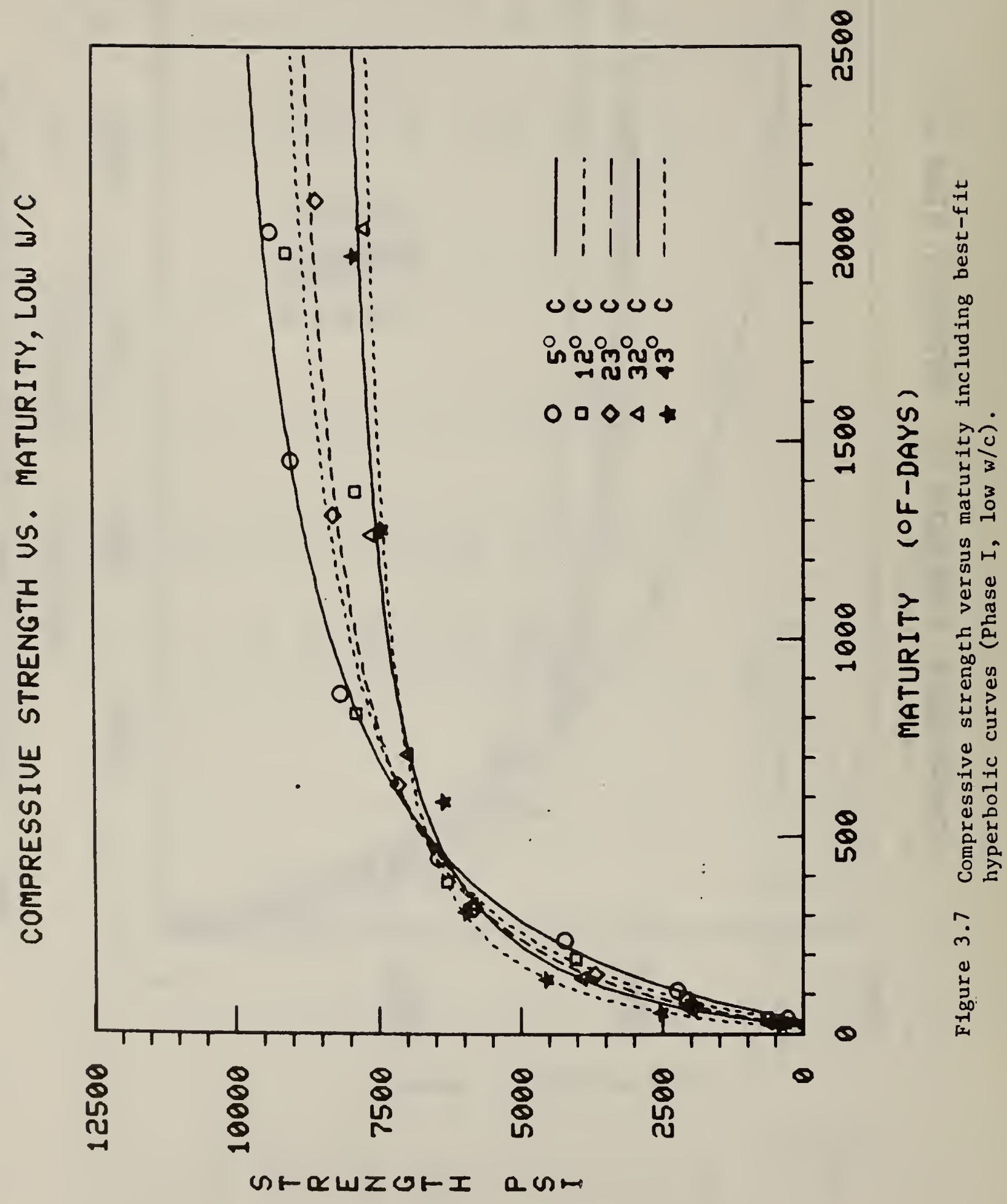




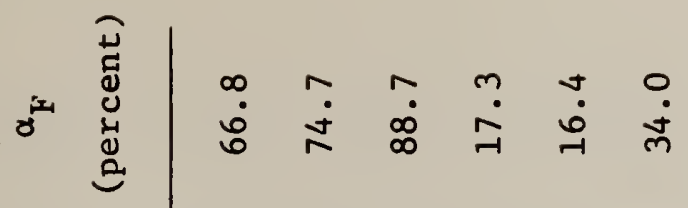

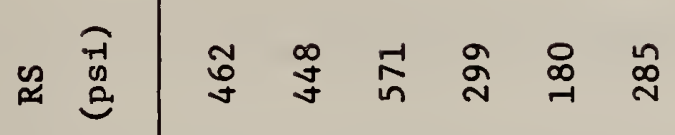

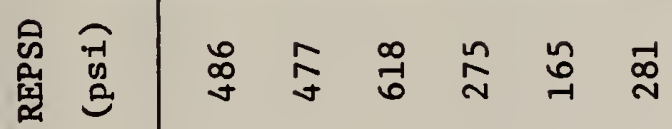

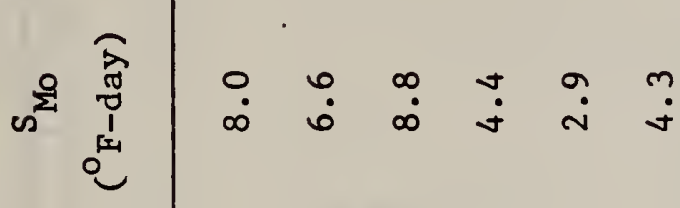

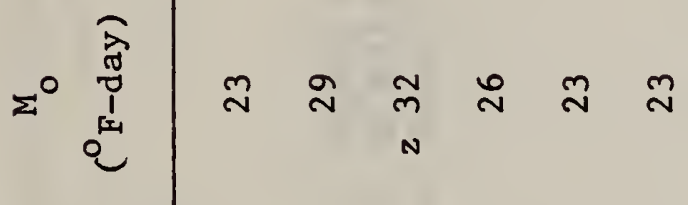

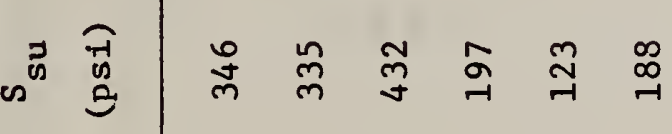

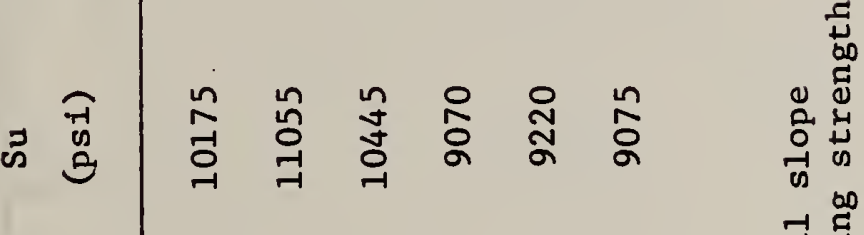

$$
\begin{aligned}
& \text { 落 }
\end{aligned}
$$

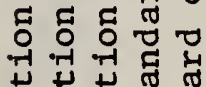

$$
\begin{aligned}
& \text { 先 } \\
& \text { ه d ه }
\end{aligned}
$$

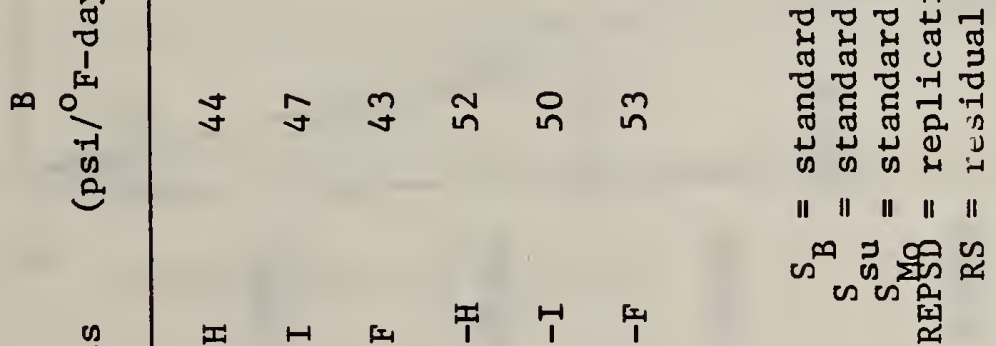

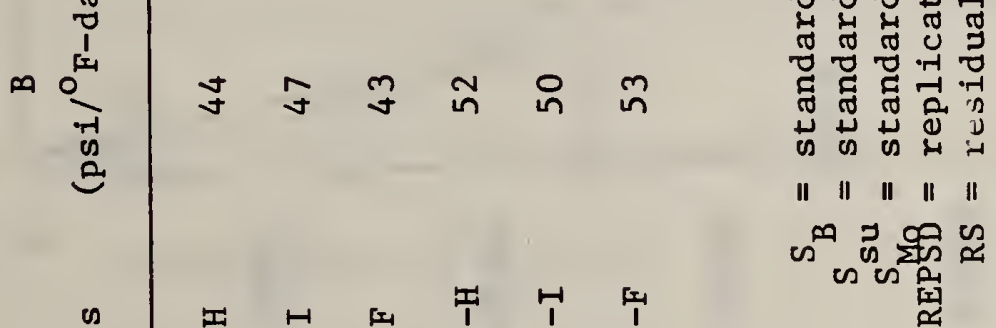

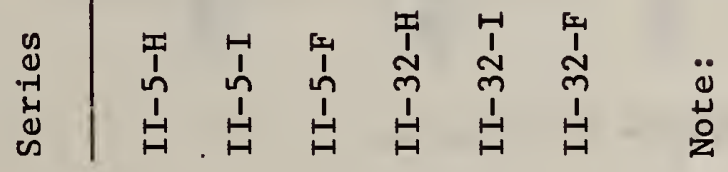




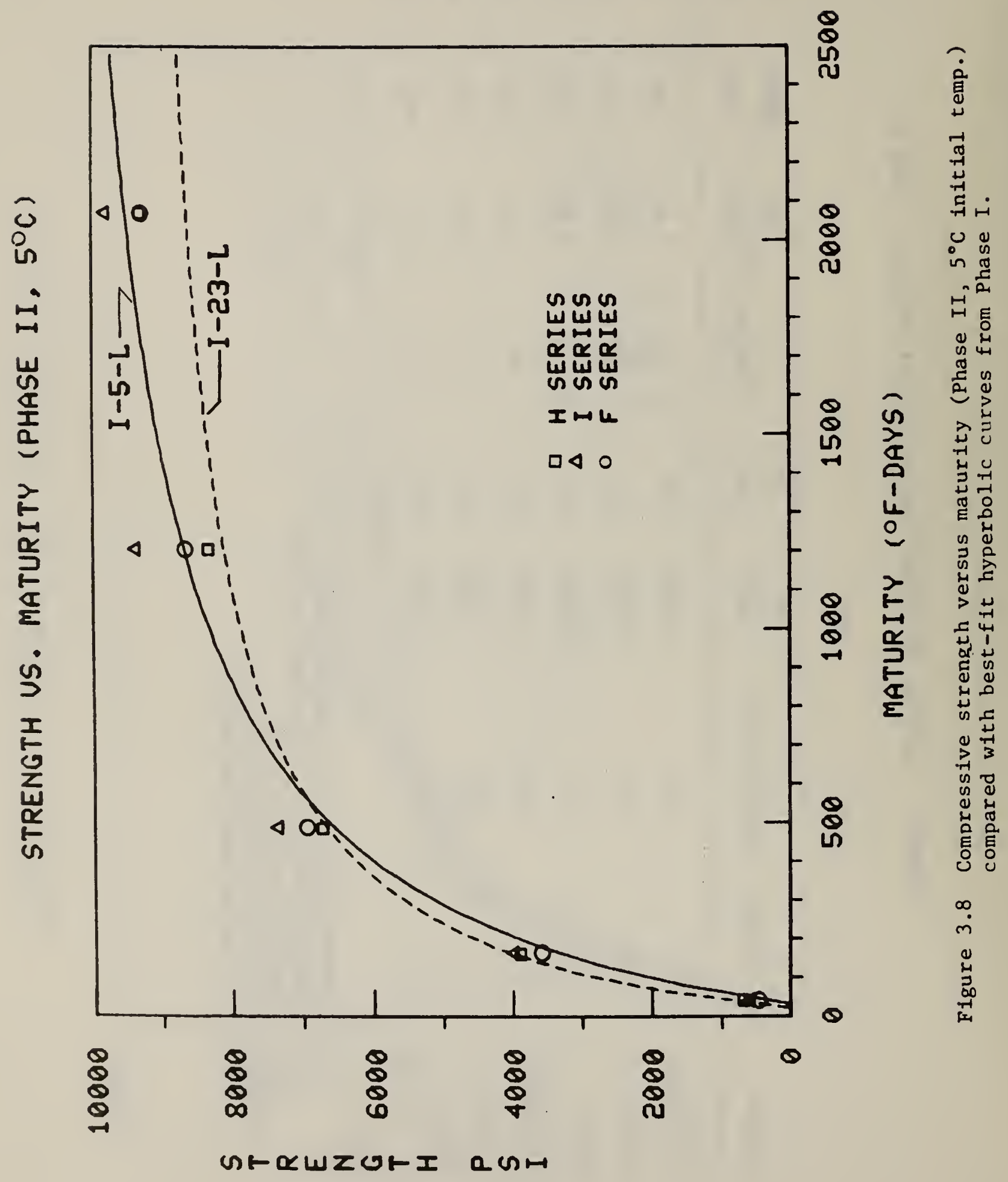




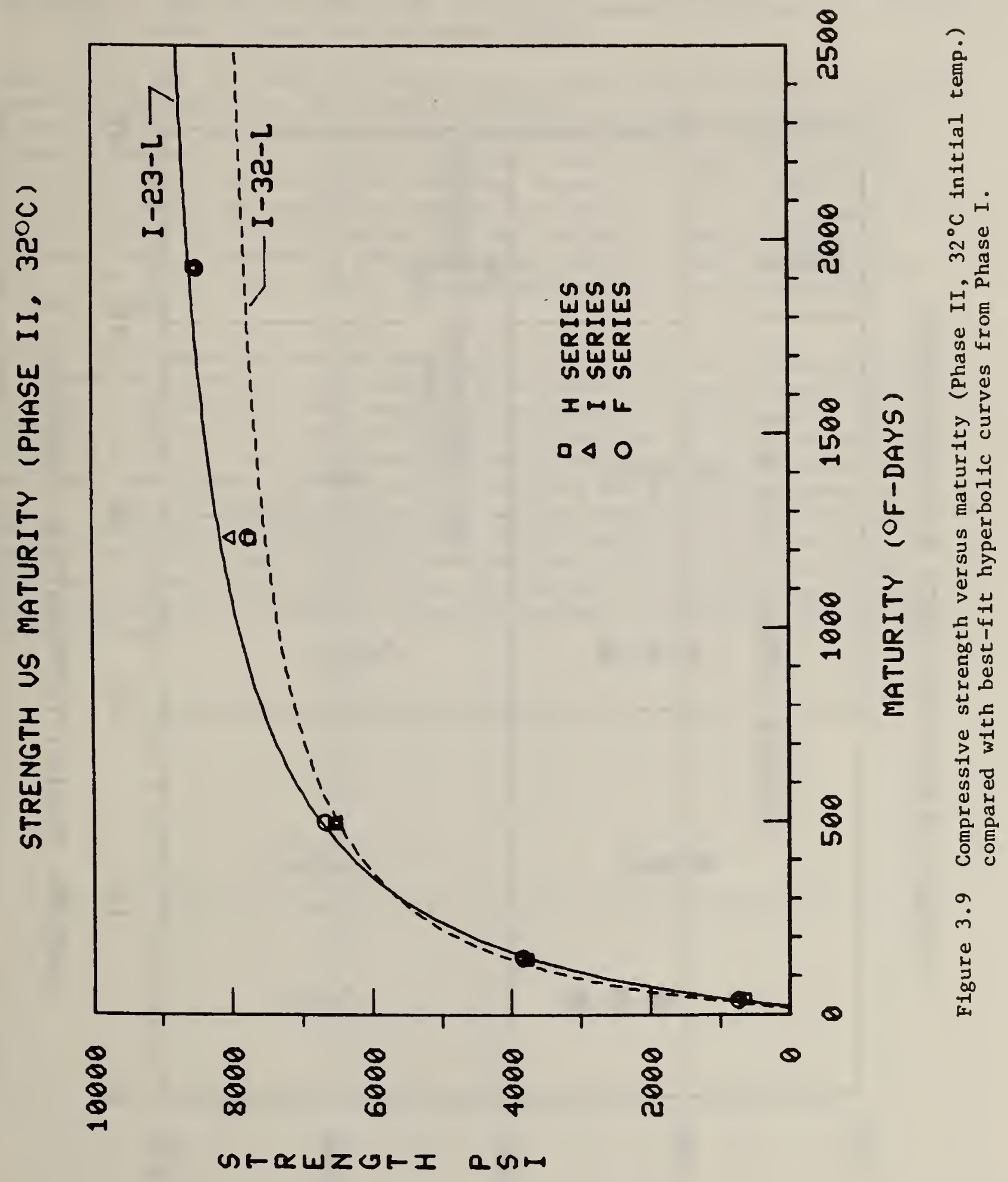




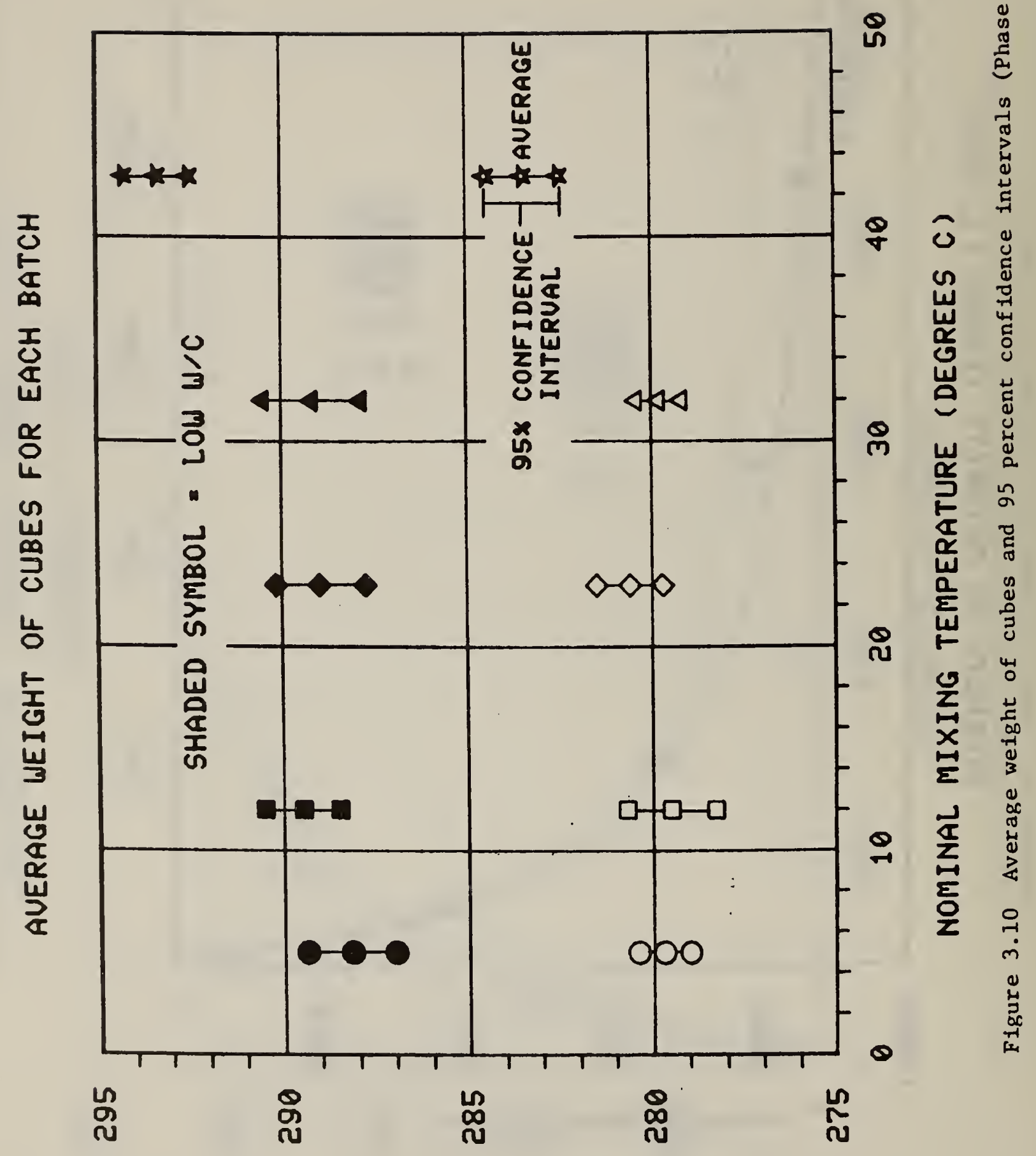

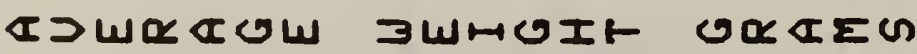


cubes were slightly heavier. This discrepancy may be due to the inability of the chamber to maintain a 50 percent relative humidity at this high temperature. Therefore, it may be concluded that the mortars cured at $43^{\circ} \mathrm{C}$ were of slightly lower water-cement ratios than the other batches.

Figures 3.11 and 3.12 show the average cube weights and 95 percent confidence intervals for the $5^{\circ}$ and $32^{\circ} \mathrm{C}$ initial treatments of Phase II, respectively. Figure 3.11 also shows the 95 percent confidence interval for the average weight of series I-5-L. It can be concluded that there were no significant differences among the weights of the cubes prepared at $5^{\circ} \mathrm{C}$ in Phases I and II. Figure 3.12 shows the confidence interval for series I-32-L. It appears that the Phase II specimens prepared at $32^{\circ} \mathrm{C}$ were slightly heavier than the companion Phase I specimens. Heavier weights would probably be associated with a lower water-cement ratio. No explanations for these differences could be found.

Another anticipated problem was the degree of within-batch uniformity due to absorption of water by the sand and evaporation. It was believed that the specimens from the end of the batch might be different from those at the beginning. Figures 3.13 through 3.17 show the weights of each cube that was tested in Phase $I$. The cubes were numbered consecutively in the order they were cast; cubes numbered 1 through 24 were from the high water-cement ratio mix and numbers 25 through 48 were from the low ratio mix. For most cases, the distributions of weights indicate a rise in weight with increasing cube number. Thus, it appears that for each mix the cubes from the end of the batch would be of slightly lower water-cement ratio. This difference is clearly manifested in Appendix B where the weights and strengths of the cubes are tabulated. 


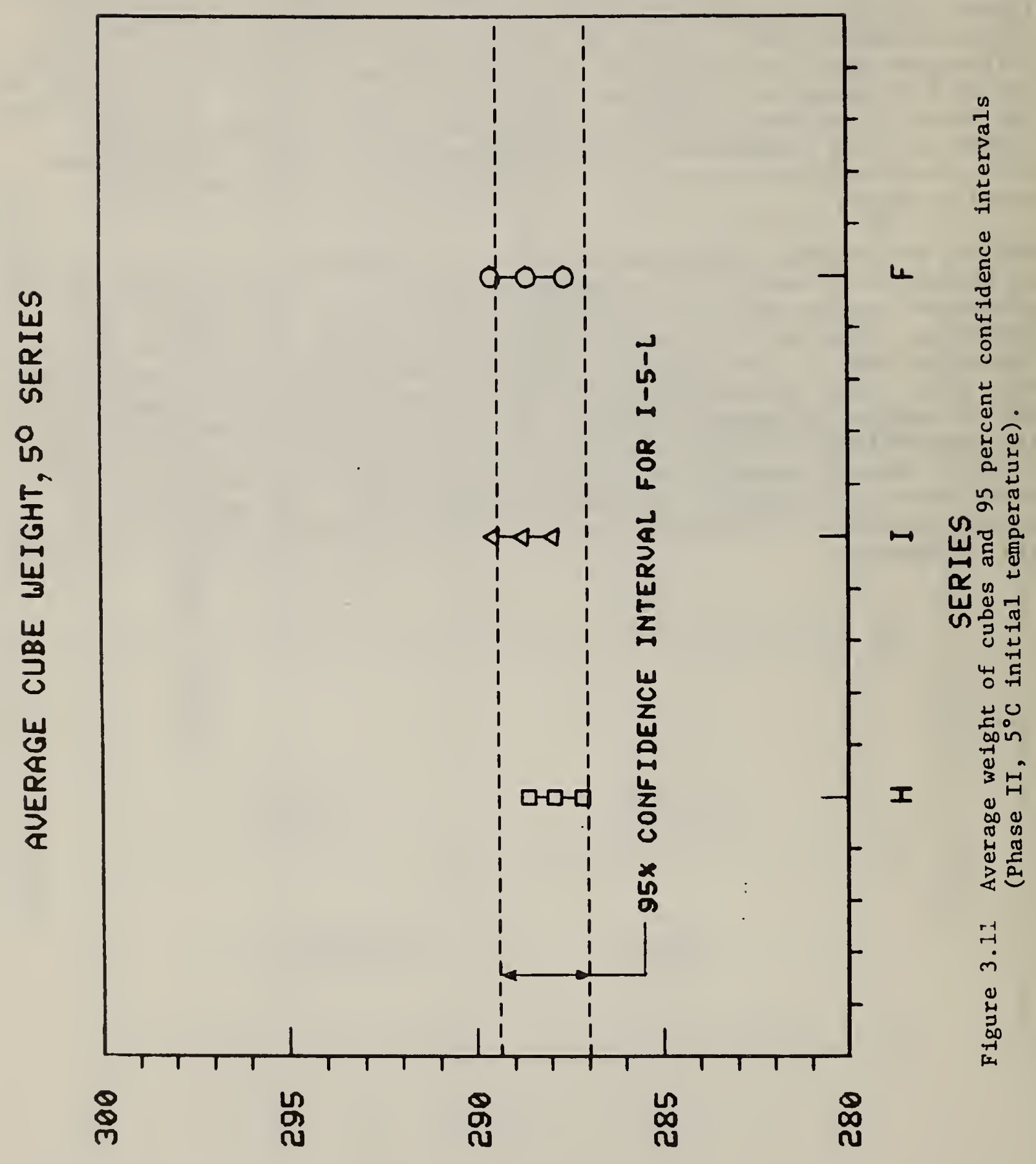

วயमலIt जOवEの 


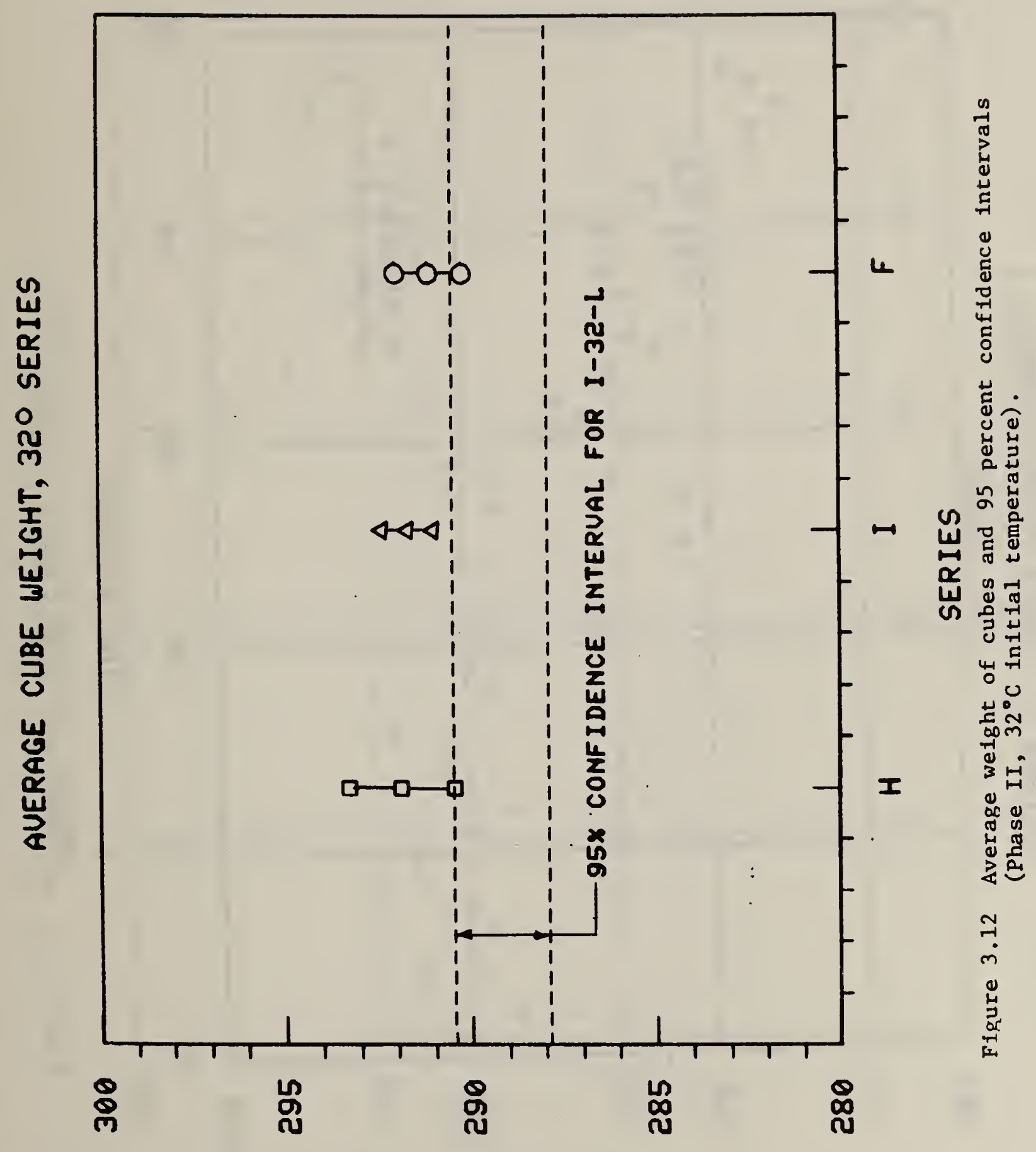

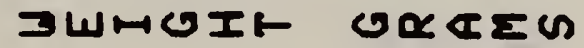




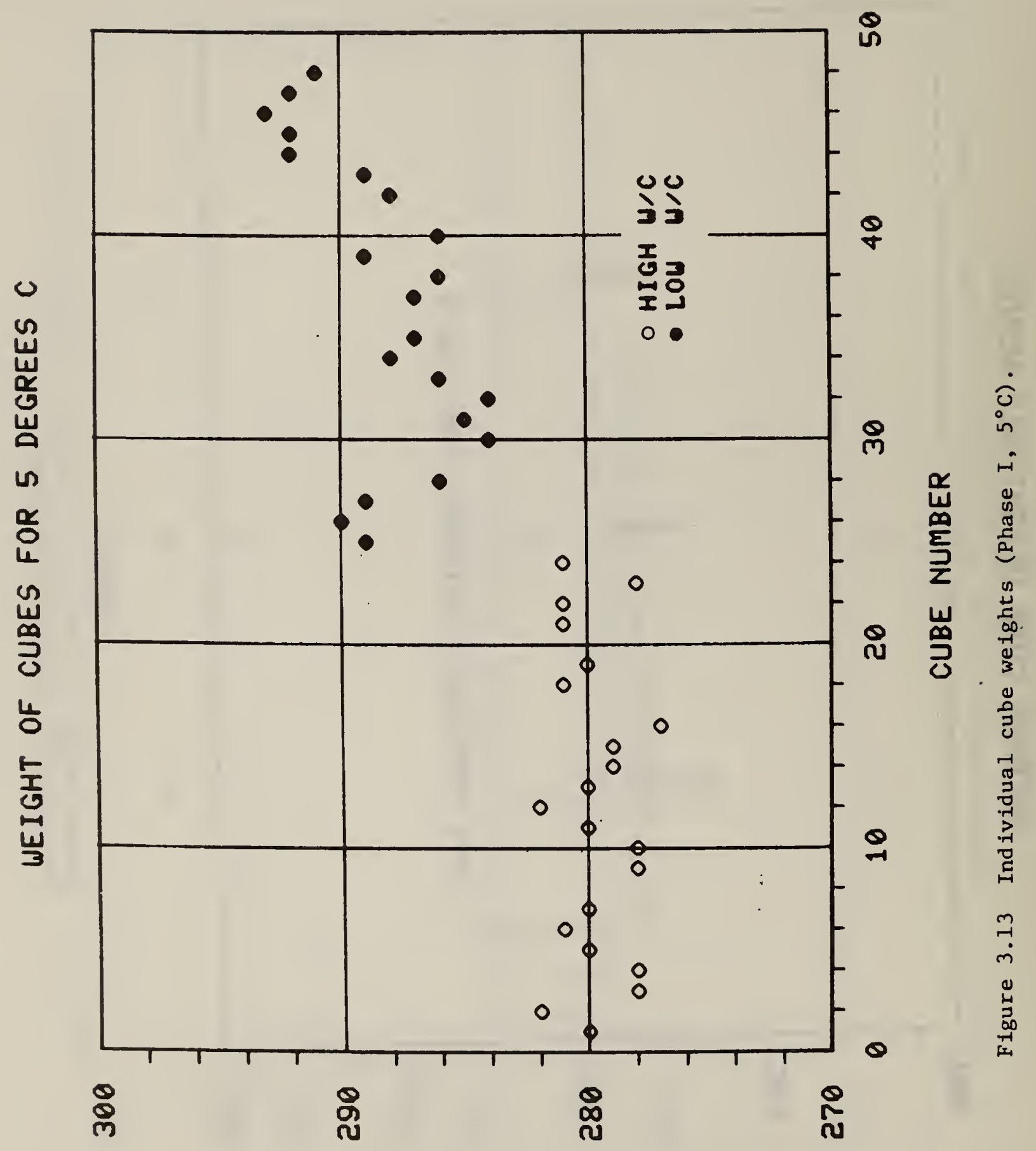

コWमUIト UवषEの 


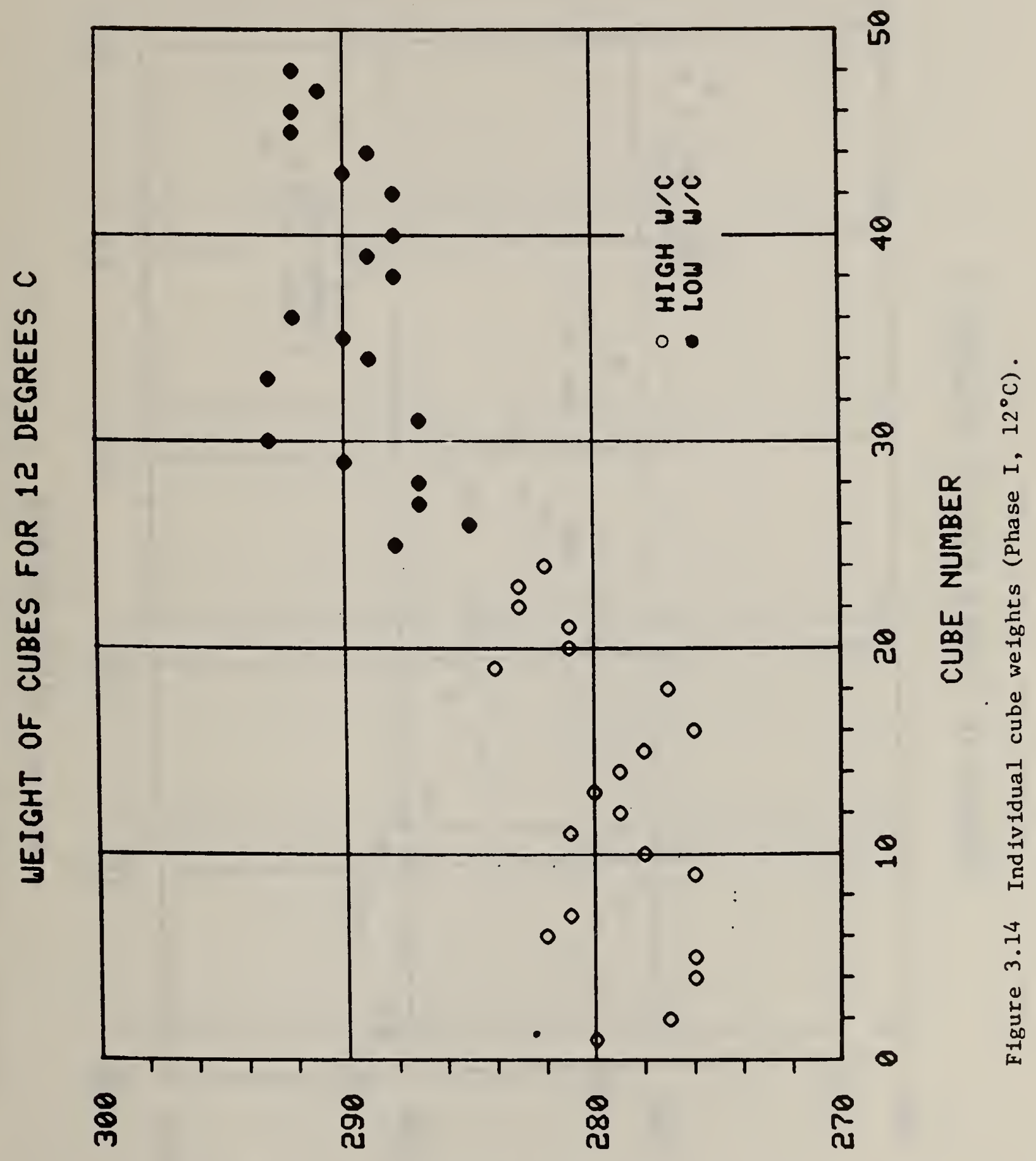

ЭWHeIF 


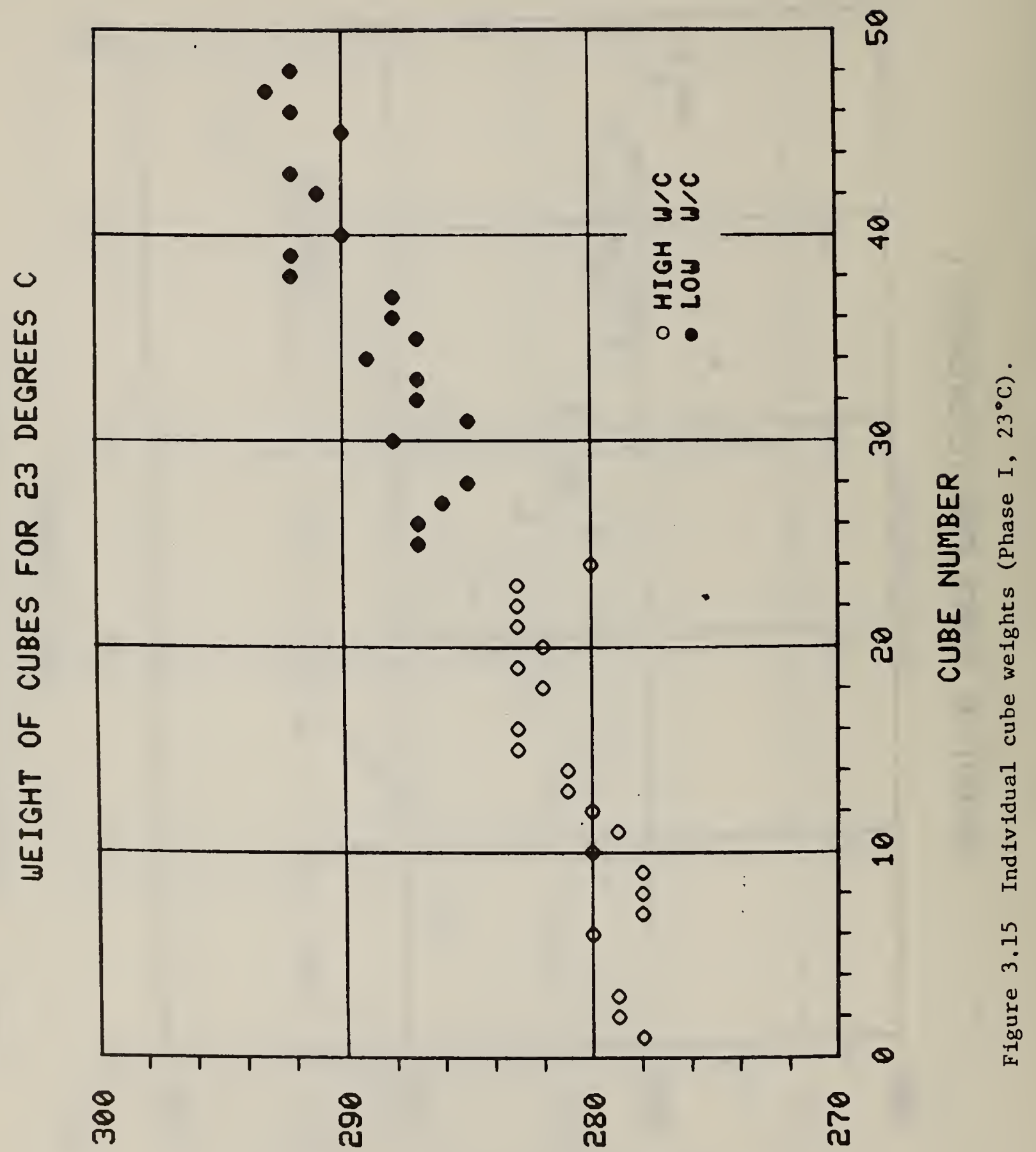

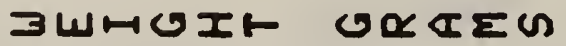




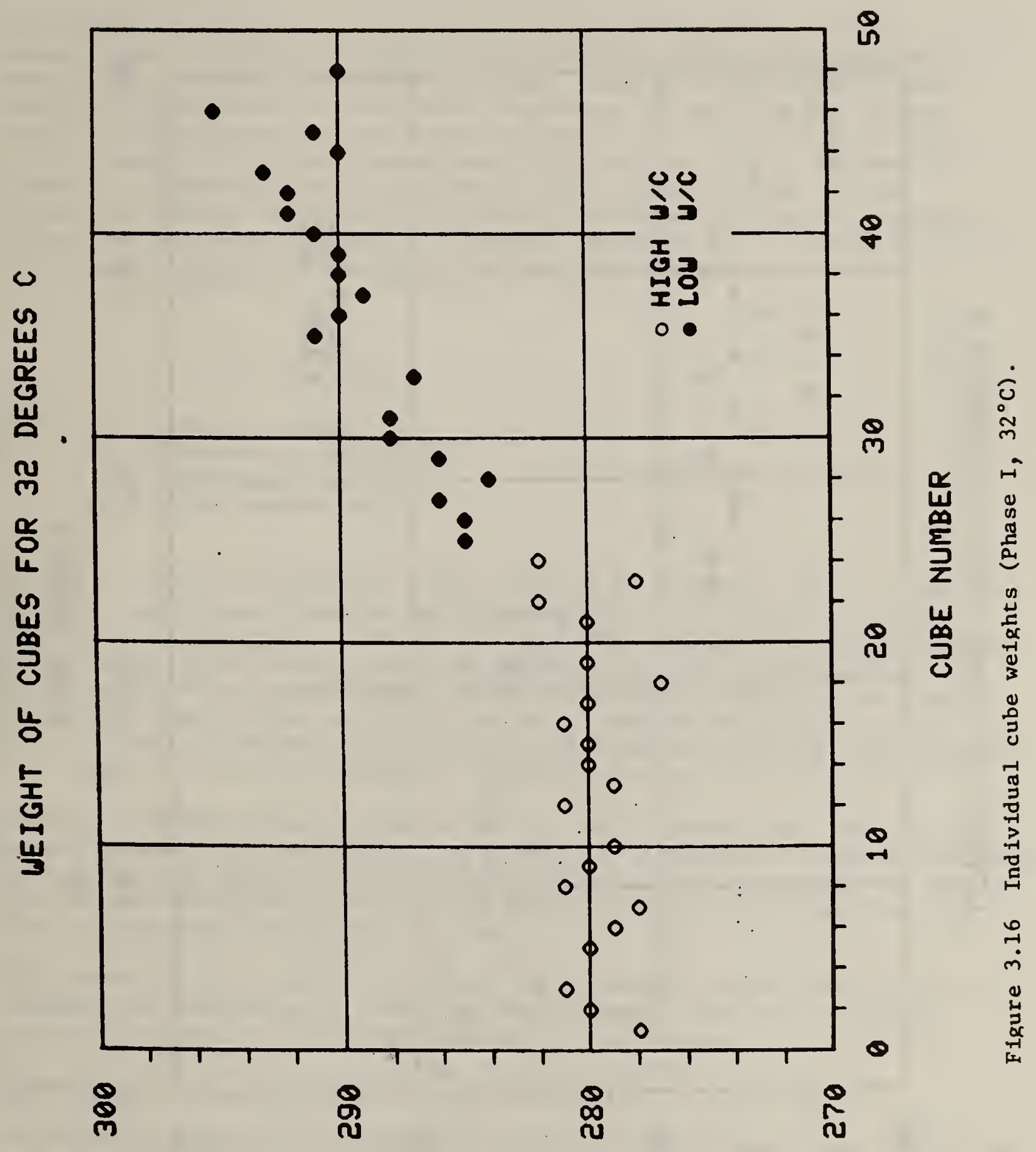

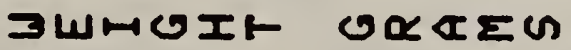




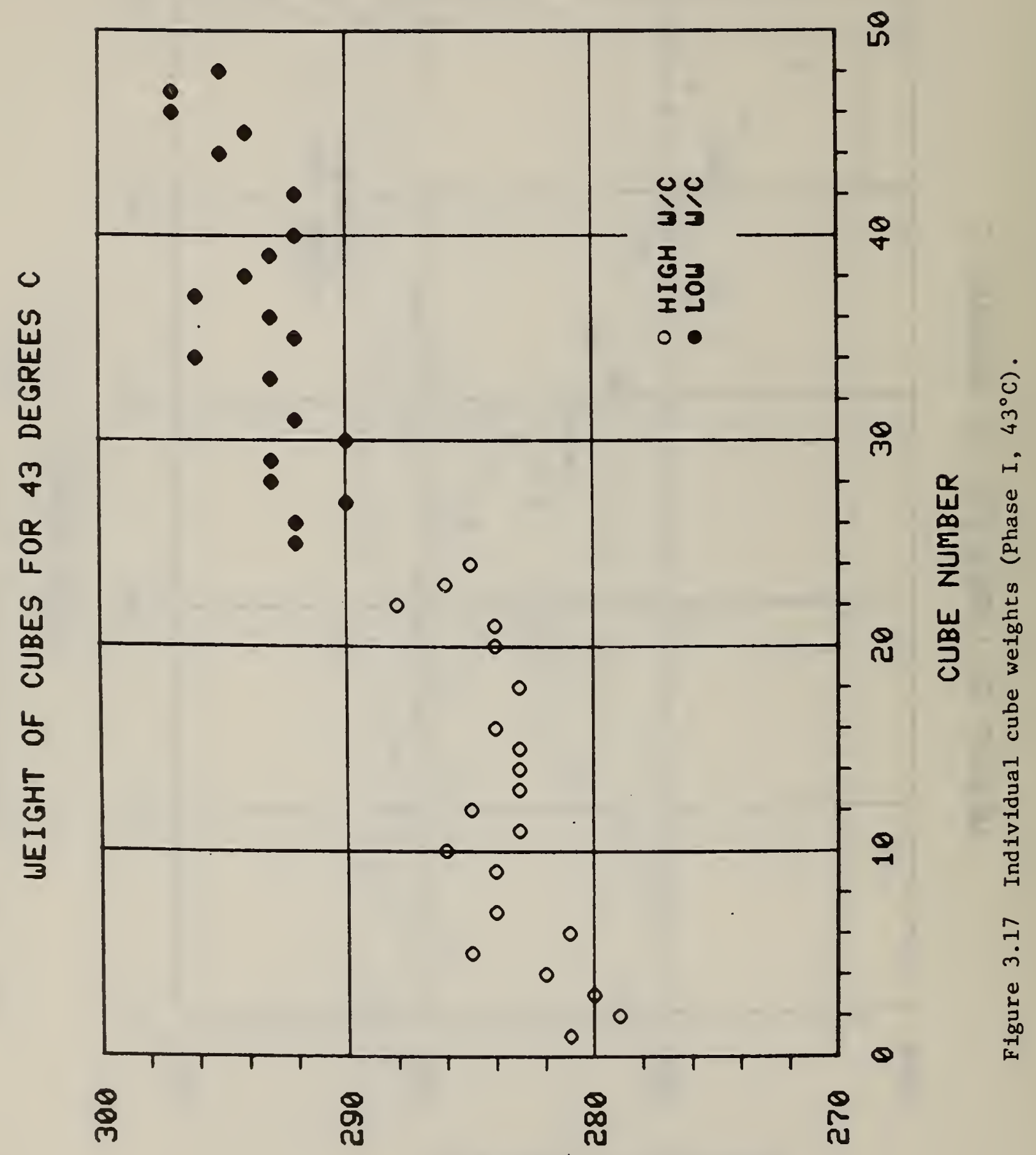

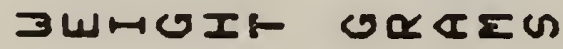




\subsection{ANALYSIS AND DISCUSSION OF RESULTS \\ 4.1 SETTING BEHAVIOR}

\section{Phase I:}

As previously mentioned, the purpose in studying the setting behavior of the mortars was to determine whether initial and final set were correlated with maturity. In Phase I, the initial setting times were interpolated from semilogarithmic plots of penetration resistance versus time from initial mixing. The computed setting times are plotted in figure 4.1 as a function of the cumulative average temperature at initial set. It is observed that there is a consistent relation between time and temperature. As the cumulative average temperature increases, the age at initial set decreases. If initial set were to occur at a constant maturity, the following relationship should exist between setting time and temperature:

$$
t_{s}=\frac{M_{s}}{\left(T-T_{0}\right)}
$$

where $t=$ time at initial set

$$
\begin{aligned}
M_{S}^{S} & =\text { maturity at initial set } \\
\mathrm{T} & =\text { temperature } \\
\mathrm{T}_{0} & =\text { datum temperature }
\end{aligned}
$$

Figure 4.1 shows the best fit curves obtained by fitting eq (4.1) to the data; $M$ and $T$ were found from the least squares fit. The values of $M$ were 7.4 and $8.2^{\mathrm{O}} \mathrm{C}$-days (13.3 and $11.1^{\mathrm{o}} \mathrm{F}$-days) for the high and low water-cement ratio mixes, respectively; while the values of $\mathrm{T}$ were -9.8 and $-10.6{ }^{\circ} \mathrm{C}$ $\left(14.3\right.$ and $\left.12.8^{\circ} \mathrm{F}\right)$, respectively. Thus, the analysis indicates that the assumption that initial set will occur at a constant maturity is a good one; also the best fit values of $T$ are not very different from the value suggested for computing maturity of hardened concrete, that is, $-11.7^{\circ} \mathrm{C}\left(11^{\circ} \mathrm{F}\right)$.

Figure 4.2 shows the maturities at initial set, computed from the best fit curves discussed in section 3.1 , as a function of cumulative average temperature at initial set. There is some tendency for a decrease in maturity at initial set as temperature increases, but the decrease is not very significant over the wide range of temperatures studied.

The assumption that initial set occurs at a constant value of maturity can be significant information in designing the placement rates of concrete in vertical formwork for different temperature conditions.

\section{Phase II:}

In Phase II, penetration tests were carried out to determine both initial and final setting times. The results were given in table 2 , and figure 4.3 shows the maturities at initial and final set versus the cumulative average temperature at that degree of setting. It should be noted that in Phase II 


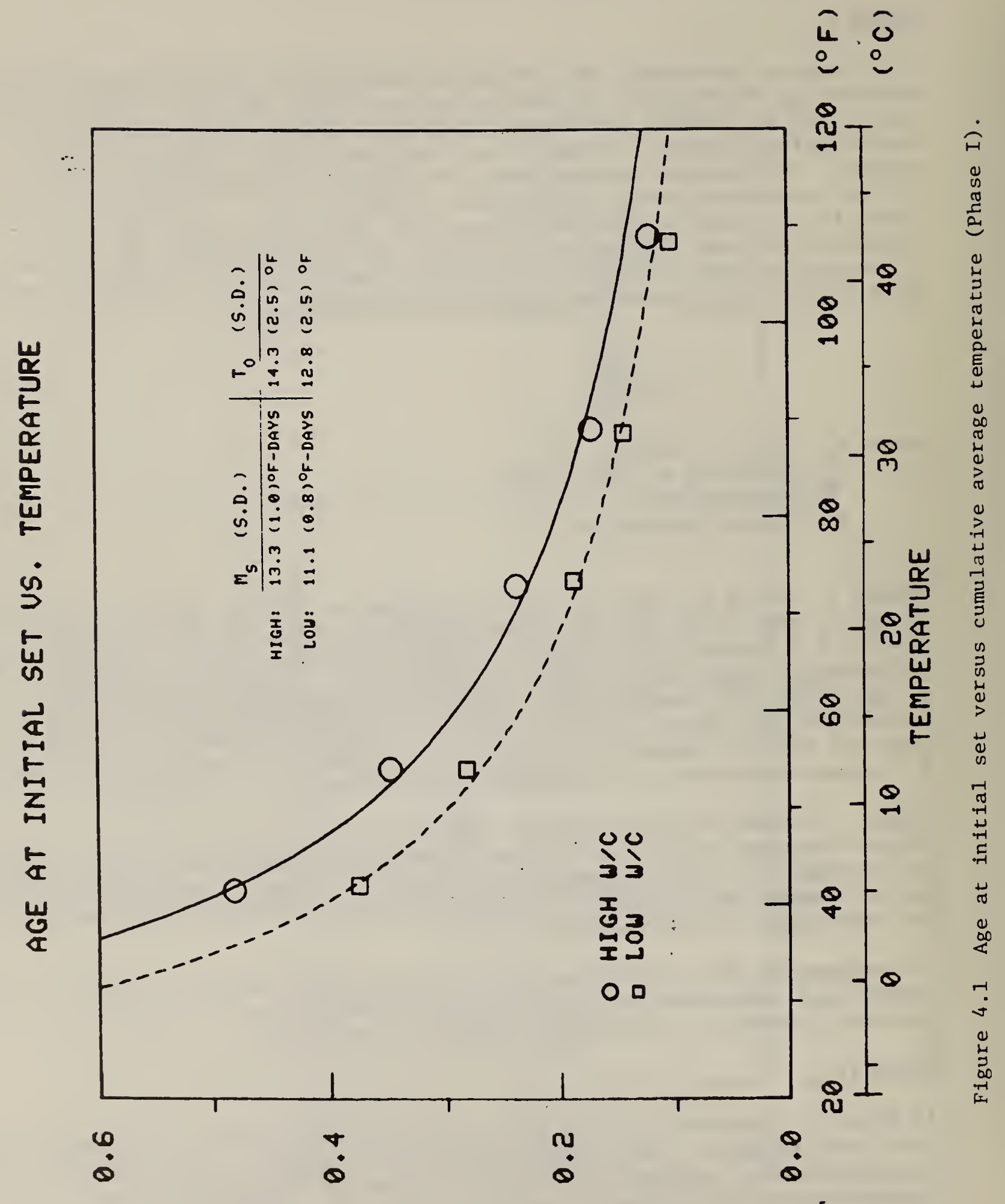

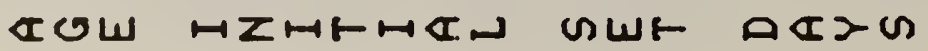




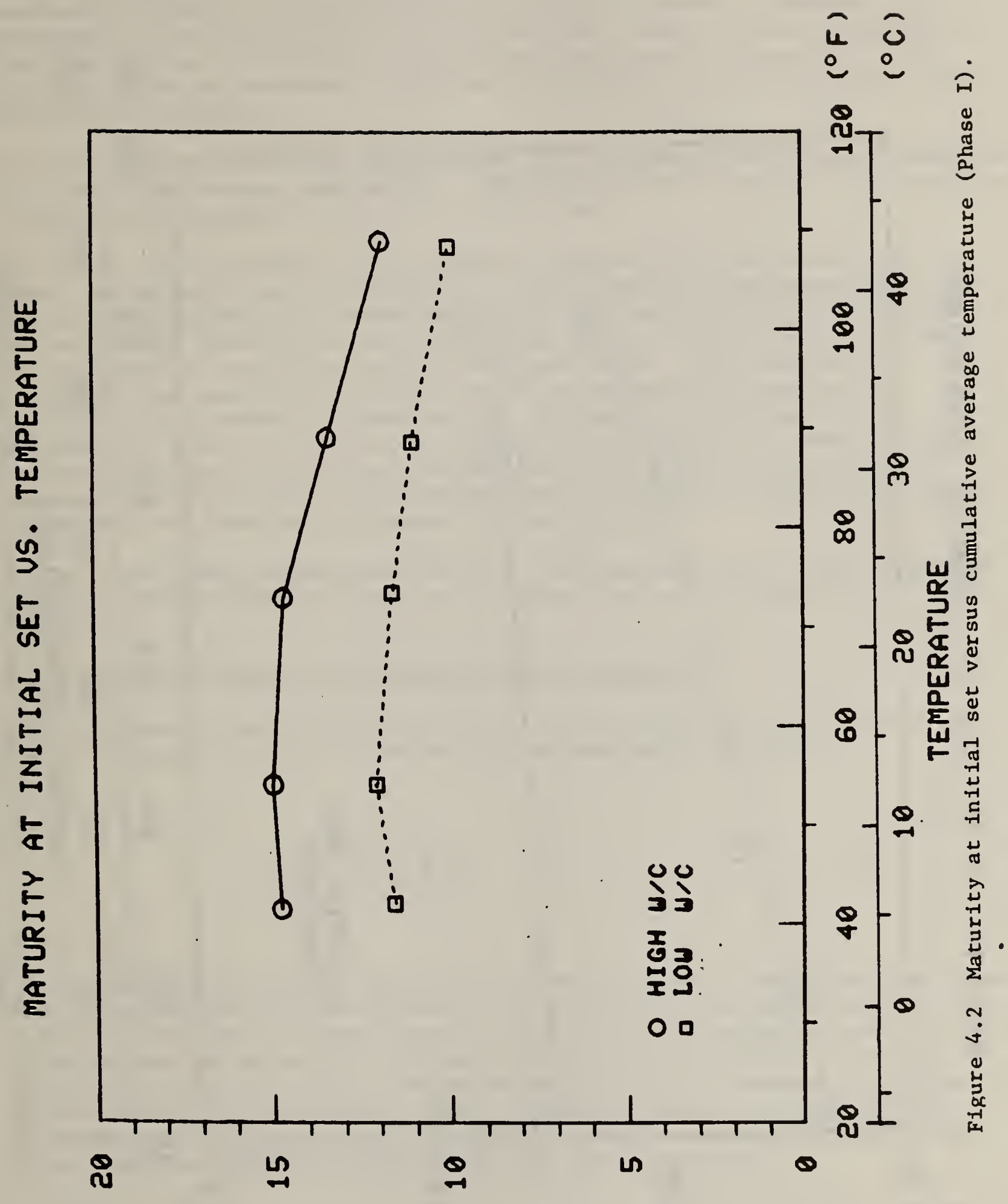

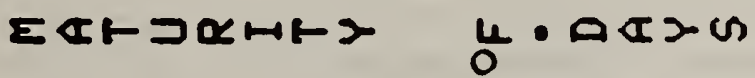




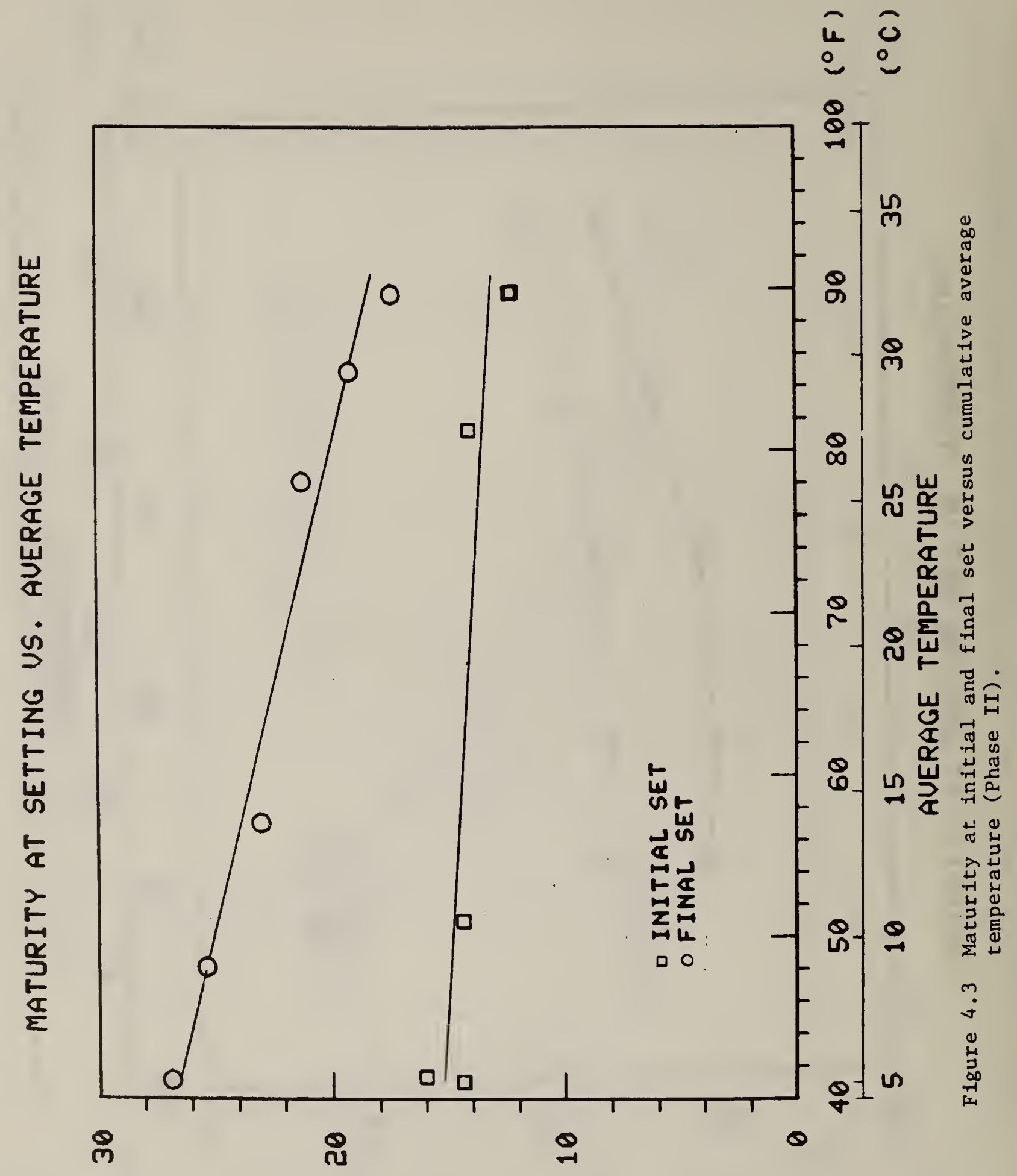

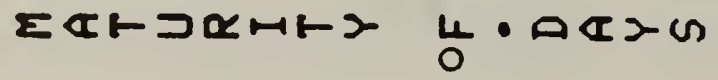


the temperature histories of the specimens were all different. It is seen that despite differences in thermal treatment, the maturities at initial set were reasonably constant; thus confirming the results of Phase I. However, the magnitudes of the maturities at initial set were slightly greater than those obtained in Phase I for the low water-cement ratio mix, no reason for this discrepancy can be suggested, other than the inherent scatter associated with this type of testing.

The maturities at final set, on the other hand, do show a significant variation with cumulative average temperature. The variation is consistent: an increase in temperature reduces the maturity at final set.

The results of the setting tests offer some insight into the behavior of cement during early ages of hydration. As mentioned in discussing figure 3.5, the real strength-maturity curve has an $S$ shape. At low maturities, there is 1ittle activity until the acceleratory phase when setting occurs is reached, and the concrete transforms into the hardened state. Since maturity at initial set was practically independent of temperature, it appears that during the early period the reaction rate increases proportionally with temperature. However, when the acceleratory stage begins, the reaction rate no longer appears to be a linear function of temperature. An increase in temperature produces more than a proportional increase in reaction rate, and the maturity at final set decreases with temperature.

The fact that final set does not occur at constant maturity is early evidence that the strength-maturity function of a given concrete will depend on temperature.

\subsection{TEMPERATURE EFFECTS ON STRENGTH-MATURITY RELATIONS}

It was assumed in section 3.2.1 that the strength-maturity function of a given concrete should be represented by the hyperbolic function:

$$
S=\frac{\left(M-M_{O}\right)}{\frac{1}{B}+\frac{\left(M-M_{O}\right)}{S u}}
$$

The offset maturity, $M$, is adopted as a simplification of the actual early age setting and hardening behavior (refer to figure 3.5). The parameters $B, S u$ and $M$ are all functions of temperature; a goal of this investigation was to determine if the parameters varied in a systematic fashion with temperature, so that appropriate relations could be suggested for applying temperature corrections to the strength-maturity function. Table 5 lists the best-fit values of these parameters and the corresponding cumulative average temperatures of specimens at the time when the first compression tests were performed.

The first parameter to investigate is parameter $B$, the slope of the curve at $M=M_{0}$. Figure 4.4 shows the values of $B$ obtained in Phase $I$ as a function of the cumulative average temperature. The points follow a consistent pattern. As expected, the values of $B$ are a function of temperature and water-c $\rightarrow m e n t$ ratio. It was felt that a more meaningful approach would be to separate these two effects. Thus, the strength-maturity function was rewritten as follows: 


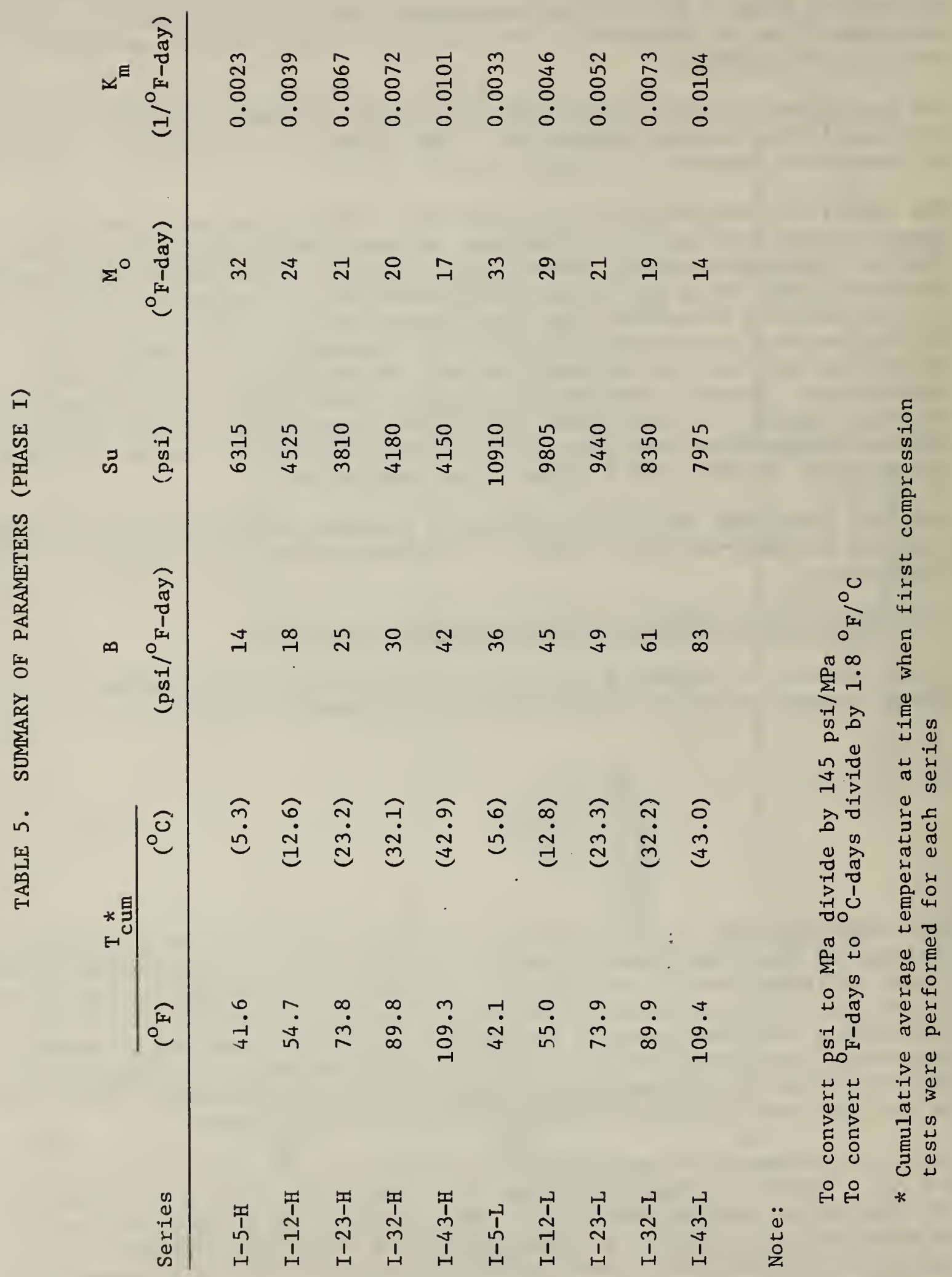




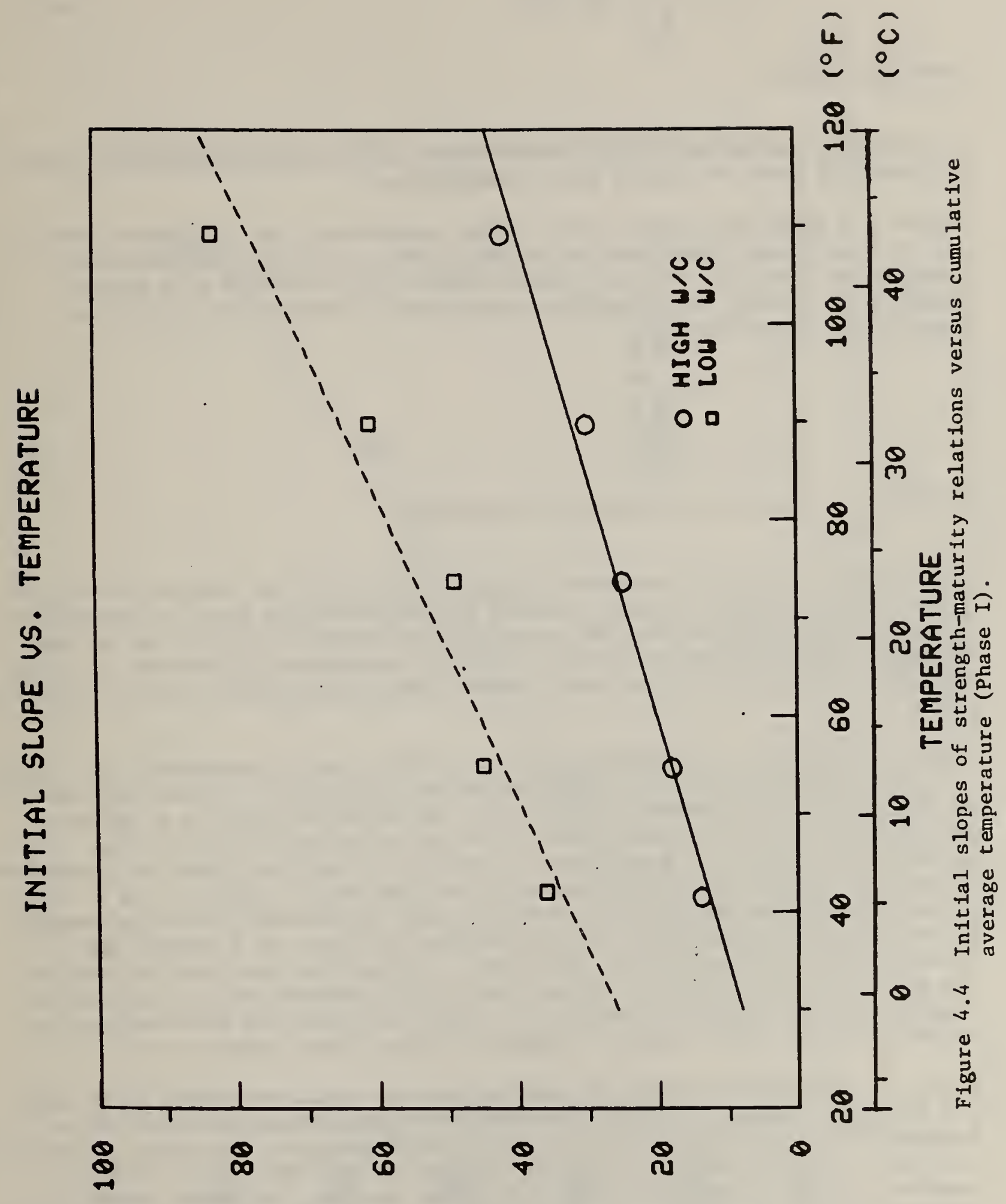

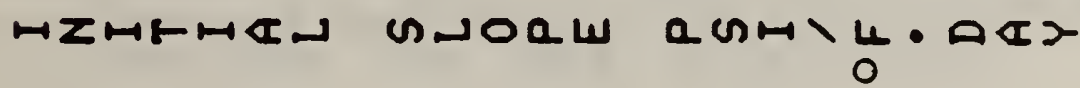




$$
S=\frac{\left(M-M_{o}\right) S u}{\frac{1}{K_{m}}+\left(M-M_{o}\right)}
$$

where $\mathrm{K}_{\mathrm{m}}=\mathrm{B} / \mathrm{Su}$.

In this way, the effect of the water-cement ratio on the initial slope could be separated from the effect due to temperature.

Figure 4.5 shows the values of $\mathrm{K}_{\mathrm{m}}$ versus temperature, and it appears that $\mathrm{K}_{\mathrm{m}}$ has no significant dependence on strength level. It will, therefore, be assumed that the data from both mortar mixes can be treated as a single sample. To express the temperature dependence in mathematical form, two models were investigated:

$$
\begin{aligned}
& \mathrm{K}_{\mathrm{m}}=\mathrm{K}_{\mathrm{m}}^{*}+\mathrm{bT} \\
& \mathrm{K}_{\mathrm{m}}=\mathrm{c} \exp \mathrm{dT}
\end{aligned}
$$

where $\mathrm{K}_{\mathrm{m}}^{*}, \mathrm{~b}, \mathrm{c}$ and $\mathrm{d}$ are regression parameters.

It was found that both functions fitted the data with the same precision, so it is suggested that a linear relation as represented by eq (4.4) provides a suitable approximate method for correcting the initial slope of the strengthmaturity relation when the in-place initial temperature of concrete is significantly different from that present during development of the calibration curve.

The next parameter to investigate is the offset maturity parameter, $M$. Figure 4.6 shows the best-fit values of $M$ obtained in Phase $I$. As expected, based on the previous discussion of final set, the offset maturity is a linear decreasing function of temperature. Also shown in this figure are the maturities at final set from Phase II, and it is seen that there is significant correlation between $M$ and the maturity at final set. Figure 4.7 is a schematic representation of the probable.early age strength-maturity curves at two extreme temperatures, and illustrates why there is a correlation between $M$ and the maturity at final set. Because the reaction rate during the setting process is not a linear function of temperature, an increase in temperature will lower the maturity at final set, which in turn reduces the offset maturity. Note also the change in slope B with temperature.

Since the differences between $M$ and maturity at final set appear to be small and since $M$ can only be found 9 rom non-linear regression analysis, it is suggested that the offset maturity can be approximated as the value of maturity at final set (this quantity could be measured in the laboratory). Then, it remains to account for the variation in $f$ inal set, $M_{f}$, as a function of temperature, T. The limited data in figure 4.6 appear to indicate that, over the investigated temperature range, the following linear approximation would be adequate: 


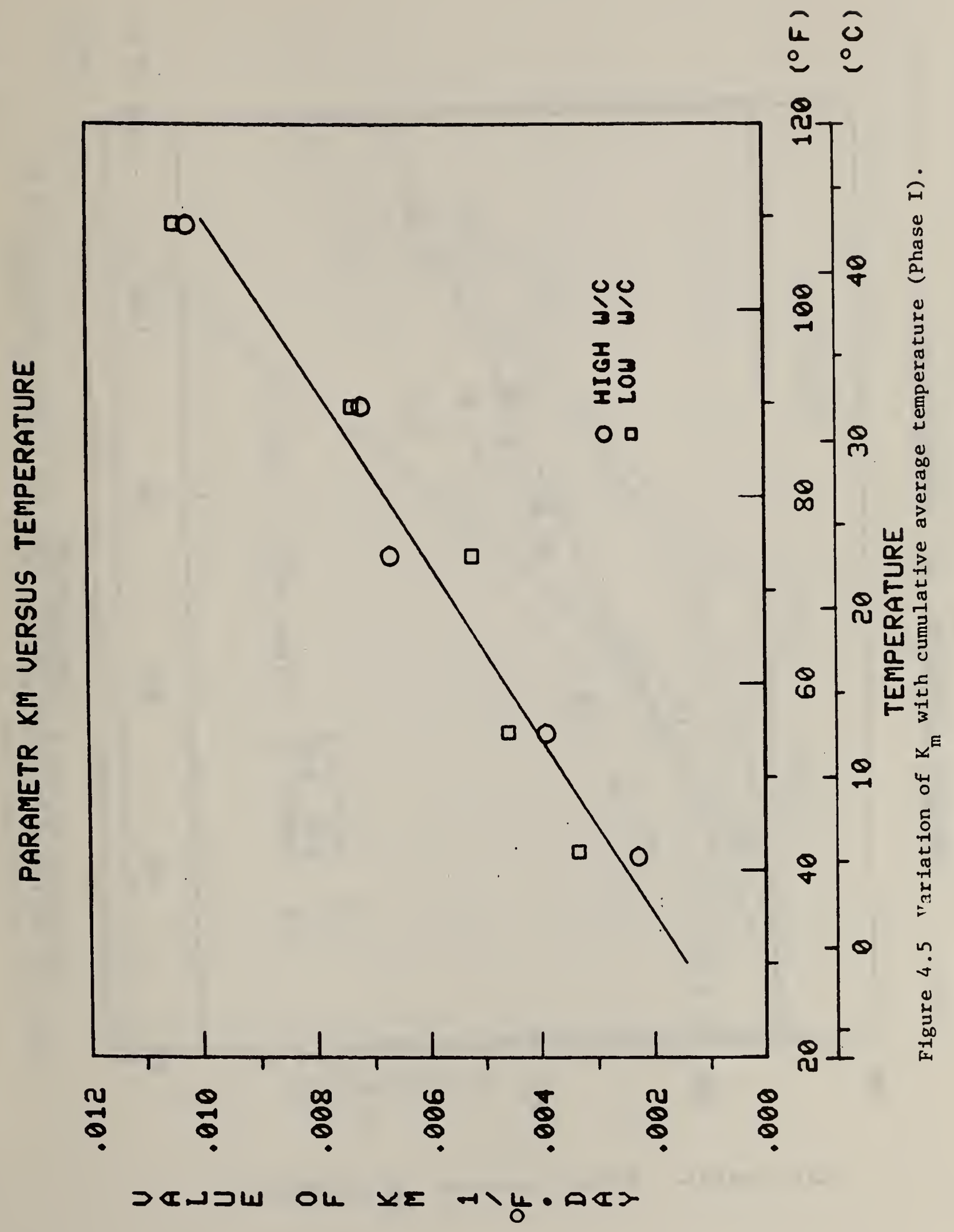




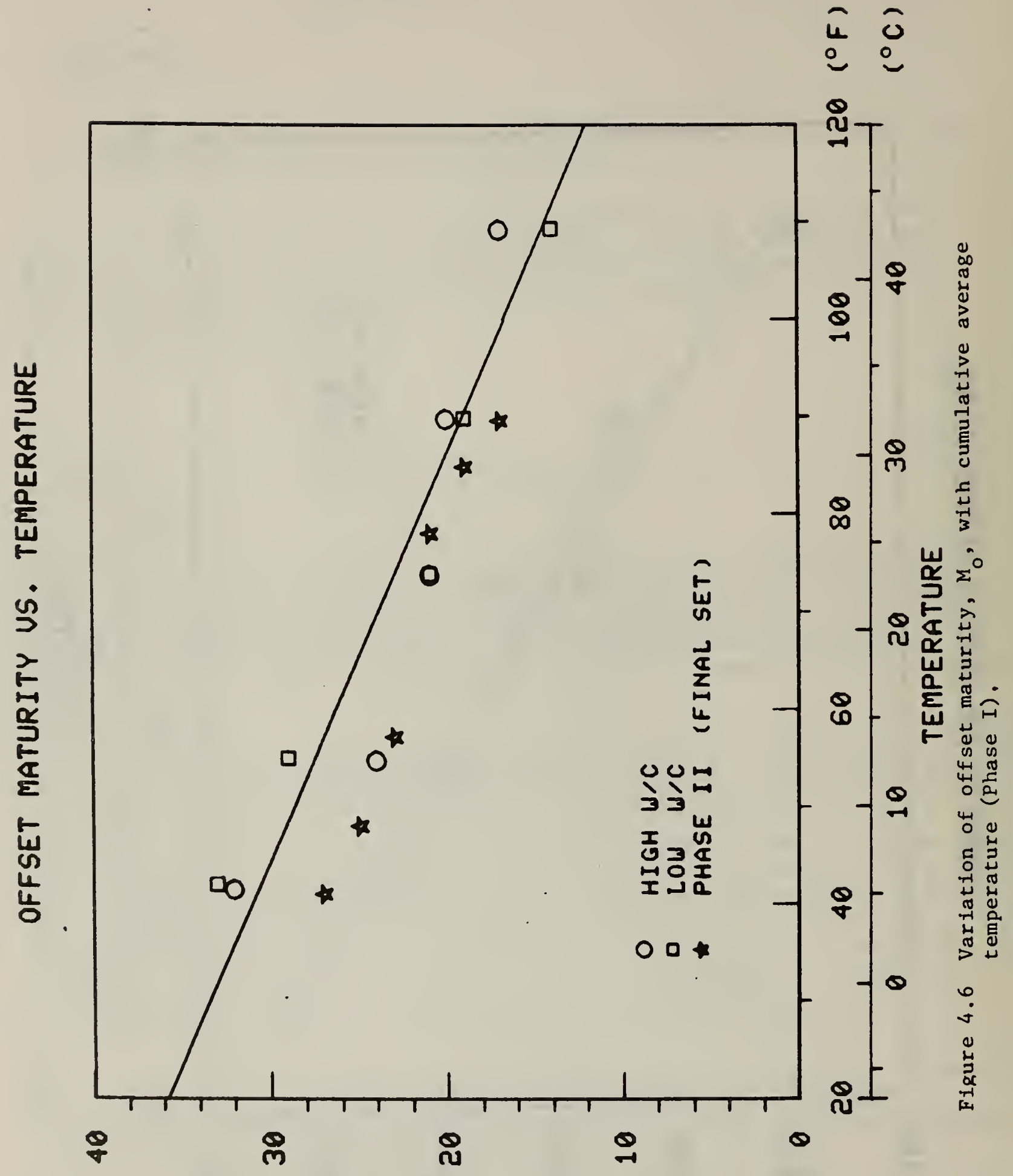

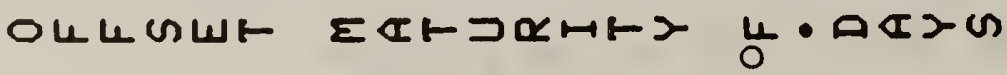




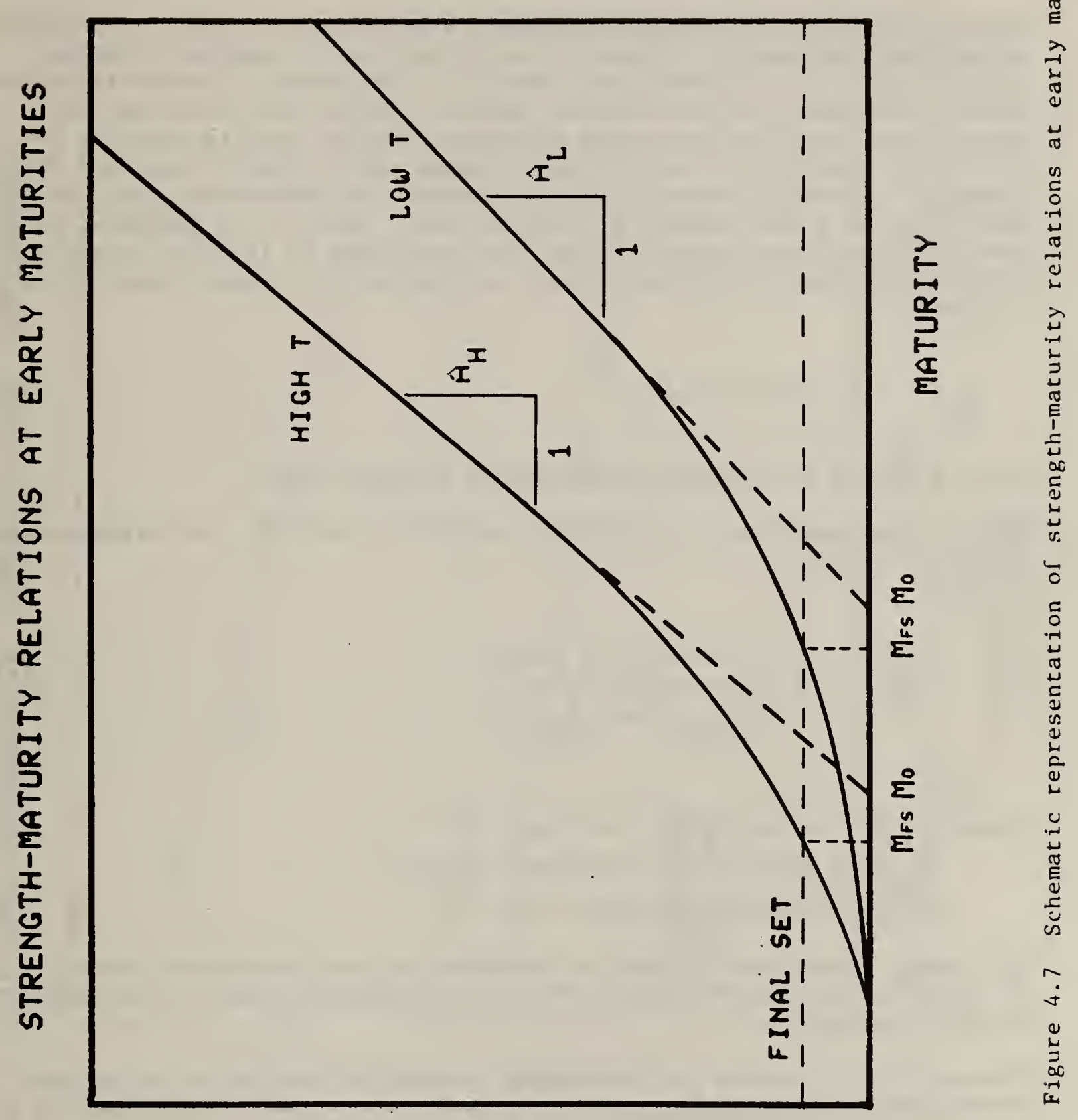

जt 


$$
M_{o} \sim M_{f s}=M^{*}-f T
$$

where $\mathrm{M}^{*}$ and $\mathrm{f}$ are parameters defining a straight line.

Finally, there is the limiting strength, Su. Figure 4.8 shows the variation in the computed best-fit values of $\mathrm{Su}$ as function of cumulative average temperature. It is evident that there is a consistent relationship between limiting strength and temperature. However, the results from the high water-cement ratio mix were more scattered than the results from the low ratio mix. Analysis of the low water-cement ratio results indicated that a linear relationship between limiting strength and temperature gave almost as good a fit as a more complex exponential fit. Thus, it is suggested that, over the temperature range studied, the dependence of limiting strength on curing temperature can be adequately represented by a linear function as follows:

$$
S u=S^{*}-g T
$$

where $S^{*}$ and $g$ are parameters defining a straight line

Substituting equations $(4.4),(4.6)$, and (4.7) into 4.3 , the strength-maturity relation becomes:

$$
S=\frac{\left[M-M_{f s}(T)\right] S u(T)}{\frac{1}{K_{m}(T)}+\left[M-M_{f s}(T)\right]}
$$

where $M_{f s}(T)=$ maturity at final set $=M^{*}-f T$

$\mathrm{K}_{\mathrm{m}}(\mathrm{T})=$ initial rate constant $=\mathrm{K}^{*}+\mathrm{bT}$

$\mathrm{Su}(\mathrm{T})=1$ imiting strength $=\mathrm{S}^{*}-\mathrm{gT}^{*}$

The linear correction factors are adequate for the temperature range of $5^{\circ}$ to $43^{\circ} \mathrm{C}$, which would include the vast majority of concrete placements during construction.

Chapter 5 will explain the fundamental assumption implied by the maturity concept which accounts for why the above temperature correction factors are needed. 


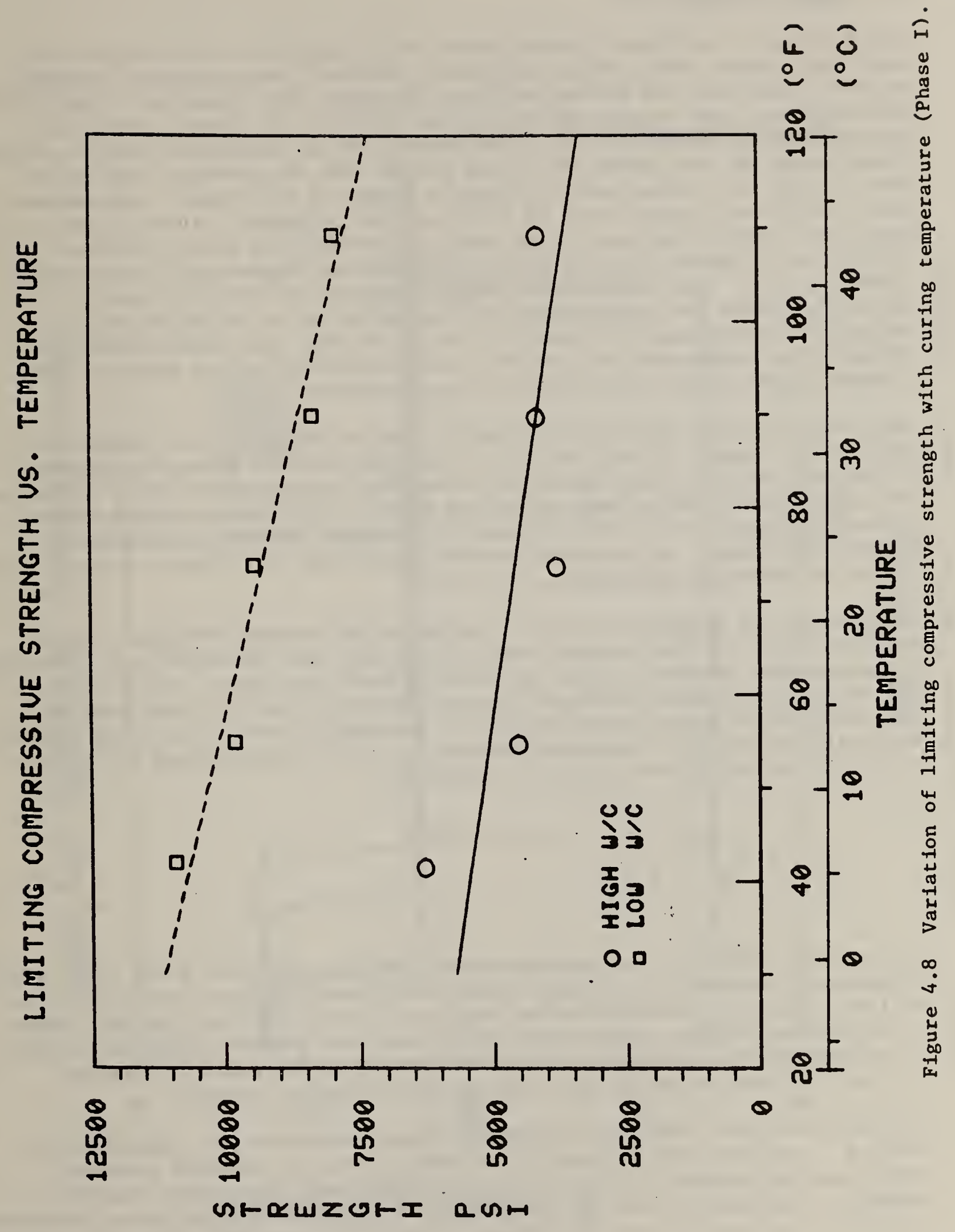




\subsection{WHEN IS "EARLY AGE"}

The purpose of the Phase II experiments was to determine the length of the early age period during which temperature affected the subsequent strengthmaturity function. To accomplish this, specimens were cured at $5^{\circ} \mathrm{C}$ and $32^{\circ} \mathrm{C}$ for different time periods and then moved to $23^{\circ} \mathrm{C}$. In planning the time periods when the moves were to be performed, it was postulated that a critical factor would be the degree of setting at the time of movement. Therefore, three stages of setting were arbitrarily chosen as the "times" when movement from the extreme temperatures to $23^{\circ} \mathrm{C}$ would be performed. These stages were final set, initial set and a time equal to one-half the time to achieve initial set. Because setting time is affected by temperature, the movement times for the $5^{\circ}$ and $32^{\circ} \mathrm{C}$ initial curing temperatures were different. Figure 4.9 shows the temperature-time histories, up to an age of 24 hours, for the six treatments of Phase II. It can be seen that the procedure of changing the temperature of the water baths was effective in bringing about a rapid change in the temperature of the specimens.

The results of the compressive strength tests of Phase II were summarized in figure 3.8, figure 3.9 and table 4 . It is desirable to determine whether differences existed among the strength-maturity curves of the three treatments for each initial curing temperature and whether differences existed between the strength-maturity curves of Phase II specimens and the corresponding Phase I specimens. To determine whether significant differences existed, the F-test of variances was used.

In applying the significance test, the sum of the squared residuals of the best fit curve for the combined data is compared with the total sum of squared residuals when separate curves are used for each data group. For example, if the sum of the squared residuals for the regression curve of the combined data is $R_{0}$ with corresponding degrees of freedom $N_{0}$, and if the total squared residuals ${ }^{\circ}$ for separate regression curves is $R$ with total degrees of freedom of $\mathrm{N}$, the following $\mathrm{F}$-statistic is calculated:

$$
F=\frac{R_{0}-R}{R} \frac{N}{N_{O}-N}
$$

The computed value of $\mathrm{F}$ is compared with tabulated values of $\mathrm{F}$ for $(\mathrm{N}-\mathrm{N})$ and $\mathrm{N}$ degrees of freedom at a chosen significance level. If the computed ${ }^{\circ} \mathrm{F}$-value is larger than the tabulated value, then it is concluded that, at the chosen level of significance, differences exist among the separate regression curves. In this study the significance level was chosen as 0.05 , and the average strengths at each maturity were used in the regression analyses.

The results of the tests of differences among data groups are summarized in table 6. The left-hand portion of the table gives the residual standard deviations and degrees of freedom for the individual data groups that were compared. Bartlett's test for homogeneity of variance resulted in a chi-square value of 3.64 which is not significant at the 0.05 level and so we are justified 


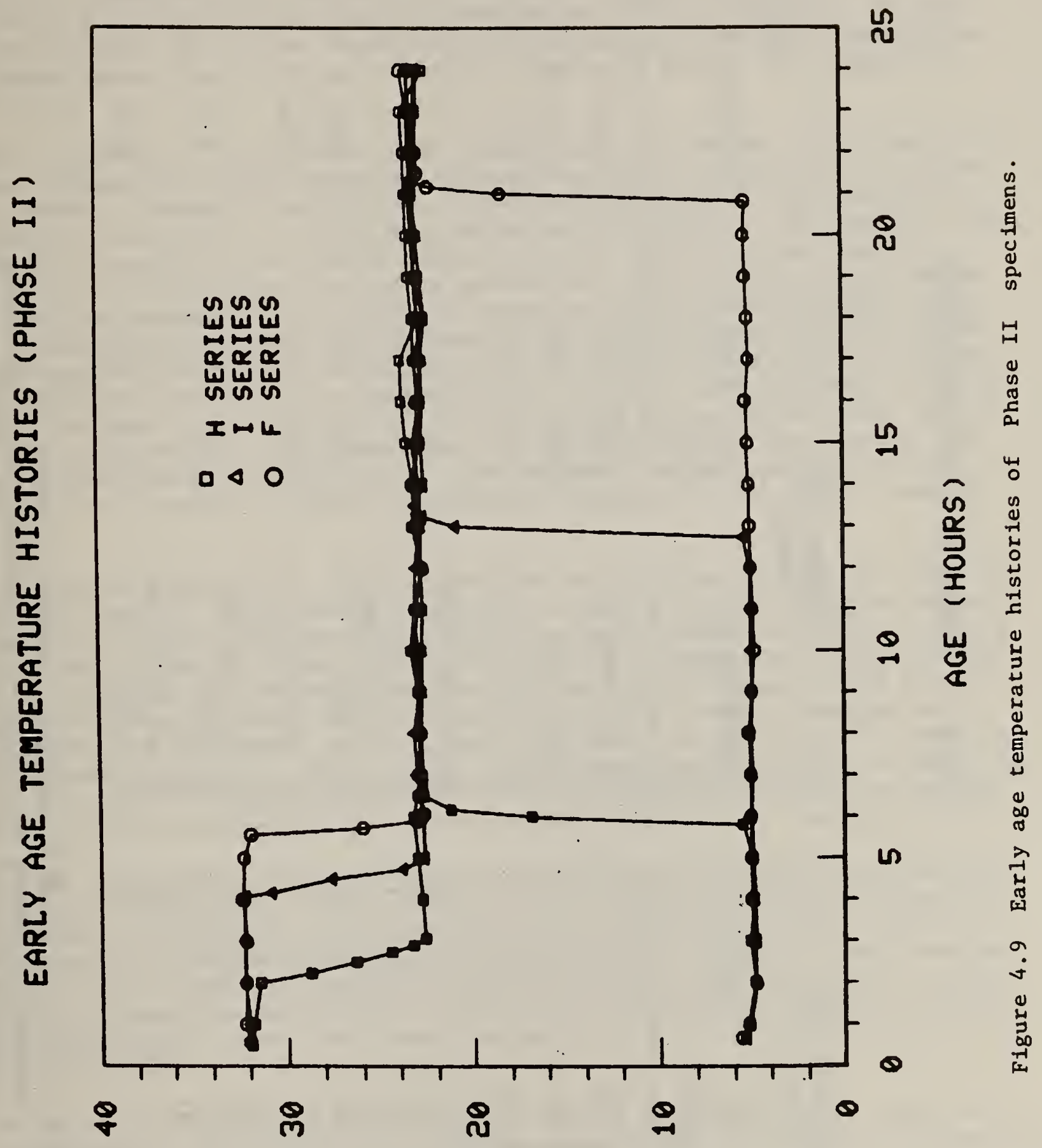

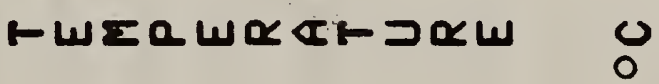




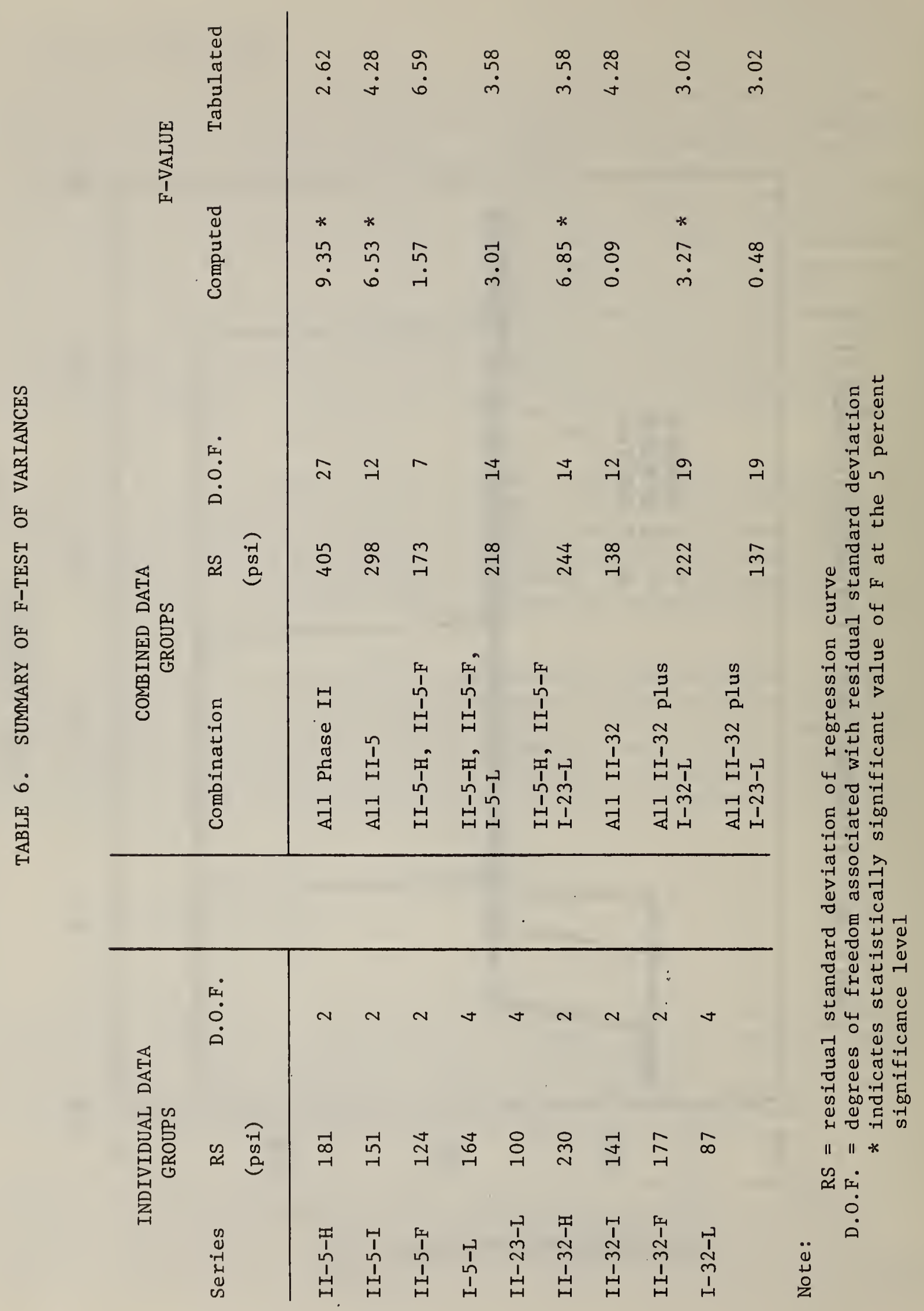


in comparing these data groups. The right-hand portion of the table gives the residual standard deviations and degrees of freedom for various combined data groups; also shown are the computed and tabulated (at the 0.05 significance leve1) values of the F-statistic. The sum of the squared residuals is the product of the degrees of freedom and the square of the residual standard deviation.

The first combined group included all the Phase II treatments. The computed value of $F$ was greater than the tabulated value ( 9.35 versus 2.62 ), so one concluded that the initial temperature treatments at $5^{\circ}$ and $32^{\circ} \mathrm{C}$ altered the strength-maturity function for subsequent curing at $23^{\circ} \mathrm{C}$. This result was expected.

Next, the three $5^{\circ} \mathrm{C}$ treatments were grouped, and the F-value (6.53) indicated that differences existed among the strength-maturity relations for the three treatments. However, the differences were not as expected. Examination of figure 3.8 and table 4 reveals that the major difference in this group is the limiting strength of the series removed from $5^{\circ} \mathrm{C}$ at initial set, which is greater than those of the two other treatments. Based on the explanation of Verbeck and Helmuth [12], it would be expected that limiting strength should be an increasing function of time spent at the lower temperature. It is not clear whether the higher limiting strength of the specimens moved at initial set is significant or just a rare statistical event. When the data of the $H$ and $F$ treatments were grouped, the F-value (1.57) was not significant and it can be concluded that the strength-maturity functions were the same for the two extreme exposure times at $5{ }^{8} \mathrm{C}$. This suggests the possibility that the data of the initial set group is anomalous compared with the $H$ and $F$ treatments.

The $\mathrm{H}$ and $\mathrm{F}$ treatments at $5^{\circ} \mathrm{C}$ were compared with constant curing at $5^{\circ}$ and at $23^{\circ} \mathrm{C}$ in Phase $\mathrm{I}$. The computed F-values (3.01 and 6.85 ) indicate that these treatments resulted in strength-maturity functions similar to constant curing at $5^{\mathrm{O}}$ but dissimilar to constant curing at $23^{\circ} \mathrm{C}$. Examination of figure 3.8 , table 3 and table 4, however, reveals that the initial shapes of the $H$ and $F$ strength-maturity relations were closer to the $23^{\circ} \mathrm{C}$ constant temperature treatment, but the shapes at later maturities were closer to the $5^{\circ} \mathrm{C}$ constant temperature treatment. Thus, it may be concluded that the initial exposure at $5{ }^{\circ} \mathrm{C}$ altered the limiting strength but did not significantly alter the initial slope of the strength-maturity curves compared with constant curing at $23^{\circ} \mathrm{C}$.

For the $32^{\circ} \mathrm{C}$ initial treatments, the results did not follow the same pattern as the $5{ }^{\circ} \mathrm{C}$ treatments. First, there was no significant difference among the three $32^{\circ} \mathrm{C}$ treatments as indicated by the very low F-value $(0.09)$ in table 6 . When the $32^{\circ} \mathrm{C}$ treatments were grouped with the Phase I data, it was found that the $32^{\circ} \mathrm{C}$ treatments had the same strength-maturity curves as constant curing at $23^{\circ} \mathrm{C}$. Thus, the conclusion in this case is that initial curing at $32^{\circ} \mathrm{C}$ did not significantly alter the strength-maturity relations compared with constant curing at $23^{\circ} \mathrm{C}$.

The lack of similarity in the effects of the $5^{\circ} \mathrm{C}$ and $32^{\circ} \mathrm{C}$ initial exposures on the resultant strength-maturity relations reveals that the effects of early age 
temperature are more complicated than had been anticipated when the test program was designed. It appears that the degree of setting is not the critical factor to use for quantifying which stage should be classified as "early age."

Perhaps an underlying reason for the differences in behavior of the $5^{\circ}$ and $32^{\circ} \mathrm{C}$ treatments may be the effects of temperature on the growth of calcium hydroxide crystals. Berger and McGregor have shown that calcium hydroxide crystal growth rates at $15^{\circ} \mathrm{C}$ were greater than at $25^{\circ}$ and $35^{\circ} \mathrm{C}$, and the growth rates at $25^{\circ}$ and $35^{\circ} \mathrm{C}$ were similar [33]. 


\subsection{BASIS OF CLASSICAL MATURITY CONCEPT}

It may be argued that the quantity

$$
M=\int\left(T-T_{0}\right) d t
$$

has no meaning when trying to describe a physical phenomenon involving chemical reactions, such as the hydration of cement. It has been suggested* that the effects of time and temperature on the strength development of concrete can be predicted based on simple kinetic rate theory. Also, it might be asked why the hyperbolic function was adopted as the best representation of the strengthmaturity relation. This chapter will attempt to reconcile these points.

First, let us consider the shape of the strength versus time relation of concrete cured at constant temperature. If one assumes that the rate of strength development will be a function of the quantity of unreacted cement, and if the strength of concrete is assumed to be directly related to the amount of cement hydration that has occurred, the following rate equation may be proposed:

$$
\frac{d(S / S u)}{d t}=k(1-s / S u)
$$

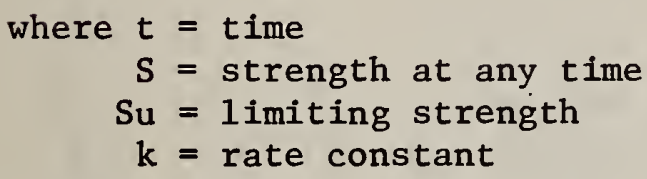

Upon integration, we obtain

$$
-\ln \left(1-\frac{S}{S u}\right)=k t+c
$$

where the constant of integration, $C$, is evaluated by the boundary condition $S=0$ for $t=t_{0}$. The offset time $t_{0}$, which is analogous to $M_{0}$ as illustrated in figure 4.7, is used to account for the fact that strength gain as expressed by eq (5.2) will not occur until the acceleratory stage is reached. The final result, assuming that strength gain follows a simple first order reaction law, is as follows:

$$
S=S u\left[1-\exp \left(-k\left(t-t_{0}\right)\right)\right]
$$

The above exponential function was applied to the average strength-age data of Phase $I$ and the constants $\mathrm{Su}, \mathrm{k}$ and $\mathrm{t}_{\mathrm{o}}$ were found for each series (see table 7 ).

* E. L. Schaffer, personal communication. 


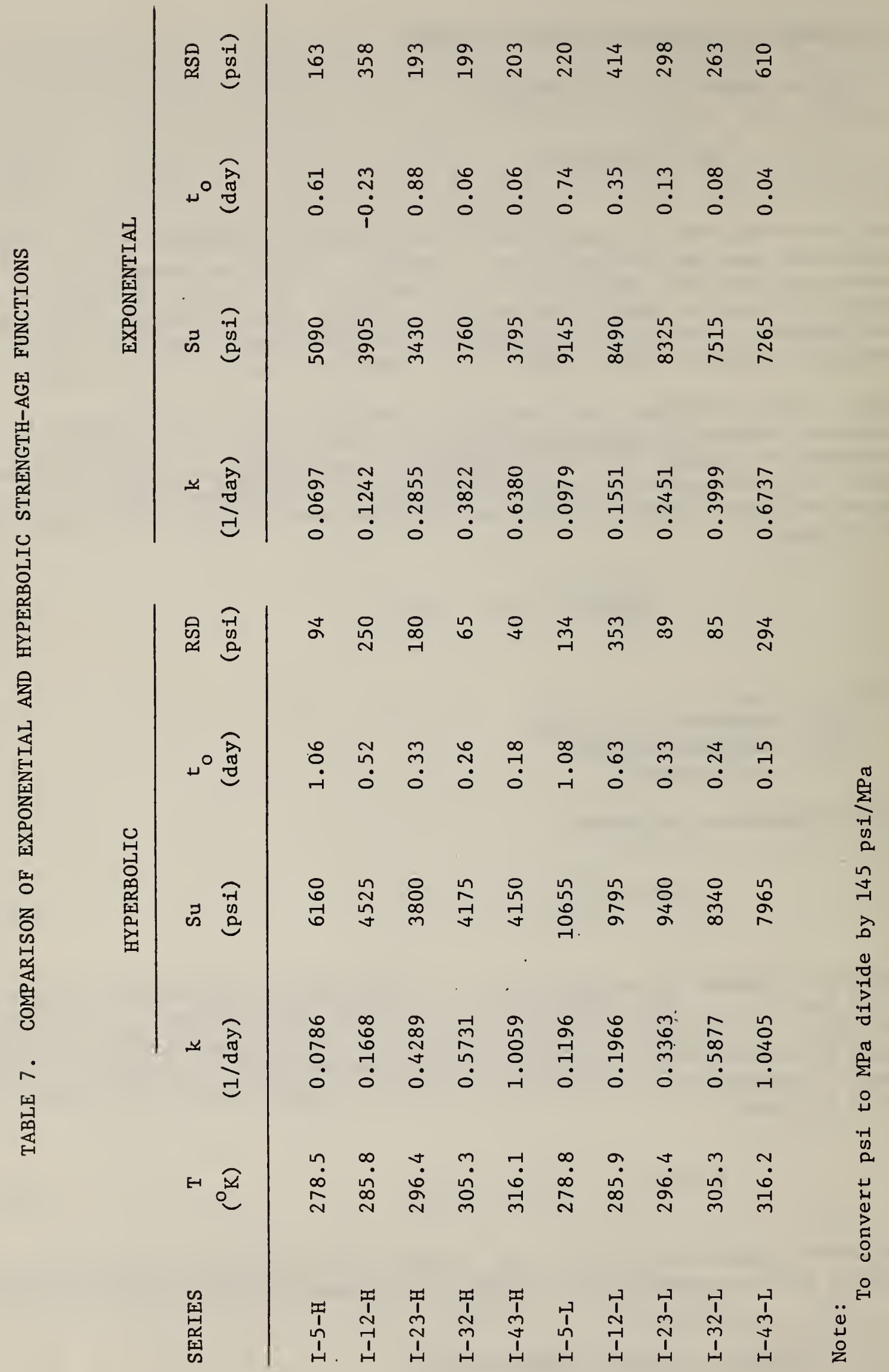




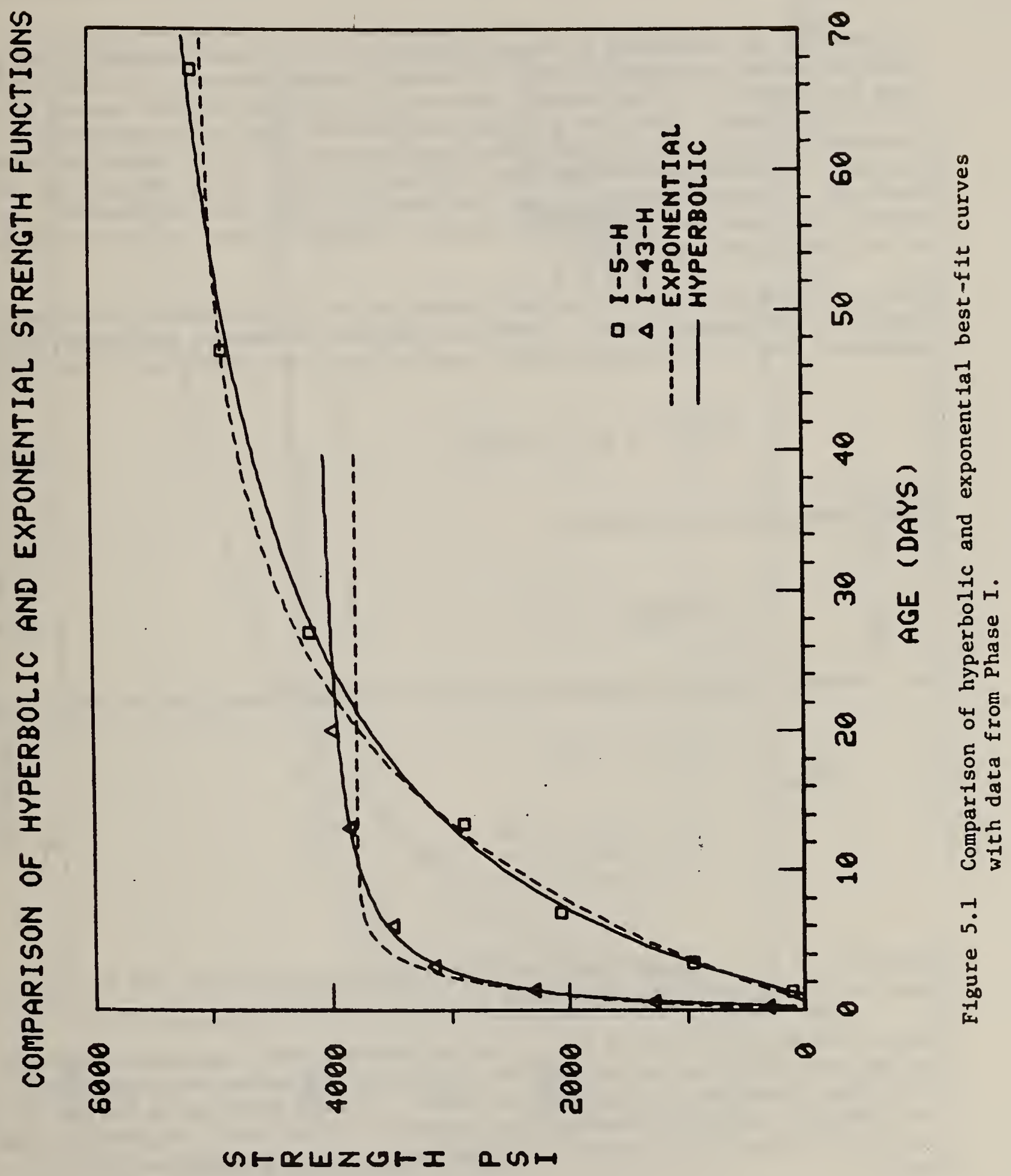


Figure 5.1 shows how the exponential function fits the data of two series from Phase $\mathrm{I}$. The fit is reasonable, but the exponential curve reaches the limiting strength too quickly and the predicted values of this strength appear too low. The conclusion is that the first order rate equation is not the most appropriate one to use.

In terms of our knowledge of cement hydration, it is understandable why a first order reaction is inappropriate. As cement grains hydrate, ions must diffuse from the unreacted cores through hydrated products to the pore spaces where they precipitate. Thus, as hydration progresses there is a continually increasing barrier to further hydration (the hydrate layer around the cement grains). Various models have been proposed [32」 to try to explain the phenomena involved in cement hydration, but they have not been very successful. In general they are complex and only apply to simple systems in which only one or two compounds are present.

The rate equation (eq 5.2) can be altered so as to approximate the added obstacles of hydrate layers. Based on empirical evidence, Bernhardt [30] suggested that a second order rate equation was more appropriate, as follows:

$$
\frac{d(S / S u)}{d t}=k(1-S / S u)^{2}
$$

Upon integration, one obtains

$$
\frac{1}{1-\mathrm{S} / \mathrm{Su}}=\mathrm{kt}+\mathrm{C}
$$

The constant $\mathrm{C}$ can be found using the same boundary condition as above. Thus,

and

$$
c=1-k t_{0}
$$

$$
S=\frac{\left(t-t_{0}\right) S u}{\frac{1}{k}+\left(t-t_{0}\right)}
$$

Equation 5.7 is a hyperbolic curve with limiting strength Su and an initial slope at $t=t_{0}$ equal to $(k \cdot S u)$.

Table 7 shows the values of $\mathrm{Su}, t$ and $\mathrm{k}$ obtained from regression analysis. The residual standard deviations for the hyperbolic model are significantly lower than those for the exponential model. Figure 5.1 shows a better fit for the hyperbolic model in representing a sample of the data. Figures 5.2 and 5.3 show the best fit hyperbolic strength-age curves for each series in Phase I. 


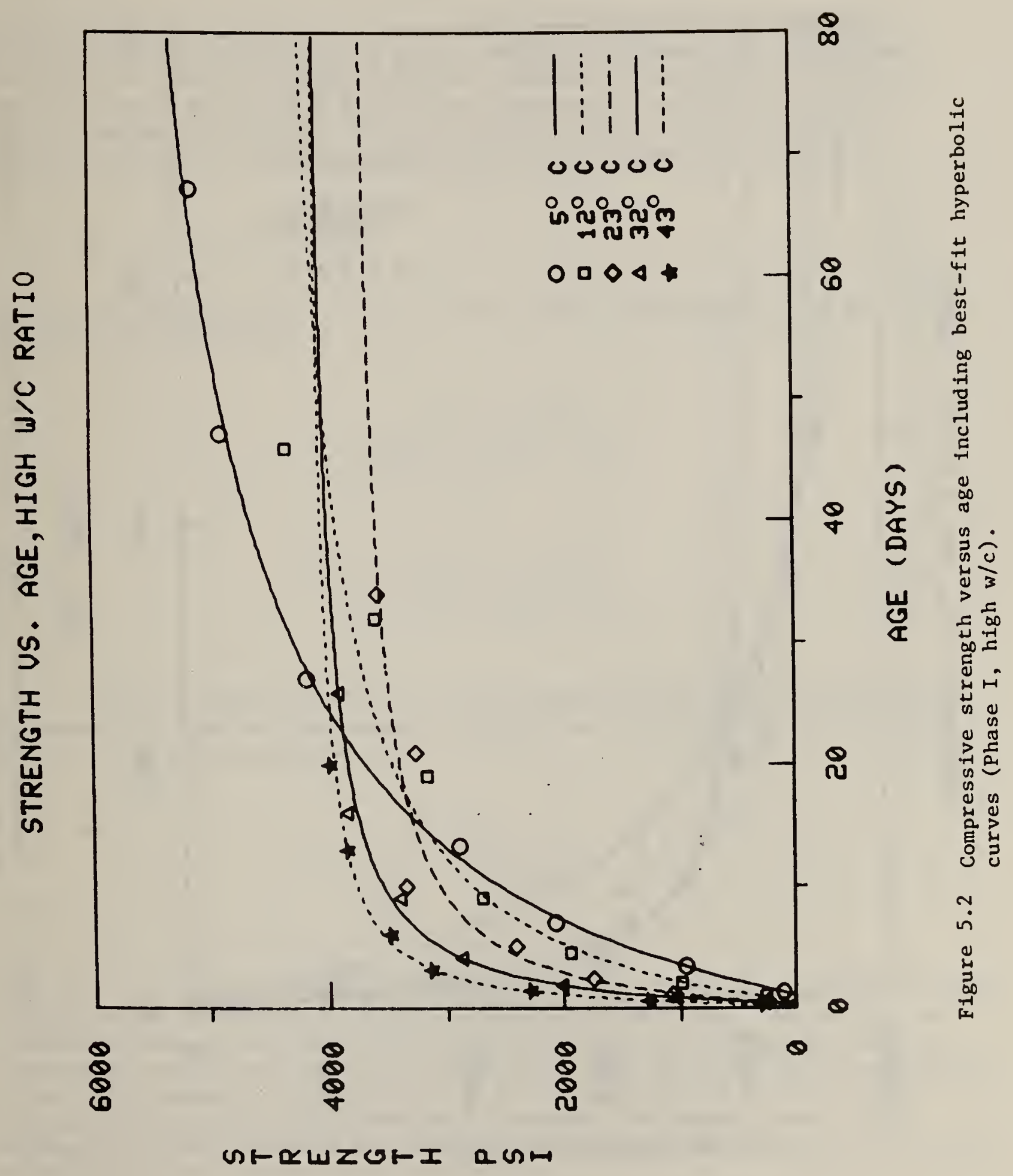




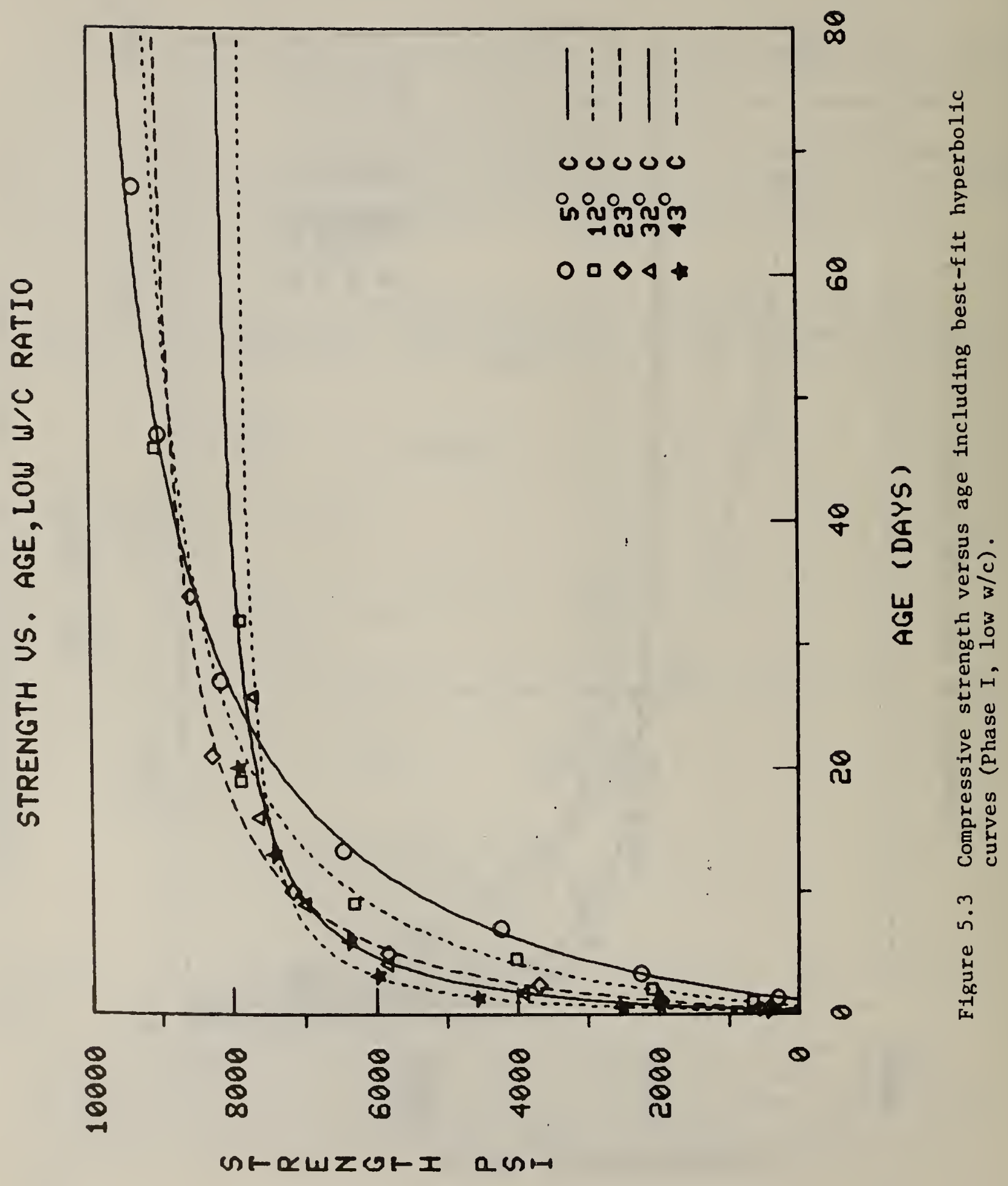


The data support the suggestion that a second order reaction rate (eq 5.5 ) is appropriate for the strength development of concrete after final setting has occurred. If eq (5.7) were to be used to predict strength as function of age and temperature, the variations of these parameters with temperature must be known. The variation of $\mathrm{Su}$ with temperature has already been discussed in chapter 4 .

Figure 5.4 shows the values of $k$ for the hyperbolic model as a function of temperature. It appears that $k$ is not strongly influenced by water-cement ratio and it appears to be a non-1inear function of temperature. Assuming, however, that $k$.is a linear function of temperature, and that $k$ is equal to zero at the temperature, $T$, below which no strength gain is observed in hardened concrete, $k$ could be represented by the following expression:

$$
k=k_{m}\left(T-T_{0}\right)
$$

where $\mathrm{K}_{\mathrm{m}}$ is the slope of the line. If eq (5.8) is substituted into eq (5.7), we obtain the following:

$$
S=\frac{\left(t-t_{0}\right) S u}{\frac{1}{K_{m}\left(T-T_{0}\right)}+\left(t-t_{0}\right)}
$$

or

$$
S=\frac{\left(T-T_{0}\right)\left(t-t_{0}\right) S u}{\frac{1}{K_{m}}+\left(T-T_{0}\right)\left(t-t_{0}\right)}
$$

Let us further simplify eq $(5.10)$ by introducing the quantity $M$ to represent the product of time and temperature above $T_{0}$, and introduce the quantity $M_{0}$ to represent the corresponding product at age $t_{0}$.

$$
S=\frac{\left(M-M_{0}\right)}{\frac{1}{K_{m} S u}+\frac{\left(M-M_{0}\right)}{S u}}
$$

Equation (5.11) is precisely the hyperbolic strength-maturity function presented in section 3.2.1 with the term $K$ Su replacing $B$ in eq (3.4). We now see the fundamental assumption implied by the maturity concept, and why the concept gives poor results when applied to concretes curing at vastly different temperatures. The assumed linear variation of $\mathrm{k}$ with temperature is not adequate to represent the effects of temperature on strength development; hence, when samples of a given concrete are cured at two dissimilar temperatures, there will be two different strength-maturity relations. 


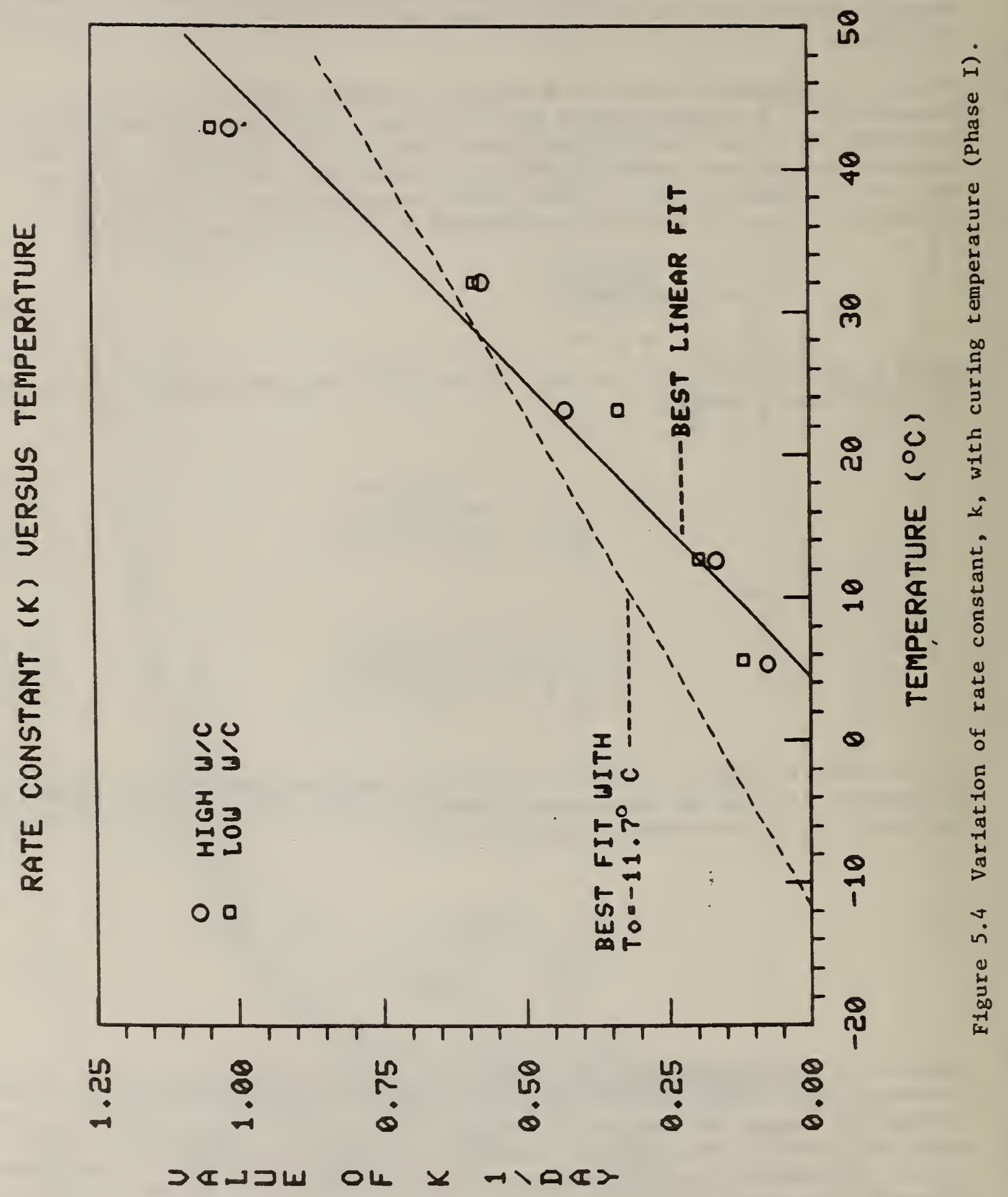


As a matter of interest, figure 5.4 shows the best fit straight line obtained by fitting eq $(5.8)$ and the best fit line obtained by using $\mathrm{T}_{0}=-11.7^{\circ} \mathrm{C}$ $\left(11^{\circ} \mathrm{F}\right)$. The best fit value of $\mathrm{T}$ is $4.4^{\circ} \mathrm{C}\left(40^{\circ} \mathrm{F}\right)$, this would mean that concrete cured at $4.4^{\circ} \mathrm{C}$ would not gain strength. Thus, $\mathrm{T}$ must be chosen as less than $4.4^{\circ} \mathrm{C}$ to account for the observed hardening below $4.4^{\circ} \mathrm{C}$. We see that for $T=-11.7^{\circ} \mathrm{C}$, the predicted value of $\mathrm{k}$ will be very different from the true value and hence, as shown by the results of this study, the strength-maturity relations will show a significant effect due to curing temperature.

It is now understood why Sadgrove [20] suggested the use of eq (1.7) to compute equivalent age. The parabolic expression is an attempt to produce a better approximation of the k-temperature curve than Saul's implied straight ine approximation.

Since the Saul maturity function (eq 1.1) does not appear to be the best approach for accounting for the combined effects of temperature and time on strength development of concrete, it may be desirable to seek an alternative approach for computing maturity. This is the subject of the following chapter. 
To explore whether there is an alternative approach for computing maturity, we begin with the strength-age relation presented in chapter 5:

$$
S=\frac{\left(t-t_{0}\right) S u}{\frac{1}{k}+\left(t-t_{0}\right)}
$$

Rearranging terms, this can be rewritten as follows:

$$
S=\frac{k\left(t-t_{0}\right) S u}{1+k\left(t-t_{0}\right)}
$$

To incorporate temperature effects, it is necessary to determine the variation of $k$ and $t$ with curing temperature. Note that Su will also be a function of temperature, but that dependence has already been discussed (see figure 4.8 ).

Since hydration is an exothermic reaction, it has been suggested that the rate constant, $k$, can be related to temperature according to the Arrhenius equation, as follows:

$$
k=A \exp \left(-E / T_{k}\right)
$$

where $\mathrm{A}=$ constant

$E=$ the activation energy divided by the gas constant

$\mathrm{T}_{\mathrm{k}}=$ absolute temperature

Thus, as a first attempt, eq $(6: 2)$ was fitted to the values of $k$ versus absolute temperature (columns 3 and 2 in Table 7 ). The results are shown in figure 6.1; the agreement between the best-fit curve and the values of $k$ is excellent. In addition, the following power law was also fitted:

$$
k=B \exp (C T)
$$

where $B$ and $C$ are regression coefficients and $T$ is temperature.

The power law also gave a good fit but not quite as good as the Arrhenius function; the residual standard deviation for the power 1 aw was 0.037 , while it was 0.033 for the Arrhenius function. It was, therefore, concluded that the effect of temperature on $k$ could be better represented by the Arrhenius function.

The relationship between the best fit values of $t$ and temperature (columns 5 and 2 in Table 7) is indicated in figure 6.2. The first observation is that $t_{0}$ is essentially independent of the water-cement ratio of the mortar. Also 


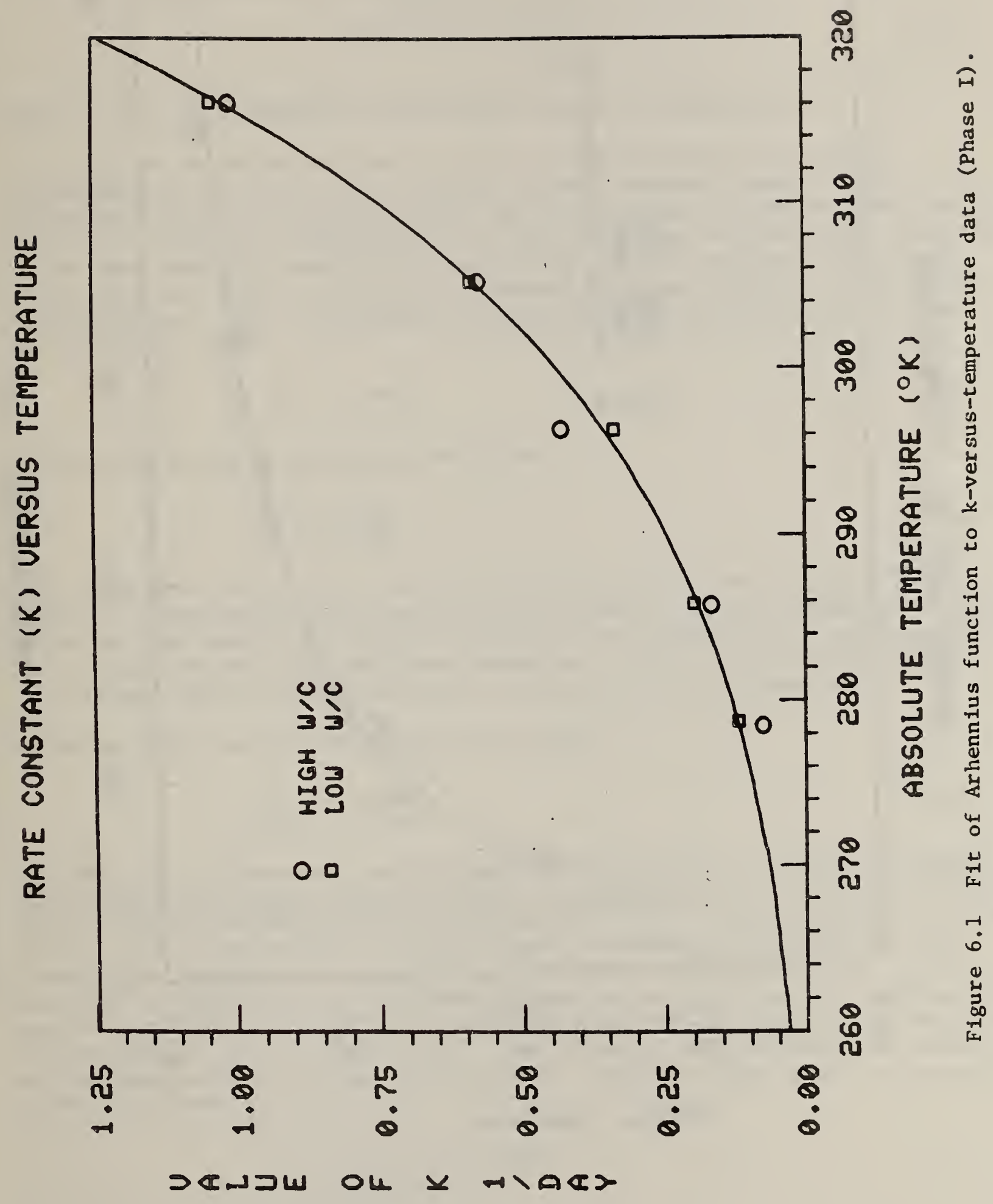




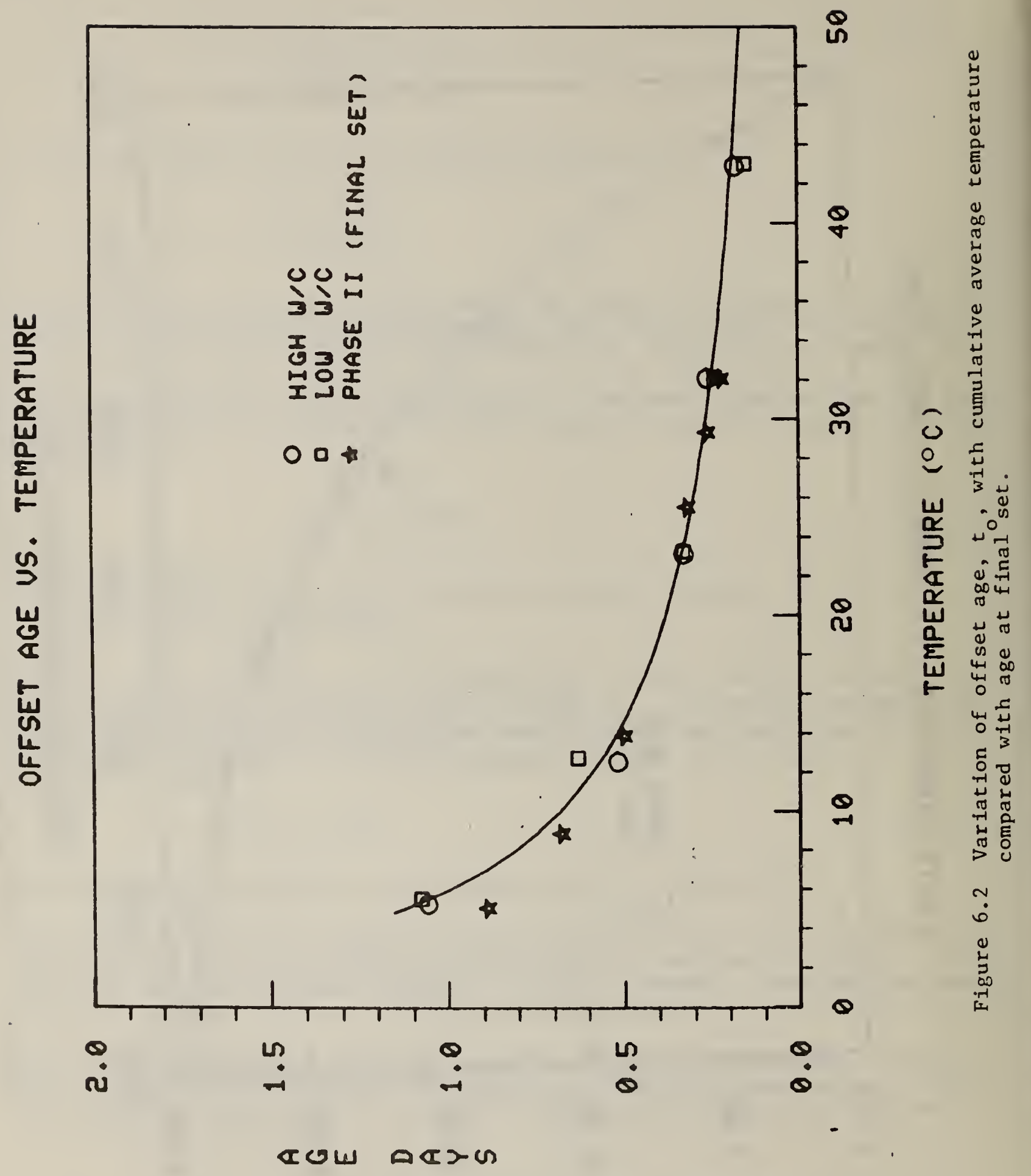


shown in figure 6.2 are the final set times obtained from Phase II, and it is seen that, with good approximation, $t$ can be taken as equal to the age at final set, $t_{f_{s}}$. There appears to be $a$ well-defined relation between $t_{0}$ and temperature which can be represented as follows:

$$
t_{0}=\frac{b}{a+T} \sim t_{f S}
$$

where $a$ and $b$ are regression coefficients and $T$ is temperature.

Therefore, by substituting into eq (6.1) the temperature dependences represented by eqs $(4.7),(6.2)$ and (6.4), one obtains a single equation to represent strength development under isothermal (constant temperature) curing conditions. Further examination of eq (6.1) suggests an alternative approach to the Saul maturity function for accounting for the combined effects of temperature and time on strength development. Let us introduce the quantity "effective age", Ae, to represent the product of the rate constant, $k$, and age beyond $t_{0}$ :

$$
A e=k\left(t-t_{0}\right)
$$

Equation (6.1) can be rewritten as follows:

$$
S=\frac{S u A e}{1+A e}
$$

According to eq (6.6), the curve representing strength versus effective age would be a hyperbola with an initial slope equal to $\mathrm{Su}$ and asymptotic to $\mathrm{Su}$ as effective age approaches infinity. Since Su is affected by curing temperature, for a given concrete mixture, there would be a family of strength-effective age curves; each curve representing a different curing temperature.

Equation (6.6) can also be written as follows:

$$
\frac{\mathrm{S}}{\mathrm{Su}}=\frac{\mathrm{Ae}}{1+\mathrm{Ae}}
$$

Equation (6.7) expresses a very significant relationship: relative strength development is a single-valued function of effective age. To illustrate how well the strength-data from this study obey eq (6.7), the strengths of the low water-cement ratio mortars in Phase I were non-dimensionalized by dividing them by the appropriate values of Su presented in column 4 of Table 7 . The relative strengths are plotted versus effective age in figure 6.3. Effective age was computed according to eq (6.5) and employing the temperature functions represented by eqs $(6.2)$ and $(6.4)$. The following were the best-fit values of the parameters in the above temperature functions (they result in the curves shown in figures 6.1 and 6.2 ):

$$
\begin{aligned}
& \mathrm{A}=7.96 \times 10^{6} \text { (1/day) } \\
& \mathrm{E}=5015{ }^{\mathrm{O}} \mathrm{K} \\
& \mathrm{b}=9{ }^{\circ} \mathrm{C} \text {-days } \\
& \mathrm{a}=3^{\circ} \mathrm{C} .
\end{aligned}
$$


Also shown in figure 6.3 is the hyperbola represented by the right-hand side of eq (6.7). Note that effective age is a dimensionless quantity. Overall, the points fall very close to the hyperbolic curve, and it may be concluded that relative strength development is indeed related to effective age according to eq (6.7) irrespective of curing temperature.

Thus, the concept of effective age may be an appropriate alternative to the Saul function to properly account for the combined effects temperature and time on strength development. To apply this new method requires knowing three factors:

1) the relation between the basic reaction rate, $k$, and temperature,

2) the relation between curing temperature and limiting strength, and

3) the relation between temperature and age at initial set.

Future research will be required to understand how these three factors are affected by changes of the constituents of a concrete mix. Also it needs to be demonstrated how this method would be applied when temperature is not constant. 


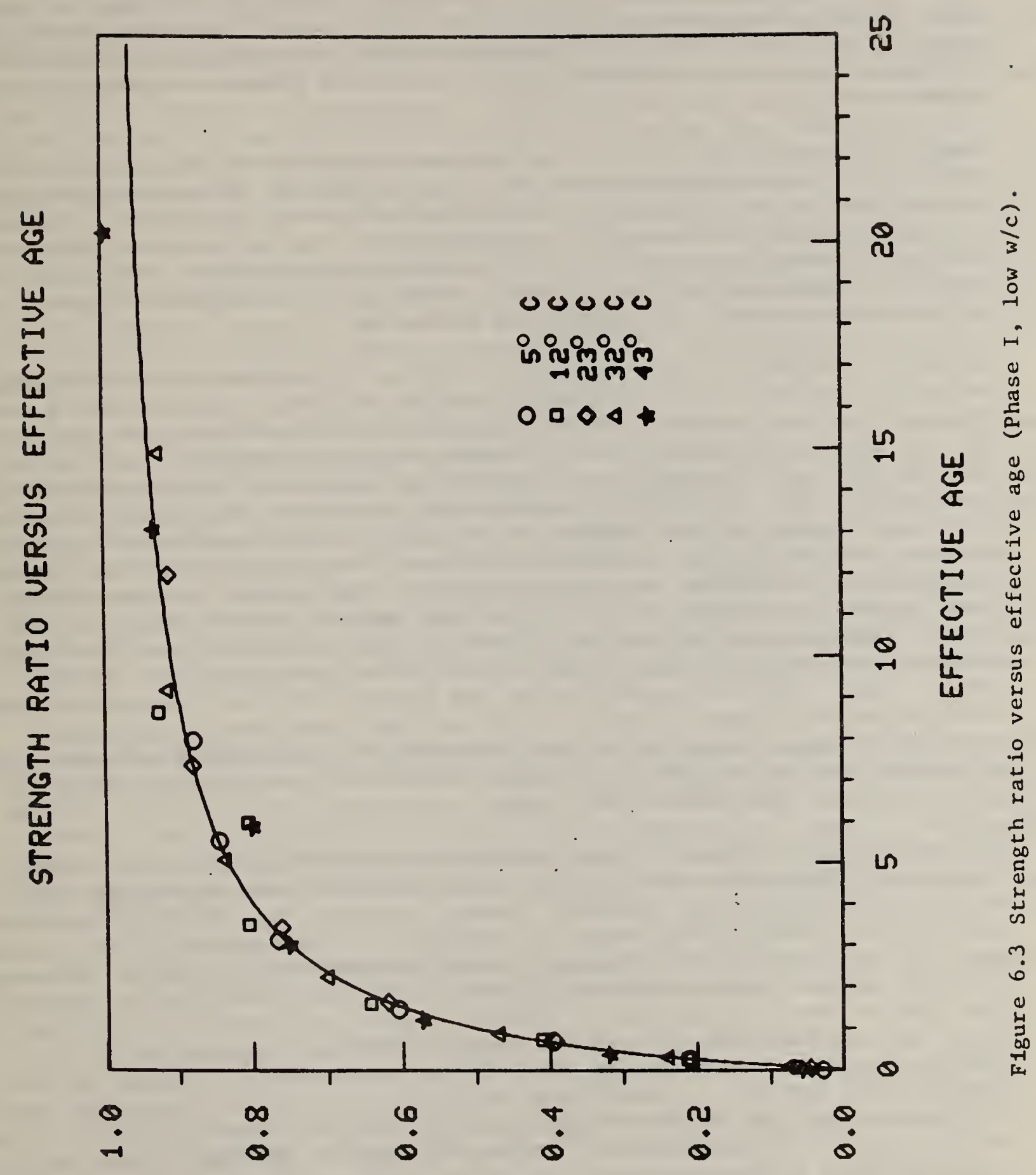

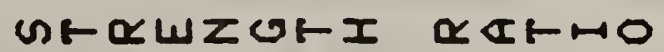




\subsection{SUMMARY AND RECOMMENDATIONS}

Phase I of the research was undertaken to gain a quantitative understanding of the effects of curing temperature on the strength-maturity relation of concrete. In order to simplify testing, mortar was used in place of concrete since it was believed that portland cement would be the main ingredient affected by temperature. Curing temperatures of $5^{\circ}, 12^{\circ}, 23^{\circ}, 32^{\circ}$ and $43^{\circ} \mathrm{C}$ were used. Compressive strength tests were performed at regular maturity intervals, and penetration resistance tests were conducted on fresh mortar to gain an understanding of temperature effects on setting time.

Concerning the effects of temperature on setting time, it was found that for a given mortar mix initial set occurred at approximately the same maturity (as computed by the Saul function). The fact that initial set occurs at approximately the same maturity may be useful in designing the rate of concrete placement into vertical formwork (such as walls) under different temperature conditions. In Phase II, final setting times were also determined and they were found to occur at decreasing maturity as temperature increased.

In order to determine the quantitative effects of temperature on the strengthmaturity relation, a three-parameter equation was used to approximate actual. strength-maturity curves. The assumed model is a hyperbolic curve defined by 1) an "offset maturity", $M_{0}$, when strength begins to develop, 2) an initial slope at $\mathrm{M}_{0}$, and 3 ) an asymptotic limiting strength, Su, as maturity increases to infinity. The variations of these three parameters with curing temperature were used to quantify the temperature effects. It was found that the limiting strength decreased in an approximately linear fashion with increasing curing temperature; the initial slope increased in an approximately linear fashion with increasing temperature; and the offset maturity varied inversely with curing temperature. The results of Phase II tests indicated that the offset maturity was approximately the same as the maturity at final set, and the latter value would be recommended for use in application of the three-parameter strength-maturity model. Thus, it was concluded that simple temperature corrections could be applied to the parameters of the strength-maturity relation, to enhance the reliability of strength predictions based upon the maturity concept over a wide temperature range.

The purpose of the Phase II experiments was to determine the extent of the "early age" beyond which temperature would no longer have significant effects on the strength-maturity relation. Mortar specimens were initially cured at $5^{\circ}$ and $32^{\circ} \mathrm{C}$; at predetermined stages of setting, the temperatures of the specimens were changed to $23^{\circ} \mathrm{C}$ for subsequent curing and compression testing. Movement from the extreme temperatures to $23^{\circ} \mathrm{C}$ were made at 1 ) time equal to one-half the time to reach initial set, 2) time of initial set, and 3) time of final set. Stages of setting were chosen rather than equal time periods at the extreme temperatures because it was believed that the former factor was more likely to be decisive in controlling the point beyond which temperature would no longer affect the strength-maturity relation. The results, however, appeared to contradict this supposition. For the $5^{\circ} \mathrm{C}$ initial treatments, the limiting strengths were greater than the case of constant curing at $23^{\circ} \mathrm{C}$ and similar to the value for constant curing at $5^{\circ} \mathrm{C}$; the initial slopes, on the other hand, were similar to the value for constant curing at $23^{\circ} \mathrm{C}$. The $32^{\circ} \mathrm{C}$ initial 
treatments did not show the same trends; In all cases, the strength-maturity relations were nearly identical to $23^{\circ} \mathrm{C}$ constant curing. Thus, it appears that degree of setting is not the critical factor governing the extent of "early age."

The systematic variations of the parameters of the strength-maturity model observed in Phase I caused us to ask whether an alternative approach to the Saul maturity function could be used to represent the combined effects of time and temperature on strength development. Hence, a detailed analysis of the strengthage data of Phase I was performed. Kinetic rate theory was used to provide justification for an hyperbolic strength-age function, and comparison with the data showed such a model to be superior to a first-order exponential model. It was also shown that if the rate constant in the strength-age relation was assumed to be a linear function of temperature, the resulting strength-age function was precisely the hyperbolic strength-maturity relation employed in analysis of the Phase I data. However, the computed values of the rate constant were found to be a non-linear function of temperature. Thus, a newly recognized implicit assumption in the classical maturity method has been identified, and we now understand why the "cross-over" effect occurs in strength-maturity relations for curing at dissimilar temperatures.

Analysis of the strength-age data revealed that the rate constant was independent of the strength level of the mix (that is, water-cement ratio) and that it was related to curing temperature according to the Arhennius equation. By employing the Arrhenius function, rather than a linear function to represent the variation of the rate constant with temperature, a single equation was developed to represent the strength-age relations for different curing temperatures. The product of time and the rate constant yields a non-dimensional quantity, which has been named "effective age" and indicates the fraction of limiting strength that has been attained by that time. A plot of fractional strength data versus effective age showed that a single hyperbolic curve was a good representation of the data.

In summary, the research has indicated that there exist rational means by which a strength-maturity calibration curve may be altered so that its reliability is maintained over a wide temperature range. Also, it appears that the concept of "effective age" offers another approach for accounting for time and temperature effects on strength-development. However, before making recommendations on field application of the suggested procedures, three fundamental questions need to be addressed:

1) Will concrete display the same responses to different curing temperatures as the mortar specimens used in this research?

2) How are the proposed correction factors or the effective age concept to be applied under conditions of daily temperature fluctuations?

3) What characteristics of cement chemistry have the greatest effect on the response to different curing temperatures?

These questions should serve as a guide in planning future research in this area, and the answers to the questions will provide information to formulate recommendations for an approach that can be employed to reliably predict in-place strength of concrete at early ages and under varying thermal histories. 


\subsection{REFERENCES}

1. Carino, N. J., The Maturity Concept - It's Development and Future, NBS publication, in review, 1980.

2. Malhotra, V. M., Maturity Concept and the Estimation of Concrete Strength A Review, Department of Energy, Mines and Resources, Mines Branch, Ottawa, Information Circular IC-277, 43 pages (1971).

3. McIntosh, J. D., Electrical Curing of Concrete, Magazine of Concrete Research, 1 , No. 1, 21-28 (Jan. 1949).

4. Nurse, R. W., Steam Curing of Concrete, Magazine of Concrete Research $\underline{1}$, No. 2, 79-88 (June 1949).

5. Saul, A. G. A., Principles Underlying the Steam Curing of Concrete at Atmospheric Pressure, Magazine of Concrete Research 2, No. 6, 127-140 (March 1951).

6. Bergstrom, S. G., Curing Temperature, Age and Strength of Concrete, Magazine of Concrete Research 5, No. 14, 61-66 (Dec. 1953).

7. Plowman, J. M., Maturity and the Strength of Concrete, Magazine of Concrete Research 8, No. 22, 13-22 (March 1956).

8. Discussion of Reference 16, Magazine of Concrete Research $\underline{8}$, No. 24, 169-183 (Nov. 1956).

9. McIntosh, J. D., The Effects of Low-Temperature Curing on the Compressive Strength of Concrete, R.I.L.E.M. Symposium on Winter Concreting, (Copenhagen, 1956).

10. Klieger, P., Effect of Mixing and Curing Temperatures on Concrete Strength, Journal of the American Concrete Institute 54, No. 12, 1063-1082 (June 1958).

11. Alexander, K. M. and Taplin, J. H., Concrete Strength, Cement Hydration and the Maturity Rule, Australian Journal of Applied Science 13, 277-284 (1962).

12. Verbeck, G. J. and Helmuth, R. H., Structure and Physical Properties of Cement Paste, Proceedings of the Fifth International Symposium on the Chemistry of Cement, Part III, 1-32 (Tokyo 1968).

13. Swenson, E. G., Estimation of Strength Gain of Concrete, Engineering Journal September, 1967.

14. Hudson, S. B. and Steele, G. W., Prediction of Potential Strength of Concrete from Early Tests, Highway Research Record, No. 370, Highway Research Board, 25-35 (1971).

15. Hudson, S. B. and Steele, G. W., Developments in the Prediction of Potential Strength of Concrete from Results of Early Tests, Transportation Research Record, No. 558, Transportation Research Board, 1-12 (1975). 
16. Chin, F. K., Relation Between Strength and Maturity of Concrete, Journal of the American Concrete Institute 68, No. 3, 196-203 (March 1971).

17. Pommersheim, J. M. and Clifton, J. R., Prediction of Strength-Maturity Relationships for Portland Cement Systems, NBS publication in review, 1980.

18. Chin, F. K., Strength Tests at Early Ages and at High Setting Temperatures, Transportation Research Record, No. 558, Transportation Research Board, 69-76 (1975).

19. Weaver, J: and Sadgrove, B. M., Striking Times of Formwork-Tables of Curing Periods to Achieve Given Strengths, Construction Industry Research and Information Association, Report 36, (London, Oct. 1971).

20. Sadgrove, B. M., Prediction of Strength Development in Concrete Structures, Transportation Research Record, No. 558, Transportation Research Board, 19-28 (1975).

21. Bickley, J. A., Practical Application of the Maturity Concept to Determine In-Situ Strength of Concrete, Transportation Research Record, No. 558, Transportation Research Board, 45-49 (1975).

22. Mukherjee, P. K., Practical Application of Maturity Concept to Determine In-Situ Strength of Concrete, Transportation Research Record, No. 558, Transportation Research Board, 87-92 (1975).

23. Nisbet, E. G. and Maitland, S. T., Mass Concrete Sections and the Maturity Concept, Canadian Journal of Civil Engineering, Vol. 3, 1976.

24. Lew, H. S., and Reichard, T. W., Mechanical Properties of Concrete at Early Ages, Journal of the American Concrete Institute 75, No. 10, 533-542 (Oct. 1978).

25. Lew, H. S. and Reichard, T. W., Prediction of Strength of Concrete from Maturity, Accelerated Strength Testing, SP-56, American Concrete Institute, 229-248 (1978).

26. Carino, N. J. and Lew, H. S., Applicability of the Maturity Concept to Predict Strength of Field-Cured Concrete, NBS publication in review, 1980.

27. Volz, C. K., New Developments in the Maturity Concept, M. S. Report, The University of Texas at Austin, (December 1979).

28. ASTM Annual Book of Standards, Part 14, (1979).

29. Sprouse, J. H. and Peppler, R. B., Setting Time, Chapter 9 in Significance of Tests and Properties of Concrete and Concrete-Making Materials, ASTM STP 169B, 105-121 (1978).

30. Bernhardt, C. J., Hardening of Concrete at Different Temperatures, R.I.L.E.M. Symposium on Winter Concreting, (Copenhagen, 1956). 
31. Filliben, J. J., DATAPLOT - An Interactive System for Graphics, Fortran Function Evaluation and Linear/Non-Linear Fitting, Proceedings of the Statistical Computing Section of the American Statistical Association, 1978.

32. Pommersheim, J. and Clifton, J. R., Mathematical Models of Cement Hydration, Cements Research Progress; Chapter 13, 281-307 (1979).

33. Berger, R. L. and McGregor, J. D., Effect of Temperature and Water-Solid Ratio on Growth of Calcium Hydroxide Crystals Formed During Hydration of Tricalcium Silicate; Journal of the American Ceramic Society 56, No. 2, 73-79 (1973). 
APPENDIX A

PENETRATION RESISTANCE DATA

\begin{tabular}{|c|c|c|c|c|c|}
\hline \multirow[b]{2}{*}{ SERIES } & \multicolumn{2}{|c|}{ PENETRATION READINGS } & \multirow{2}{*}{$\frac{\text { AGE }}{\text { (hour) }}$} & \multicolumn{2}{|c|}{ MATURITY } \\
\hline & (psi) & $(\mathrm{MPa})$ & & $\left({ }^{\circ} \mathrm{F}\right.$-days $)$ & $\left({ }^{\mathrm{O}} \mathrm{C}\right.$-days $)$ \\
\hline $\mathrm{I}-5-\mathrm{H}^{*}$ & $\begin{array}{ll}140, & 160 \\
240, & 240 \\
270, & 280 \\
370, & 430 \\
470, & 470\end{array}$ & $\begin{array}{l}0.97,1.10 \\
1.66,1.66 \\
1.86,1.93 \\
2.55,2.97 \\
3.24,3.24\end{array}$ & $\begin{array}{r}7.00 \\
8.00 \\
9.00 \\
10.33 \\
11.33\end{array}$ & $\begin{array}{r}8.33 \\
10.13 \\
11.42 \\
13.13 \\
14.42\end{array}$ & $\begin{array}{l}4.91 \\
5.63 \\
6.34 \\
7.29 \\
8.01\end{array}$ \\
\hline $\mathrm{I}-12-\mathrm{H}$ & $\begin{array}{l}180,180 \\
240,270 \\
360,430 \\
470,500 \\
520,550\end{array}$ & $\begin{array}{l}1.24,1.24 \\
1.66,1.86 \\
2.48,2.97 \\
3.24,3.45 \\
3.59,3.79\end{array}$ & $\begin{array}{l}5.50 \\
6.58 \\
7.75 \\
8.25 \\
8.50\end{array}$ & $\begin{array}{r}9.92 \\
11.88 \\
13.92 \\
14.83 \\
15.25\end{array}$ & $\begin{array}{l}5.21 \\
6.60 \\
7.73 \\
8.24 \\
8.47\end{array}$ \\
\hline $\mathrm{I}-23-\mathrm{H}$ & $\begin{array}{cl}50, & 60 \\
230, & 210 \\
340, & 300 \\
480, & 430 \\
620, & 590\end{array}$ & $\begin{array}{l}0.34,0.41 \\
1.59,1.45 \\
2.34,2.07 \\
3.31,2.97 \\
4.28,4.07\end{array}$ & $\begin{array}{l}3.00 \\
4.50 \\
5.00 \\
5.50 \\
6.00\end{array}$ & $\begin{array}{r}7.79 \\
11.67 \\
12.96 \\
14.21 \\
15.50\end{array}$ & $\begin{array}{l}4.33 \\
6.48 \\
7.20 \\
7.89 \\
8.61\end{array}$ \\
\hline $\mathrm{I}-32-\mathrm{H}$ & $\begin{array}{l}110,120 \\
440,500 \\
520,500 \\
610,660 \\
640,710\end{array}$ & $\begin{array}{l}0.76,0.83 \\
3.03,3.45 \\
3.57,3.45 \\
4.21,4.55 \\
4.41,4.90\end{array}$ & $\begin{array}{l}3.00 \\
4.00 \\
4.17 \\
4.33 \\
4.42\end{array}$ & $\begin{array}{r}9.76 \\
13.00 \\
13.55 \\
14.09 \\
14.36\end{array}$ & $\begin{array}{l}5.42 \\
7.22 \\
7.53 \\
7.83 \\
7.98\end{array}$ \\
\hline $\mathrm{I}-43-\mathrm{H}$ & $\begin{array}{ll}180, & 180 \\
330, & 310 \\
390, & 370 \\
630, & 590 \\
610, & 580\end{array}$ & $\begin{array}{l}1.24,1.24 \\
2.28,2.14 \\
2.69,2.55 \\
4.34,4.07 \\
4.21,4.00\end{array}$ & $\begin{array}{l}2.25 \\
2.58 \\
2.75 \\
3.00 \\
3.08\end{array}$ & $\begin{array}{r}9.21 \\
10.56 \\
11.24 \\
12.25 \\
12.59\end{array}$ & $\begin{array}{l}5.12 \\
5.87 \\
6.24 \\
6.81 \\
6.99\end{array}$ \\
\hline $\mathrm{I}-5-\mathrm{L}$ & $\begin{array}{ll}180, & 150 \\
270, & 250 \\
390, & 360 \\
420, & 470 \\
550, & 560\end{array}$ & $\begin{array}{l}1.24,1.03 \\
1.86,1.72 \\
2.69,2.48 \\
2.90 .3 .24 \\
3.79,3.86\end{array}$ & $\begin{array}{l}6.00 \\
7.00 \\
8.00 \\
8.67 \\
9.33\end{array}$ & $\begin{array}{r}7.75 \\
9.04 \\
10.33 \\
11.21 \\
12.08\end{array}$ & $\begin{array}{l}4.31 \\
5.02 \\
5.74 \\
6.23 \\
6.71\end{array}$ \\
\hline I-12-L & $\begin{array}{ll}210, & 190 \\
310, & 300 \\
370, & 370 \\
540, & 590 \\
620, & 660\end{array}$ & $\begin{array}{l}1.45,1.31 \\
2.14,2.07 \\
2.55,2.55 \\
3.72,4.07 \\
4.28,4.55\end{array}$ & $\begin{array}{l}4.50 \\
5.58 \\
6.25 \\
7.00 \\
7.25\end{array}$ & $\begin{array}{r}8.13 \\
10.04 \\
11.25 \\
12.58 \\
13.00\end{array}$ & $\begin{array}{l}4.52 \\
5.58 \\
6.25 \\
6.99 \\
7.22\end{array}$ \\
\hline
\end{tabular}

* See section 2.3 for key to these symbols 
PENETRATION READINGS

\begin{tabular}{|c|c|c|c|c|c|}
\hline SERIES & (psi) & $(\mathrm{MPa})$ & (hour) & $\left({ }^{\circ} \mathrm{F}-\right.$ day $)$ & $\left({ }^{\circ} \mathrm{C}-\right.$ day $)$ \\
\hline$I-23-L$ & $\begin{array}{cl}60, & 40 \\
210, & 190 \\
350, & 320 \\
570, & 470 \\
650, & 600\end{array}$ & $\begin{array}{l}0.41,0.28 \\
1.45,1.31 \\
2.41,2.21 \\
3.93,3.24 \\
4.48,4.14\end{array}$ & $\begin{array}{l}2.50 \\
3.50 \\
4.00 \\
4.50 \\
4.75\end{array}$ & $\begin{array}{r}6.50 \\
9.08 \\
10.38 \\
11.67 \\
12.29\end{array}$ & $\begin{array}{l}3.61 \\
5.04 \\
5.77 \\
6.48 \\
6.83\end{array}$ \\
\hline$I-32-L$ & $\begin{array}{ll}100, & 100 \\
310, & 270 \\
400, & 360 \\
590, & 560 \\
610, & 600\end{array}$ & $\begin{array}{l}0.69,0.69 \\
2.14,1.86 \\
2.76,2.48 \\
4.07,3.86 \\
4.20,4.14\end{array}$ & $\begin{array}{l}2.50 \\
3.00 \\
3.25 \\
3.50 \\
3.58\end{array}$ & $\begin{array}{r}8.08 \\
9.72 \\
10.54 \\
11.35 \\
11.62\end{array}$ & $\begin{array}{l}4.49 \\
5.40 \\
5.86 \\
6.31 \\
6.46\end{array}$ \\
\hline$I-43-L$ & $\begin{array}{ll}140, & 130 \\
230, & 240 \\
380, & 380 \\
590, & 570 \\
640, & 700\end{array}$ & $\begin{array}{l}0.97,0.90 \\
1.59,1.66 \\
2.62,2.62 \\
4.07,3.93 \\
4.41,4.83\end{array}$ & $\begin{array}{l}1.75 \\
2.08 \\
2.33 \\
2.52 \\
2.63\end{array}$ & $\begin{array}{r}7.13 \\
8.47 \\
9.49 \\
10.23 \\
10.70\end{array}$ & $\begin{array}{l}3.96 \\
4.71 \\
5.27 \\
5.68 \\
5.94\end{array}$ \\
\hline$I I-5-I$ & $\begin{array}{ll}130, & 140 \\
230, & 200 \\
330, & 360 \\
420, & 400 \\
460, & 520 \\
800, & 840 \\
1600, & 1480 \\
1880, & 2400 \\
2520, & 2680 \\
3960 & -\end{array}$ & $\begin{array}{cc}0.90, & 0.97 \\
1.57, & 1.38 \\
2.28, & 2.48 \\
2.90, & 2.76 \\
3.17, & 3.59 \\
5.52, & 5.79 \\
11.03, & 10.21 \\
12.97, & 16.55 \\
17.38, & 18.48 \\
27.31 & -\end{array}$ & $\begin{array}{r}8.00 \\
9.50 \\
10.75 \\
11.75 \\
12.50 \\
13.50 \\
14.33 \\
15.00 \\
15.25 \\
16.17\end{array}$ & $\begin{array}{l}10.18 \\
12.06 \\
13.63 \\
14.88 \\
15.83 \\
17.91 \\
20.05 \\
21.79 \\
22.84 \\
24.79\end{array}$ & $\begin{array}{r}5.65 \\
6.70 \\
7.57 \\
8.27 \\
8.79 \\
9.95 \\
11.14 \\
12.11 \\
12.69 \\
13.77\end{array}$ \\
\hline II-5-F & $\begin{array}{ll}124, & 128 \\
180, & 170 \\
340, & 300 \\
340, & 380 \\
530, & 470 \\
680, & 750 \\
960, & 940 \\
1760, & 1760 \\
2480, & 2400 \\
3200, & 2920\end{array}$ & $\begin{array}{c}0.86,0.88 \\
1.24,1.17 \\
2.34,2.07 \\
2.34,2.62 \\
3.66,3.24 \\
4.69,5.17 \\
6.62,6.48 \\
12.14,12.14 \\
17.10,16.55 \\
22.07,20.14\end{array}$ & $\begin{array}{r}6.25 \\
8.00 \\
9.50 \\
10.50 \\
11.50 \\
12.75 \\
14.00 \\
16.42 \\
18.00 \\
19.58\end{array}$ & $\begin{array}{r}7.81 \\
10.02 \\
11.92 \\
13.18 \\
14.44 \\
16.00 \\
17.58 \\
20.61 \\
22.61 \\
24.61\end{array}$ & $\begin{array}{r}4.34 \\
5.57 \\
6.62 \\
7.32 \\
8.02 \\
8.89 \\
9.77 \\
11.45 \\
12.56 \\
13.67\end{array}$ \\
\hline II-5-H & $\begin{array}{cl}160, & 160 \\
270, & 300 \\
410, & 530 \\
780, & 900 \\
1440, & 1320 \\
1960, & 1960 \\
2800, & 2600 \\
3800, & 3520 \\
3440, & 3400 \\
3920, & 4080\end{array}$ & $\begin{array}{c}1.10,1.10 \\
1.86,2.07 \\
2.83,3.66 \\
5.38,6.21 \\
9.93,9.10 \\
13.52,13.52 \\
19.31,17.93 \\
26.21,24.28 \\
23.72,23.45 \\
27.03,28.14\end{array}$ & $\begin{array}{r}7.00 \\
7.75 \\
8.50 \\
9.25 \\
10.00 \\
10.58 \\
11.00 \\
11.50 \\
11.75 \\
12.00\end{array}$ & $\begin{array}{l}10.18 \\
12.12 \\
14.05 \\
15.99 \\
17.12 \\
19.42 \\
20.49 \\
21.79 \\
22.44 \\
22.08\end{array}$ & $\begin{array}{r}5.66 \\
6.73 \\
7.81 \\
8.88 \\
9.96 \\
10.79 \\
11.38 \\
12.11 \\
12.47 \\
12.82\end{array}$ \\
\hline
\end{tabular}


PENETRATION READINGS

SERIES

II-32-I

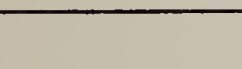

125,160

245,360

440,400

560,580

920,1140

1520,1620

2500,2540

3160,3280

4920,4300

- 4800
(MPa)
AGE

(hours)
MATURITY

( ${ }^{\mathrm{F}}$-days) ( ${ }^{\circ} \mathrm{C}$-days $)$

\begin{tabular}{|c|c|c|c|c|c|}
\hline II-32-F & $\begin{array}{ll}215, & 220 \\
365, & 365 \\
570, & 580 \\
820, & 810 \\
1140, & 1260 \\
1590, & 1400 \\
2640, & 2440 \\
3560, & 3400 \\
4160, & 3880 \\
5240, & -\end{array}$ & $\begin{array}{cc}1.48, & 1.52 \\
2.52, & 2.52 \\
3.93, & 4.00 \\
5.66, & 5.59 \\
7.86, & 8.69 \\
10.97, & 9.66 \\
18.21, & 16.83 \\
24.55, & 23.45 \\
28.69, & 26.76 \\
36.14, & -\end{array}$ & $\begin{array}{l}3.17 \\
3.25 \\
3.72 \\
4.0 \\
4.25 \\
4.55 \\
4.83 \\
5.08 \\
5.33 \\
5.62\end{array}$ & $\begin{array}{l}10.42 \\
11.24 \\
12.21 \\
13.24 \\
13.95 \\
14.93 \\
15.86 \\
16.73 \\
17.49 \\
18.41\end{array}$ & $\begin{array}{r}5.79 \\
6.24 \\
6.78 \\
7.36 \\
7.75 \\
8.29 \\
8.81 \\
9.29 \\
9.72 \\
10.23\end{array}$ \\
\hline II-32-H & $\begin{aligned} 155, & 160 \\
270, & 250 \\
430, & 420 \\
680, & 650 \\
890, & 900 \\
1120, & 1100 \\
1480, & 1530 \\
2120, & 2520 \\
2860, & 3000 \\
3680, & 3660\end{aligned}$ & $\begin{array}{c}1.07,1.10 \\
1.86,1.72 \\
2.97,2.90 \\
4.69,4.48 \\
6.14,6.21 \\
7.72,7.59 \\
10.21,10.55 \\
14.62,17.38 \\
19.72,20.69 \\
25.38,25.24\end{array}$ & $\begin{array}{l}3.42 \\
4.03 \\
4.50 \\
4.92 \\
5.33 \\
5.67 \\
6.17 \\
6.58 \\
6.92 \\
7.42\end{array}$ & $\begin{array}{l}10.50 \\
12.08 \\
13.28 \\
14.35 \\
15.41 \\
16.26 \\
17.53 \\
18.60 \\
19.46 \\
20.76\end{array}$ & $\begin{array}{r}5.83 \\
6.71 \\
7.38 \\
7.97 \\
8.56 \\
9.03 \\
9.73 \\
10.33 \\
10.81 \\
11.53\end{array}$ \\
\hline
\end{tabular}


APPENDIX B

COMPRESSIVE STRENGTH DATA

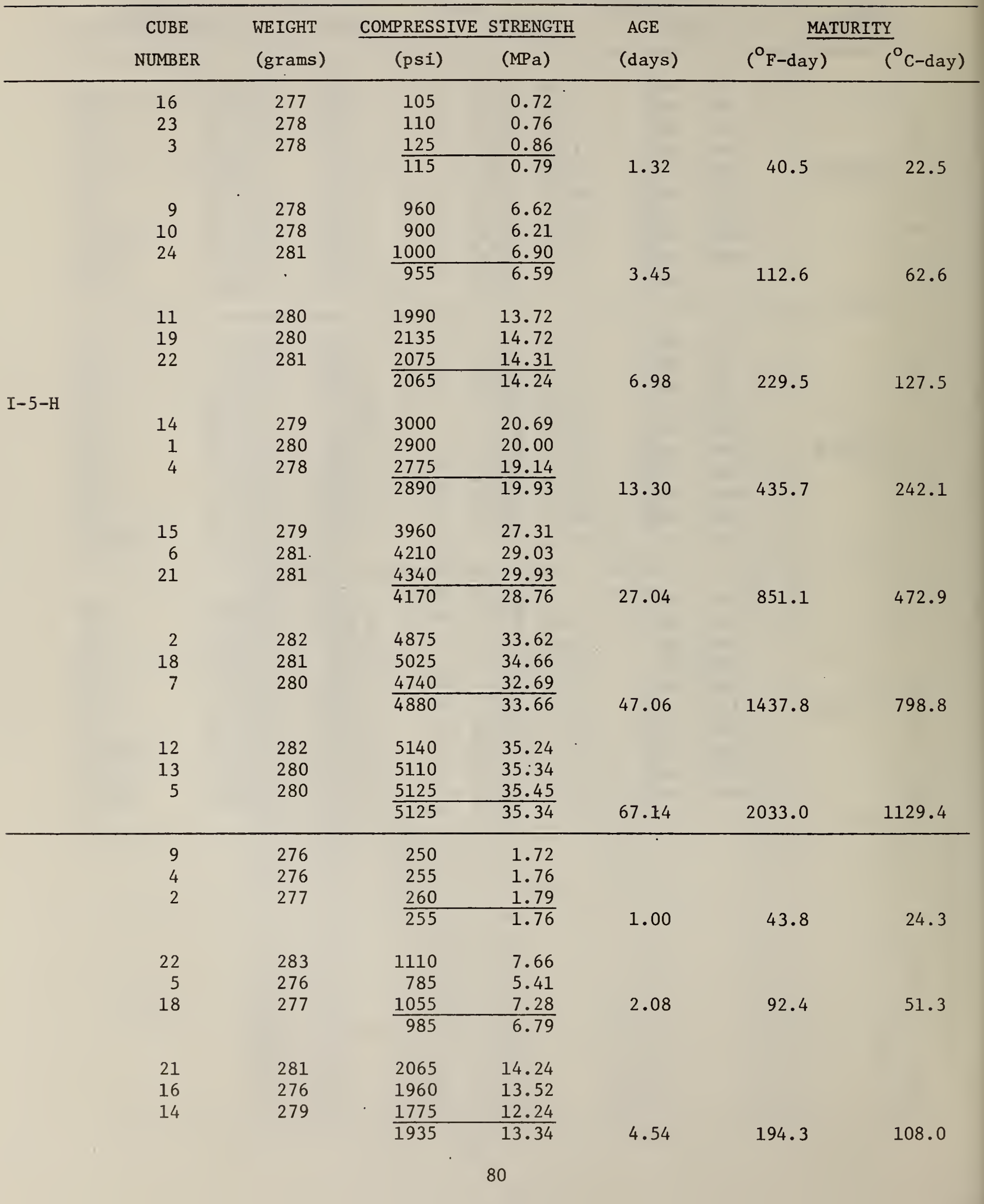




\begin{tabular}{|c|c|c|c|c|c|c|c|}
\hline \multirow[b]{2}{*}{ SERIES } & \multirow{2}{*}{$\begin{array}{c}\text { CUBE } \\
\text { NUMBER }\end{array}$} & \multirow{2}{*}{$\begin{array}{l}\text { WEIGHT } \\
\text { (grams) }\end{array}$} & \multicolumn{2}{|c|}{ COMPRESSIVE STRENGTH } & \multirow{2}{*}{$\begin{array}{c}\text { AGE } \\
\text { (days) }\end{array}$} & \multicolumn{2}{|c|}{ MATURITY } \\
\hline & & & (psi) & $(\mathrm{MPa})$ & & $\left({ }^{\mathrm{O}} \mathrm{F}-\mathrm{day}\right)$ & $\left({ }^{\circ} \mathrm{C}-\mathrm{day}\right)$ \\
\hline \multirow{16}{*}{$\mathrm{I}-12-\mathrm{H}$} & 20 & 281 & 3040 & 20.97 & & & \\
\hline & 15 & 278 & 2525 & 17.41 & & & \\
\hline & 10 & 278 & 2500 & 17.24 & & & \\
\hline & & & 2690 & 18.55 & 9.00 & 387.2 & 215.1 \\
\hline & 13 & 280 & 3275 & 22.59 & & & \\
\hline & 12 & 279 & 3160 & 21.79 & & & \\
\hline & & 281 & 3050 & 21.03 & & & \\
\hline & & & $\overline{3160}$ & 21.79 & 19.00 & 812.9 & 451.6 \\
\hline & 23 & 283 & 4215 & 29.07 & & & \\
\hline & 6 & 282 & 3400 & 23.45 & & & \\
\hline & 1 & 280 & 3150 & 21.72 & & & \\
\hline & & & 3590 & 24.76 & 31.96 & 1374.5 & 763.6 \\
\hline & 11 & 281 & 3900 & 26.90 & & & \\
\hline & 24 & 282 & 4525 & 31.21 & & & \\
\hline & 19 & 284 & 4575 & 31.55 & & & \\
\hline & & & 4335 & 29.90 & 45.96 & 1980.3 & 1100.2 \\
\hline \multirow{24}{*}{ I-23-H } & 24 & 280 & 285 & 1.97 & & & \\
\hline & 11 & 279 & 190 & 1.31 & & & \\
\hline & 20 & 282 & 270 & 1.86 & & & \\
\hline & & & $\overline{250}$ & 1.72 & 0.51 & 32.0 & 17.8 \\
\hline & 14 & 281 & 820 & 5.66 & & & \\
\hline & 19 & 283 & 1185 & 8.17 & & & \\
\hline & 21 & 283 & 1180 & 8.14 & & & \\
\hline & & & 1060 & 7.31 & 1.15 & 73.3 & 40.7 \\
\hline & 3 & 279 & 1565 & 10.79 & & & \\
\hline & 1 & 278 & 1525 & 10.52 & & & \\
\hline & 16 & 283 & 2110 & 14.55 & & & \\
\hline & & & $\overline{1735}$ & 11.97 & 2.40 & 153.7 & 85.4 \\
\hline & 8 & 278 & 2475 & 17.07 & & & \\
\hline & 15 & 283 & 2400 & 16.55 & t & & \\
\hline & 13 & 281 & 2340 & 16.14 & & & \\
\hline & & & $\overline{2405}$ & 16.59 & 5.04 & 319.0 & 177.2 \\
\hline & 22 & 283 & 3560 & 24.55 & & & \\
\hline & 7 & 278 & 2725 & 18.79 & & & \\
\hline & 23 & 283 & 3725 & 25.69 & & & \\
\hline & & & $\overline{3340}$ & 23.03 & 10.01 & 632.0 & 351.1 \\
\hline & 9 & 278 & 3075 & 21.21 & & & \\
\hline & 10 & 280 & 3250 & 22.41 & & & \\
\hline & 6 & 280 & 3440 & 23.72 & & & \\
\hline & & & $\overline{3255}$ & 22.45 & 21.00 & 1315.1 & 730.6 \\
\hline
\end{tabular}




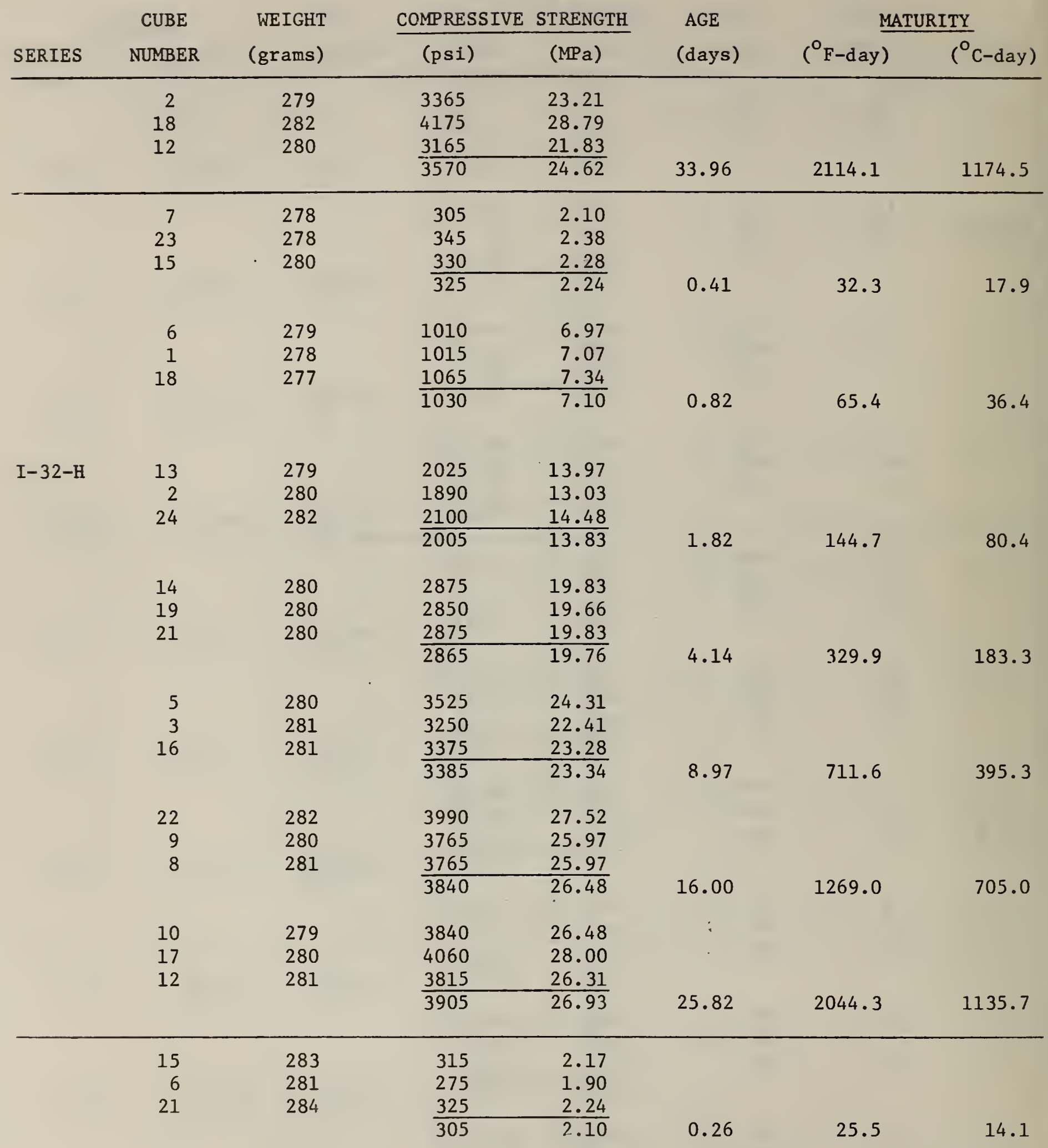




\begin{tabular}{|c|c|c|c|c|c|c|c|}
\hline \multirow[b]{2}{*}{ SERIES } & \multirow{2}{*}{$\begin{array}{c}\text { CUBE } \\
\text { NUMBER }\end{array}$} & \multirow{2}{*}{$\begin{array}{l}\text { WEIGHT } \\
\text { (grams) }\end{array}$} & \multicolumn{2}{|c|}{ COMPRESSIVE STRENGTH } & \multirow{2}{*}{$\begin{array}{c}\text { AGE } \\
\text { (days) }\end{array}$} & \multicolumn{2}{|c|}{ MATURITY } \\
\hline & & & (psi) & $(\mathrm{MPa})$ & & $\left({ }^{\circ}\right.$ F-day $)$ & $\left({ }^{\circ} \mathrm{C}-\right.$ day $)$ \\
\hline \multirow{24}{*}{$\mathrm{I}-43-\mathrm{H}$} & 9 & 284 & 1355 & 9.34 & \multirow[b]{4}{*}{0.60} & \multirow[b]{4}{*}{59.4} & \multirow[b]{4}{*}{33.0} \\
\hline & 2 & 279 & 1190 & 8.21 & & & \\
\hline & 18 & 283 & 1270 & 8.76 & & & \\
\hline & & & 1270 & 8.76 & & & \\
\hline & 3 & 280 & 2315 & 15.97 & & \multirow{5}{*}{141.2} & \multirow[b]{4}{*}{78.5} \\
\hline & 16 & 284 & 2260 & 15.59 & \multirow[b]{3}{*}{1.42} & & \\
\hline & 13 & 283 & 2300 & 15.86 & & & \\
\hline & & & 2290 & 15.79 & & & \\
\hline & 22 & 288 & 3190 & 22.00 & \multirow[b]{4}{*}{3.17} & & \multirow[b]{4}{*}{174.0} \\
\hline & 1 & 281 & 2985 & 20.59 & & \multirow[b]{3}{*}{313.1} & \\
\hline & 12 & 285 & 3225 & 22.24 & & & \\
\hline & & & 3135 & 21.62 & & & \\
\hline & 10 & 286 & 3690 & 25.45 & & \multirow[b]{4}{*}{591.5} & \multirow[b]{4}{*}{328.6} \\
\hline & 4 & 282 & 3360 & 23.17 & \multirow[b]{3}{*}{5.99} & & \\
\hline & 23 & 286 & 3415 & 23.55 & & & \\
\hline & & & 3490 & 24.07 & & & \\
\hline & 20 & 284 & 3950 & 27.24 & \multirow[b]{4}{*}{12.99} & \multirow[b]{4}{*}{1282.8} & \multirow[b]{4}{*}{712.7} \\
\hline & 14 & 283 & 3750 & 25.86 & & & \\
\hline & 7 & 284 & 3835 & 26.45 & & & \\
\hline & & & 3845 & 26.52 & & & \\
\hline & 5 & 285 & 3960 & 27.31 & & & \\
\hline & 24 & 285 & 3900 & 26.90 & & & \\
\hline & 11 & 283 & 4100 & 28.28 & & & \\
\hline & & & 3990 & 27.52 & 20.00 & 1975.8 & 1097.7 \\
\hline & 43 & 289 & 375 & 2.59 & & & \\
\hline & 30 & 284 & 255 & 1.76 & & & \\
\hline & 35 & 287 & 315 & 2.17 & & & \\
\hline & & & 315 & 2.17 & 1.29 & 40.1 & 22.3 \\
\hline & 38 & 286 & 2380 & 16.41 & & & \\
\hline & 28 & 286 & 2250 & 15.52 & & & \\
\hline & 32 & 284 & 2150 & 14.83 & & & \\
\hline & . & & 2260 & 15.59 & 3.41 & 112.2 & 62.3 \\
\hline & 33 & 286 & 4240 & 29.24 & & & \\
\hline & 37 & 287 & 4435 & 30.59 & & & \\
\hline & 31 & 285 & 4050 & 27.93 & & & \\
\hline & & & 4240 & 29.24 & 6.94 & 239.2 & 132.9 \\
\hline & 45 & 292 & 6590 & 45.45 & & & \\
\hline & 39 & 289 & 6100 & 42.07 & & & \\
\hline & 47 & 292 & 6725 & 46.38 & & & \\
\hline & & & 6470 & 44.62 & 13.27 & 445.8 & 247.7 \\
\hline$I-5-L$ & 42 & 288 & 8675 & 59.83 & & & \\
\hline & 34 & 288 & 8075 & 55.69 & & & \\
\hline & 27 & 289 & 7725 & 53.28 & . & & \\
\hline & & & 8160 & 56.28 & 27.01 & 861.2 & 478.4 \\
\hline
\end{tabular}




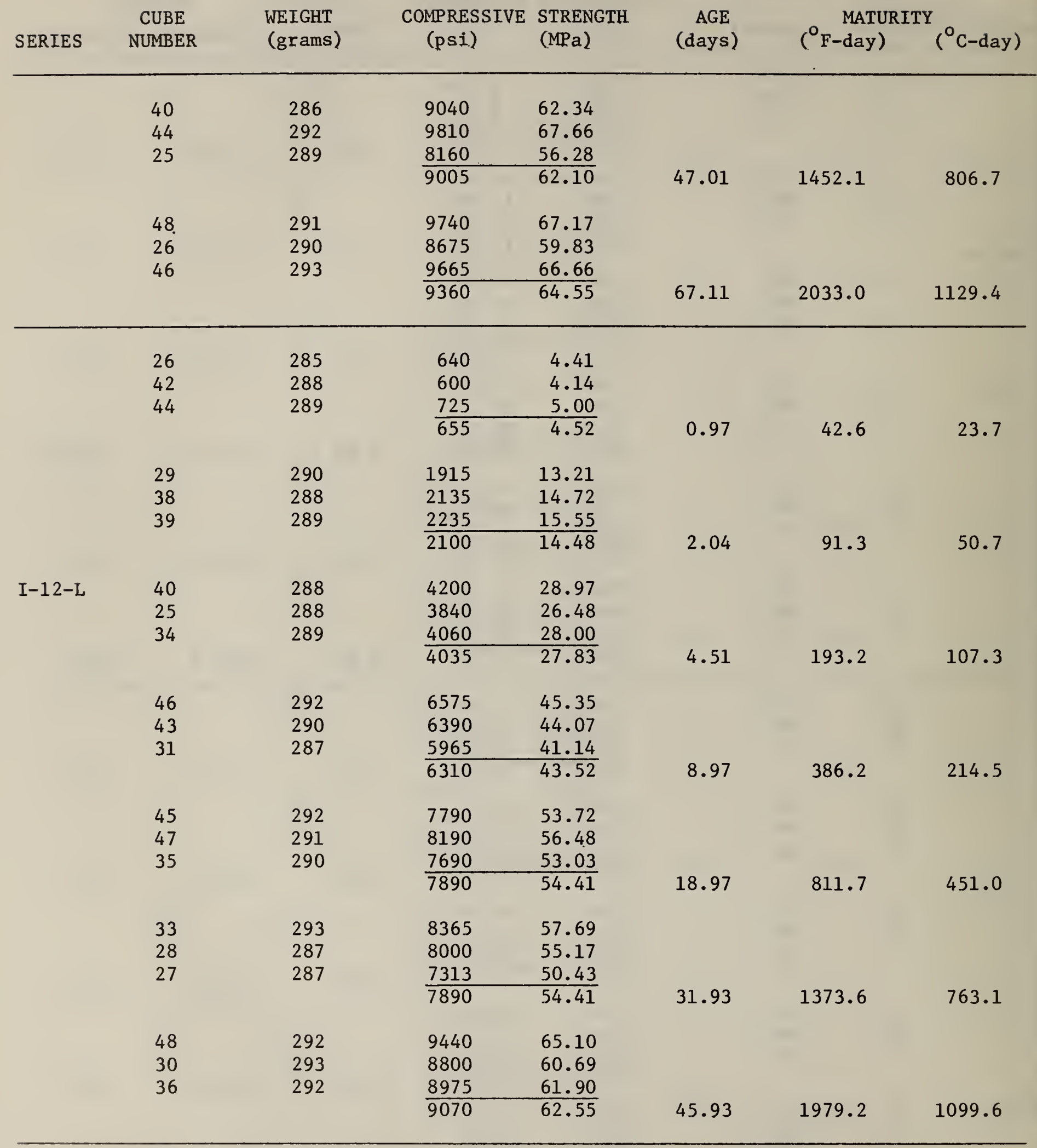




\begin{tabular}{|c|c|c|c|c|c|c|c|}
\hline \multirow[b]{2}{*}{ SERIES } & \multirow{2}{*}{$\begin{array}{c}\text { CUBE } \\
\text { NUMBBER }\end{array}$} & \multirow{2}{*}{$\begin{array}{l}\text { WEIGHT } \\
\text { (grams) }\end{array}$} & \multicolumn{2}{|c|}{ COMPRESSIVE STRENGTH } & \multirow{2}{*}{$\begin{array}{c}\text { AGE } \\
\text { (days) }\end{array}$} & \multicolumn{2}{|c|}{ MATURITY } \\
\hline & & & (psi) & $(\mathrm{MPa})$ & & $\left({ }^{\circ} \mathrm{F}\right.$-day $)$ & $\left({ }^{\circ} \mathrm{C}\right.$-day $)$ \\
\hline & 28 & 285 & 430 & 2.97 & & & \\
\hline & 31 & 285 & 420 & 2.90 & & & \\
\hline & 37 & & 450 & $\frac{3.10}{2.0}$ & & & \\
\hline & & & 435 & 3.00 & 0.48 & 29.9 & 16.6 \\
\hline & 27 & 286 & 1855 & 12.79 & & 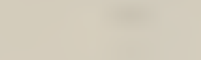 & \\
\hline & 48 & 292 & 2140 & 14.76 & & & \\
\hline & 35 & 287 & 1920 & 13.24 & & & \\
\hline & & & 1970 & 13.59 & 1.11 & 71.1 & 39.8 \\
\hline \multirow[t]{28}{*}{$I-23-L$} & 26 & 287 & 3775 & 26.03 & & & \\
\hline & 25 & 287 & 3625 & 25.00 & & & \\
\hline & 45 & 290 & 3700 & 25.51 & & & \\
\hline & & & 3700 & 25.52 & 2.36 & 152.1 & 84.5 \\
\hline & 30 & 288 & 5875 & 40.52 & & & \\
\hline & 46 & 292 & 6125 & 42.24 & & & \\
\hline & 36 & 288 & 5525 & 38.10 & & & \\
\hline & & & 5840 & 40.28 & 5.01 & 317.6 & 176.4 \\
\hline & 40 & 290 & 7150 & 49.31 & & & \\
\hline & 43 & 292 & 7200 & 49.66 & & & \\
\hline & 38 & 292 & 7175 & 49.48 & & & \\
\hline & & & 7175 & 49.48 & 9.97 & 630.4 & 350.2 \\
\hline & 32 & 287 & 8140 & 56.14 & & & \\
\hline & 33 & 287 & 8110 & 55.93 & & & \\
\hline & 39 & 292 & 8600 & 59.31 & & & \\
\hline & & & 8285 & 57.14 & 20.99 & 1314.1 & 730.1 \\
\hline & 47 & 293 & 8390 & 57.86 & & & \\
\hline & 42 & 291 & 8850 & 61.03 & & & \\
\hline & 34 & 289 & 8450 & 58.28 & & & \\
\hline & & & 8565 & $59: 07$ & 33.92 & 2112.5 & 1173.6 \\
\hline & 44 & 290 & 715 & 4.93 & 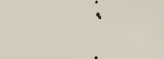 & & \\
\hline & 26 & 285 & 585 & 4.03 & · & & \\
\hline & 29 & 286 & 600 & 4.14 & & & \\
\hline & & & 630 & 4.34 & 0.38 & 29.6 & 16.4 \\
\hline & 28 & 284 & 1915 & 13.21 & & & \\
\hline & 25 & 285 & 1900 & 13.10 & & & \\
\hline & 39 & 290 & 2195 & 15.14 & & & \\
\hline & & & 2000 & 13.79 & 0.79 & 63.0 & 35.0 \\
\hline \multirow[t]{4}{*}{$\mathrm{I}-32-\mathrm{L}$} & 31 & 288 & 4040 & 27.86 & & & \\
\hline & 37 & 289 & 3950 & 27.24 & & & \\
\hline & 27 & 286 & 3775 & 26.03 & & & \\
\hline & & & $\overline{3920}$ & 27.03 & 1.79 & 142.3 & 79.0 \\
\hline
\end{tabular}




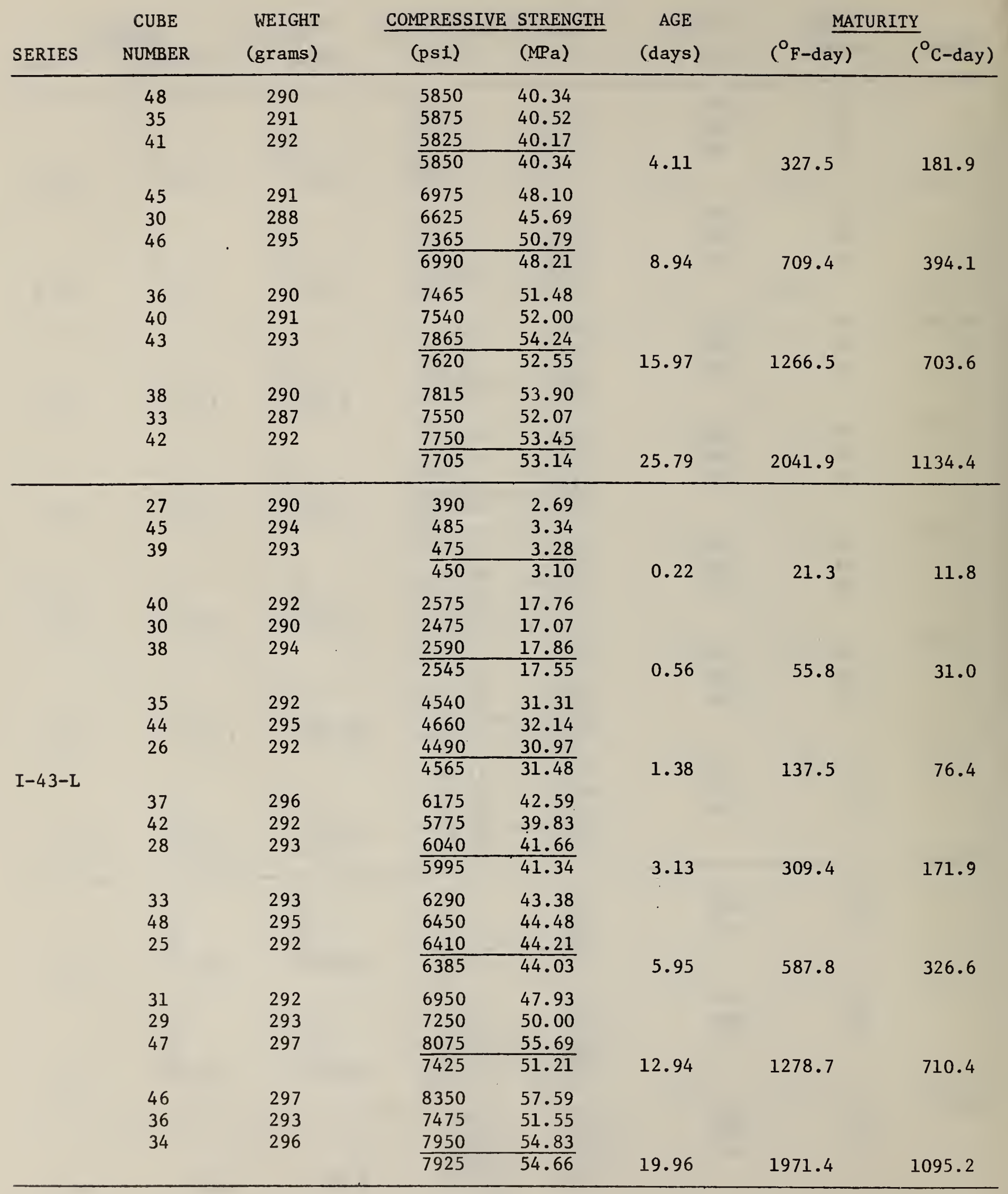




\begin{tabular}{|c|c|c|c|c|c|c|c|}
\hline \multirow[b]{2}{*}{ SERIES } & \multirow{2}{*}{$\begin{array}{c}\text { CUBE } \\
\text { NUMBER }\end{array}$} & \multirow{2}{*}{$\begin{array}{l}\text { WEIGHT } \\
\text { (grams) }\end{array}$} & \multirow{2}{*}{$\frac{\text { COMPRESSIVE }}{(\mathrm{ps} 1)}$} & \multirow{2}{*}{$\frac{\text { STRENGTH }}{(\mathrm{MPa})}$} & \multirow{2}{*}{$\begin{array}{c}\text { AGE } \\
\text { (days) }\end{array}$} & \multicolumn{2}{|c|}{$\underline{\text { MATURITY }}$} \\
\hline & & & & & & $\left({ }^{\mathrm{O}} \mathrm{F}\right.$-day $)$ & $\left({ }^{\circ} \mathrm{C}-\right.$ day $)$ \\
\hline \multirow{20}{*}{ II-5-I } & 4 & 286 & 540 & $\cdot 3.72$ & & & \\
\hline & 8 & 287 & 615 & 4.24 & & & \\
\hline & 13 & 289 & 690 & 4.76 & & & \\
\hline & & & 615 & & 0.95 & 42.2 & 23.4 \\
\hline & 5 & 290 & 3575 & 24.66 & & & \\
\hline & 12 & 289 & 3990 & 27.52 & & & \\
\hline & 18 & 289 & 4390 & $\frac{30.28}{2718}$ & 290 & & \\
\hline & & & 3985 & 27.48 & 2.90 & 164.8 & 91.6 \\
\hline & 3 & 287 & 6640 & 45.79 & & & \\
\hline & 11 & 290 & 7450 & 51.38 & & 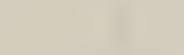 & \\
\hline & 17 & 289 & $\frac{7985}{7360}$ & $\frac{55.07}{50.76}$ & & & \\
\hline & & & 7360 & 50.76 & 8.18 & 487.4 & 270.8 \\
\hline & 6 & 290 & 8890 & 61.31 & & & \\
\hline & 10 & 289 & 9375 & 64.66 & & & \\
\hline & 16 & 288 & 9825 & 67.76 & & & \\
\hline & & & $\overline{9365}$ & 64.59 & 1.9 .87 & 1205.1 & 669.5 \\
\hline & 1 & 288 & 9325 & 64.31 & & & \\
\hline & 7 & 288 & 9665 & 66.66 & & & \\
\hline & 13 & & 10375 & 71.55 & & & \\
\hline & & & 9790 & 67.52 & 34.01 & 2072.5 & 1151.4 \\
\hline \multirow{20}{*}{ II-5-F } & 1 & 287 & 370 & 2.55 & & & \\
\hline & 8 & 288 & 445 & 3.07 & & & \\
\hline & 18 & 286 & 575 & 3.97 & & & \\
\hline & & & 460 & 3.17 & 1.13 & 42.6 & 23.6 \\
\hline & 5 & 287 & 3140 & 21.66 & & & \\
\hline & 9 & 289 & 3560 & 24.55 & 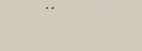 & & \\
\hline & 17 & 287 & 4050 & 27.93 & & & \\
\hline & & & 3585 & 24.72 & 3.06 & 164.3 & 91.3 \\
\hline & 4 & 287 & 6250 & 43.10 & & & \\
\hline & 11 & 289 & 6650 & 45.86 & & & \\
\hline & 16 & 288 & 7950 & 54.83 & & & \\
\hline & & & 6950 & 47.93 & 8.36 & 487.7 & 270.9 \\
\hline & 3 & 292 & 8190 & 56.48 & $\cdot$ & & \\
\hline & 10 & 290 & 8685 & 59.90 & & & \\
\hline & 13 & 290 & $\frac{9090}{0.655}$ & 62.69 & & & \\
\hline & & & 8655 & 59.69 & 20.05 & 1205.6 & 669.8 \\
\hline & 6 & 288 & 8350 & 57.57 & & & \\
\hline & 12 & 292 & 9575 & 66.03 & & & \\
\hline & 15 & 289 & 9950 & 68.62 & & & \\
\hline & & & 9290 & 64.07 & 34.18 & 2073.0 & 1151.7 \\
\hline
\end{tabular}




\begin{tabular}{|c|c|c|c|c|c|c|c|}
\hline \multirow[b]{2}{*}{ SERIES } & \multirow{2}{*}{$\begin{array}{c}\text { CUBE } \\
\text { NUMBER }\end{array}$} & \multirow{2}{*}{$\begin{array}{l}\text { WEIGHT } \\
\text { (grams) }\end{array}$} & \multicolumn{2}{|c|}{ COMPRESSIVE STRENGTH } & \multirow{2}{*}{$\begin{array}{c}\text { AGE } \\
\text { (days) }\end{array}$} & \multicolumn{2}{|c|}{ MATURITY } \\
\hline & & & (psi) & $(\mathrm{MPa})$ & & $\left({ }^{\circ} \mathrm{F}\right.$-day $)$ & $\left({ }^{\circ} \mathrm{C}-\right.$ day $)$ \\
\hline \multirow{20}{*}{ II $-5-\mathrm{H}$} & 3 & 286 & 560 & 3.86 & & & \\
\hline & 12 & 287 & 665 & 4.59 & & & \\
\hline & 15 & 287 & 885 & 5.90 & & & \\
\hline & & & 695 & 4.79 & 0.78 & 40.7 & 22.6 \\
\hline & 1 & 289 & 3340 & 23.03 & & & \\
\hline & $\overline{7}$ & 287 & 3890 & 26.83 & & & \\
\hline & 13 & 288 & 4475 & 30.86 & & & \\
\hline & & & 3900 & 26.90 & 2.70 & 161.7 & 89.8 \\
\hline & 4 & 289 & 6150 & 42.41 & & & \\
\hline & 8 & 287 & 6750 & 46.55 & & & \\
\hline & 18 & 287 & 7325 & 50.52 & & & \\
\hline & & & 6740 & 46.48 & 8.01 & 485.9 & 270.0 \\
\hline & 6 & 288 & 7925 & 54.66 & & - & \\
\hline & 11 & 290 & 8140 & 56.14 & & & \\
\hline & 17 & 288 & 8935 & 61.62 & & & \\
\hline & & & 8335 & 57.48 & 19.70 & 1203.8 & 668.8 \\
\hline & 5 & 290 & 9015 & 62.17 & & & \\
\hline & 9 & 287 & 9060 & 62.48 & & & \\
\hline & 16 & 289 & 9825 & 67.76 & & & \\
\hline & & & 9300 & 64.14 & 33.84 & 2071.5 & 1150.8 \\
\hline \multirow{20}{*}{ II-32-I } & 6 & 291 & 705 & 4.86 & & & \\
\hline & 9 & 289 & 740 & 5.10 & & & \\
\hline & 17 & 291 & 840 & 5.79 & & & \\
\hline & & & 760 & 5.24 & 0.60 & 40.8 & 22.7 \\
\hline & 3 & 292 & 3760 & 25.93 & & & \\
\hline & 11 & 292 & 3700 & 25.52 & & & \\
\hline & 16 & 292 & 4090 & 28.21 & & & \\
\hline & & & 3850 & 26.55 & 2.35 & 149.4 & 83.0 \\
\hline & 1 & 291 & 6550 & 45.17 & & & \\
\hline & 10 & 291 & 6225 & 42.93 & & & \\
\hline & 13 & 292 & 6715 & 46.31 & & & \\
\hline & & & 6495 & 44.79 & 8.02 & 498.6 & 277.0 \\
\hline & 4 & 294 & 8025 & 55.34 & & & \\
\hline & 8 & 290 & 7850 & 54.14 & & & \\
\hline & 15 & 294 & 8125 & 56.03 & & & \\
\hline & & & 8000 & 55.17 & 20.05 & 1235.6 & 686.4 \\
\hline & 5 & 293 & 8515 & 58.72 & & & \\
\hline & 7 & 291 & 8400 & 57.93 & & & \\
\hline & 18 & 292 & 8525 & 58.79 & & & \\
\hline & & & 8480 & 58.48 & 31.34 & 1929.7 & 1072.1 \\
\hline
\end{tabular}




\begin{tabular}{|c|c|c|c|c|c|c|c|}
\hline \multirow[b]{2}{*}{ SERIES } & \multirow{2}{*}{$\begin{array}{c}\text { CUBE } \\
\text { NUMBER }\end{array}$} & \multirow{2}{*}{$\begin{array}{l}\text { WEIGHT } \\
\text { (grams) }\end{array}$} & \multirow{2}{*}{$\frac{\text { COMPRESSIVE }}{(\mathrm{psi})}$} & \multirow{2}{*}{$\frac{\text { STRENGTH }}{(\mathrm{MPa})}$} & \multirow{2}{*}{$\begin{array}{c}\text { AGE } \\
\text { (days) }\end{array}$} & \multicolumn{2}{|c|}{ MATUR ITY } \\
\hline & & & & & & $\left({ }^{\circ} \mathrm{F}\right.$-day $)$ & $\left({ }^{\circ} \mathrm{C}-\right.$ day $)$ \\
\hline & 5 & 289 & 730 & 5.03 & & & \\
\hline & 11 & 289 & 725 & 5.00 & & & \\
\hline & 13 & & 820 & 5.66 & & & \\
\hline & & & 760 & 5.24 & 0.57 & 39.2 & 21.8 \\
\hline & 3 & 289 & 3860 & 26.62 & & & \\
\hline & 10 & 289 & 3575 & 24.66 & & & \\
\hline & 18 & 293 & 4075 & 28.10 & & & \\
\hline & & & 3840 & 26.48 & 2.31 & 148.3 & 82.4 \\
\hline & 6 & 292 & 6625 & 45.69 & & & \\
\hline & 12 & 291 & 6590 & 45.45 & & & \\
\hline & 17 & 292 & 6860 & 47.31 & & & \\
\hline & & & 6690 & 46.14 & 7.99 & 497.3 & 276.3 \\
\hline \multicolumn{8}{|l|}{ II-32-F } \\
\hline & $\begin{array}{l}1 \\
7\end{array}$ & 292 & 7985 & 55.07 & & & \\
\hline & 16 & 293 & 8135 & 56.10 & & & \\
\hline & & & 7755 & 53.48 & 20.01 & 1234.3 & 685.7 \\
\hline & 4 & 292 & 8325 & 57.41 & & & \\
\hline & 8 & 293 & 8590 & 59.24 & & & \\
\hline & 15 & 292 & 8525 & 58.79 & & & \\
\hline & & & 8480 & 58.48 & 31.31 & 1928.2 & 1017.2 \\
\hline & 3 & 288 & 615 & 4.24 & & & \\
\hline & 11 & 288 & 660 & 4.55 & & & \\
\hline & 13 & 292 & 695 & 4.79 & & & \\
\hline & & & 655 & 58.48 & 0.62 & 40.0 & 22.2 \\
\hline & 1 & 290 & 3815 & 26.31 & & & \\
\hline & 10 & 290 & 3690 & 25.45 & & 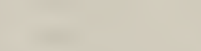 & \\
\hline & 18 & 295 & 3810 & 26.28 & & & \\
\hline & & & 3770 & 45.17 & 2.27 & 143.8 & 79.9 \\
\hline \multicolumn{8}{|l|}{ II-32-H } \\
\hline & $\begin{array}{l}4 \\
8\end{array}$ & $\begin{array}{l}292 \\
292\end{array}$ & $\begin{array}{l}6300 \\
6775\end{array}$ & 43.45 & & & \\
\hline \multirow[t]{10}{*}{ 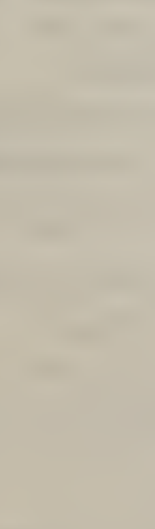 } & 17 & $\begin{array}{l}292 \\
295\end{array}$ & $\begin{array}{l}6775 \\
6575\end{array}$ & $\begin{array}{l}46.72 \\
45.34\end{array}$ & · & & \\
\hline & & 20 & $\frac{0513}{6550}$ & $\frac{45.34}{45.17}$ & 7.95 & 493.4 & 274.1 \\
\hline & 5 & 292 & 7725 & 53.28 & & & \\
\hline & 12 & 290 & 7175 & 49.48 & & & \\
\hline & 16 & 296 & 8275 & 57.07 & & & \\
\hline & & & 7725 & 53.28 & 19.98 & 1230.5 & 683.6 \\
\hline & 6 & 292 & 8590 & 59.24 & & & \\
\hline & 7 & 292 & 8600 & 59.31 & & & \\
\hline & 13 & 295 & 8415 & 58.03 & & & \\
\hline & & & 8535 & 58.86 & 31.27 & 1930.6 & 1072.5 \\
\hline
\end{tabular}


NBS-114A (REV. 2-8C)

U.S. DEPT. OF COMM.

1. PUBLICATION OR REPORT NO.

BIBLIOGRAPHIC DATA

SHEET (See in struction s)

NBSIR $81-2244$

2. Performing Organ. Report Nof 3. Publication Date

March 1981

4. TITLE AND SUBTITLE

Temperature Effects on the Strength-Maturity

Relation of Mortar

5. $\operatorname{AUTHOR}(S)$

Nicholas J. Carino

6. PERFORMING ORGANIZATION (If joint or other than NBS, see instructions)

7. Contract/Grant No.

NATIONAL BUREAU OF STANDARDS

DEPARTMENT OF COMMERCE.

WASHINGTON, D.C. 20234

9. SPONSORING ORGANIZATION NAME AND COMPLETE ADDRESS (Street, City, State, ZIP)

10. SUPPLEMENTARY NOTES

$\square$ Document describes a computer program; SF-185, FIPS Software Summary, is attached.

11. ABSTRACT (A 200-word or less factual summary of most significant information. If document includes a significant bibliography or literature survey, mention it here)

A study was performed to gain a fund amental understanding of the traditional maturity method used to predict the in-place strength of concrete. Reserach was undertaken to answer two questions: 1) What are the quantitative effects of curing temperature on the compressive strength-maturity relation of concrete? 2) Is there an age beyond which temperature no longer affects the strength-maturity relation of concrete? To simplify testing, mortar cubes were used as specimens for compressive strength determinations. Penetration resistance measurements were performed to determine initial and final setting times. Phase $I$ of the research addressed the first question and involved preparing and curing specimens at $5^{\circ}, 12^{\circ}, 23^{\circ}, 32^{\circ}$ and $43^{\circ} \mathrm{C}$. Phase II addressed the second question and involved curing specimens at $5^{\circ}$ and $32^{\circ} \mathrm{C}$ for short periods, followed by additional curing at $23^{\circ} \mathrm{C}$. It was found that initial set occurred at approximately the same. maturity regardless of the curing temperature. A three-parameter hyperbolic equation was used to represent the strength-maturity relation. The parameters, determined by regression analysis, were found to vary systematically with curing temperature. Theoretical justification for the hyperbolic equation is presented and a key assumption in the maturity method is identifled. The strength versus age data were also analyzed and a new concept, effective age, is suggested as a possible alternative for representing the combined effects of time and temperature on the compressive strength development of concrete.

12. KEY WORDS (Six to twelve entries: alphabetical order: capitalize only proper names: and separate key words by semicolons)

concrete; compressive strength; curing temperature; early age; final set; hydration; initial set; laboratory testing; maturity; mortar; regression analysis; strength prediction; temperature effects.

13. AVAILABILITY

600 Unlimited

$\square$ For Official Distribution. Do Not Release to NTIS

$\square$ Order From Superintendent of Documents, U.S. Government Printing Office, Washington, D.C. 20402.

14. NO. OF PRINTED PAGES

O.]. Order From National Technical Information Service (NTIS), Springfield, VA, 22161
98

15. Price

$\$ 9.50$ 

